Estudo e definição de mecanismos para redução do custo de aplicação do teste de programas concorrentes

Mario Cesar da Cunha Machado 

SERVIÇO DE PÓS-GRADUAÇÃO DO ICMC-USP

Data de Depósito: 13 de junho de 2011

Assinatura:

\section{Estudo e definição de mecanismos para redução do custo de aplicação do teste de programas concorrentes}

\section{Mario Cesar da Cunha Machado}

Orientador: Prof. Dr. Paulo Sérgio Lopes de Souza

Dissertação apresentada ao Instituto de Ciências Matemáticas e de Computação - ICMC-USP, como parte dos requisitos para obtenção do título de Mestre em Ciências - Ciências de Computação e Matemática Computacional. VERSÃO REVISADA.

USP - São Carlos

Junho/2011 
Ficha catalográfica elaborada pela Biblioteca Prof. Achille Bassi e Seção Técnica de Informática, ICMC/USP, com os dados fornecidos pelo(a) autor(a)

Machado, Mario Cesar da Cunha
Estudo e definição de mecanismos para redução do
custo de aplicaça do teste de programas concorrentes
/ Mario Cesar da Cunha Machado; orientador Paulo
Sérgio Lopes de Souza -- São Carlos, 2011.
94 p.
Dissertação (Mestrado - Programa de Pós-Graduação en
Ciências de Computação e Matemática Computacional) --
Instituto de Ciências Matemáticas e de Computação,
Universidade de São Paulo, 2011.
1. Teste de Software. 2. Programação Concorrente.
S. Teste de Programas Concorrentes. I. Souza, Paulo
Sérgio Lopes de , orient. II. Título.




\section{Agradecimentos}

Agradeço muito a Deus por todos os momentos de esperança e por proteger e guiar minha vida até aqui.

A toda minha família pelo amor, apoio e auxílio na vinda para São Carlos. Em especial aos meus pais Cesar e Arley e minha irmã Aline, sem vocês o mestrado não seria possível.

Ao meu orientador Paulo Sérgio Lopes de Souza e à professora Simone do Rocio Senger de Souza, pela oportunidade, profissionalismo, incentivo, orientação e paciência, sem o qual não teria realizado este trabalho.

Aos amigos do LaSDPC pela companhia (e pela hospitalidade também): Paulão, Bruno Tardiole, Bruno Guazzelli, Daniel, Thiago, Júlio, Maycon, Douglas, Edwin, Jonathan, Bruno Faical, Luis Nakamuta, Roni.

Obrigado aos amigos do LABES e agregados: Sandrão, Van, Jorge (Piu), Rodolfo, Messias, Endo, Abe, Paulo Ceará (Gambi), Mel, Nerso, Marcão, Fabiano, Adalberto, David, José (Tim), William, Danilo, Chicão. Obrigado a todos!

Aos professores da UFMS e ICMC que contribuíram para minha formação.

Aos amigos de Campo Grande e da república Tereré em São Carlos pelos momentos de alegria e por tornar a estadia em São Carlos mais agradável, Diogo, Gondim, Kenji, Alex, Alessandro, Patrick, Letrícia, Márcio, Maxwell, Rafael, Jairton, Jucimara, Vanessa, Kishi, Lucas, Ronaldo, Murilo e Leandro. Obrigado de coração! Muito obrigado aos amigos da ABU e da IPRSC pelo carinho e amizade.

Aos amigos da escalada, pelas risadas, parceria, boulders noturnos na caverninha, viagens e pelo aprendizado: Genja, Zé, Beto, Gaivota, Animal, Júlia, Naná, Greg, Elias, Paula, Frango, Russo, Koberle, Isa, Stufa, Rafa, Ana.

Ao CNPq pelo apoio financeiro. 

rogramas concorrentes possuem características que os diferenciam de programas sequenciais, tornando a atividade de teste mais complexa. Questões como definição e uso de variáveis por diferentes processos, comunicação, sincronização e comportamento não-determinístico precisam ser consideradas. Apesar dos avanços obtidos nesse contexto, um problema que ainda persiste é o custo da atividade de teste, relacionado principalmente ao número excessivo de elementos requeridos a serem testados. Neste contexto, este trabalho apresenta duas propostas: a primeira estática, focando na detecção automática de elementos requeridos não-executáveis, para os critérios relacionados a sincronizações; e a segunda dinâmica, aplicando-se o teste de alcançabilidade para apoiar a avaliação da cobertura de sequências de sincronizações, desse modo, usando informações dinâmicas para apoiar o teste de cobertura. Estas propostas foram implementadas na ferramenta ValiMPI e um experimento foi realizado a fim de verificar a eficácia da proposta. Os resultados indicam que as duas propostas implementadas neste trabalho são promissoras e auxiliam a reduzir o custo da atividade de teste. 

oncurrent programs present new features, such as: nondeterminism, concurrency, synchronization and communication. These features need to be considered during testing activity, making this activity more complex. Despite the results achieved in this context, a problem that still remains is the application cost of the testing, especially the cost related to the high number of required elements generated by the test criteria proposed to concurrent programs. In this context, this work presents two contributions: the first one using a static approach, automatically detecting non-executable elements related to synchronization between process; and the second one using a dynamic approach, applying reachability testing to support the coverage evaluation of the executed sequences, reducing the number of executed sequences and the number of test cases. These contributions were implemented in the ValiMPI tool and experiments were conducted to evaluate them. The results indicate that these contributions can improve the concurrent program testing, reducing the application cost of the testing activity. 

$\begin{array}{lll}\text { Abstract } & \text { v }\end{array}$

$\begin{array}{lll}\text { Lista de Siglas } & \text { xv }\end{array}$

1 Introdução $\quad 1$

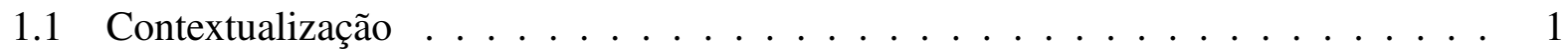

1.2 Motivação e objetivos . . . . . . . . . . . . . . . . . . . . . 2

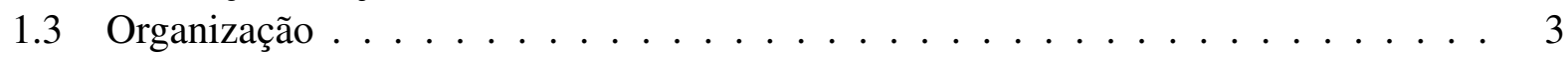

2 Programação concorrente 5

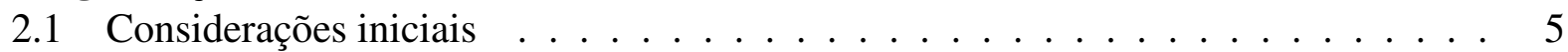

2.2 Fundamentos básicos . . . . . . . . . . . . . . . . . 5

2.2.1 Arquiteturas paralelas . . . . . . . . . . . . . . 7

2.2.2 Modelos de programas paralelos . . . . . . . . . . . . . . 8

2.3 Suporte ao desenvolvimento de programas concorrentes . . . . . . . . . . . . 10

2.3.1 Ferramentas . . . . . . . . . . . . . . . . 12

2.4 Erros mais comuns em programas concorrentes . . . . . . . . . . . . . . . 12

2.5 Considerações finais . . . . . . . . . . . . . . . . . . . 14

3 Teste de software $\quad 15$

3.1 Considerações iniciais . . . . . . . . . . . . . . . . . . . . . . . . . . . . .

3.2 Fundamentos do teste de software . . . . . . . . . . . . . . 15

3.2.1 Técnicas de teste . . . . . . . . . . . . . . . . . 17

3.3 Critérios de teste estruturais . . . . . . . . . . . . . . . . 18

3.3.1 Comparação entre critérios de teste . . . . . . . . . . . . . . 22

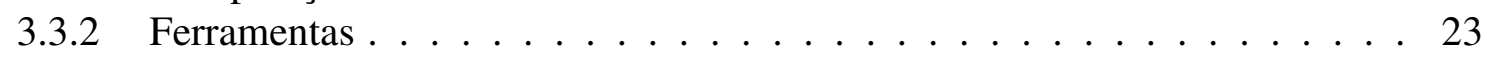

3.4 Considerações finais . . . . . . . . . . . . . . . . . 24

4 Teste de programas concorrentes $\quad 25$

4.1 Considerações iniciais . . . . . . . . . . . . . . . . . . . 25

4.2 Modelos e critérios de teste . . . . . . . . . . . . . . . . . 26

4.2.1 Critérios de teste estruturais . . . . . . . . . . . . . 26

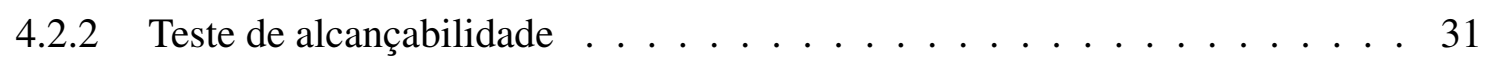


4.2.3 Geração de sequências de teste . . . . . . . . . . . . . . . . . . 35

4.2.4 Comparação entre os modelos de teste . . . . . . . . . . . . . . . . . 37

4.3 Ferramentas de teste . . . . . . . . . . . . . . . . . . 40

4.4 Ferramenta ValiPar . . . . . . . . . . . . . . . . . . . 40

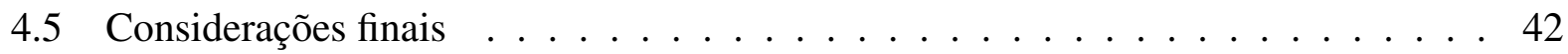

5 Eliminação de elementos não-executáveis $\quad \mathbf{4 3}$

5.1 Considerações iniciais . . . . . . . . . . . . . . . . . 43

5.2 Identificação de elementos não-executáveis . . . . . . . . . . . . . . . . . 44

5.3 Implementação da técnica na ValiMPI . . . . . . . . . . . . . . . . . . . . . . . . . . . . . . . .

5.4 Abrangência desta técnica e suas limitações . . . . . . . . . . . . . . . . . . . . . . . . . . . . . . . . . . .

5.5 Considerações finais . . . . . . . . . . . . . . . . . . . . 49

6 Teste de alcançabilidade como apoio ao teste de cobertura 51

6.1 Considerações iniciais . . . . . . . . . . . . . . . . . 51

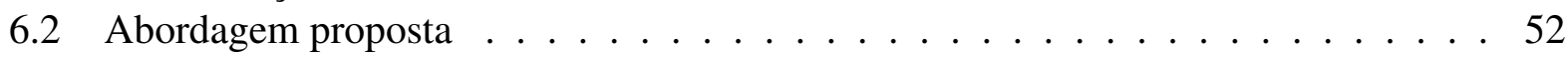

6.3 Implementação da técnica na ValiMPI . . . . . . . . . . . . . . . . 55

6.4 Abrangência desta técnica e suas limitações . . . . . . . . . . . . . . . . 58

6.5 Considerações finais . . . . . . . . . . . . . . . . . . . 59

7 Resultados Obtidos $\quad 61$

7.1 Considerações iniciais . . . . . . . . . . . . . . . . . 61

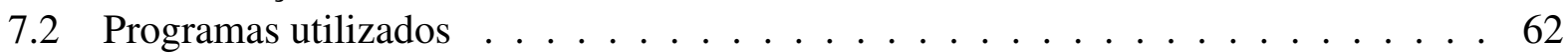

7.3 Cenários e casos de teste . . . . . . . . . . . . . . . 66

7.4 Resultados . . . . . . . . . . . . . . . . . . . 68

7.5 Considerações finais . . . . . . . . . . . . . . . . . 77

8 Conclusão $\quad 79$

8.1 Considerações Finais . . . . . . . . . . . . . . . . . . . . 79

8.2 Contribuições . . . . . . . . . . . . . . . . . 80

8.3 Trabalhos futuros . . . . . . . . . . . . . . . . 80

$\begin{array}{lll}\text { A Crivo de Eratóstenes } & 91\end{array}$ 


\section{Lista de Figuras}

2.1 Arquitetura de um multiprocessador (memória compartilhada) (Hausen, 2005). . . 8

2.2 Arquitetura de um multicomputador (memória distribuída) (Hausen, 2005). . . . . 8

2.3 Exemplo da utilização do fork/join (Toscani et al., 2003). . . . . . . . . . . . . . . 10

2.4 Exemplo da utilização do cobegin/coend (Toscani et al., 2003). . . . . . . . . . . . 11

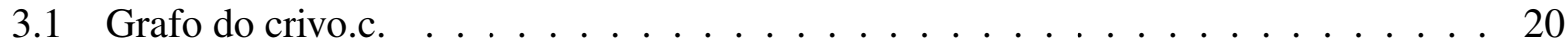

3.2 Grafo Def-Uso do crivo.c. . . . . . . . . . . . . . . . . . . 21

3.3 Relação de inclusão dos critérios de fluxo de dados, estendida com os critérios Potenciais-Usos (Maldonado et al., 2007) . . . . . . . . . . . . . . 23

4.1 GFCP do crivo concorrente. . . . . . . . . . . . . . . . . 30

4.2 Geração de variantes no teste de alcançabilidade (Lei e Carver, 2006). . . . . . . . . 32

4.3 Exemplo de construção da tabela de disputa: (a) exemplo de sequência de sincronizações e (b) tabela de disputas sendo estendida através do crescimento horizontal e vertical (Lei et al., 2007). . . . . . . . . . . . . . . . . . . . 34

4.4 Exemplo de grafo de alcançabilidade e seu grafo dual (Wong et al., 2005). . . . . . 36

4.5 Arquitetura da ValiPar (Souza et al., 2008). . . . . . . . . . . . . . 41

5.1 Exemplo de arquivo com os elementos requeridos para o critério todas-arestas-s. . . 47

5.2 Exemplo de arquivo com os elementos eliminados para o critério todas-arestas-s. . 48

6.1 Geração de variantes no teste de alcançabilidade (Lei e Carver, 2006). . . . . . . . . 52

6.2 GFCP do crivo concorrente. . . . . . . . . . . . . . . . . . 56

6.3 Exemplo de arquivo gerado: trace.slave.p1. . . . . . . . . . . . . . 56

6.4 Exemplo de arquivo gerado: syncQueue. . . . . . . . . . . . . . . . 57

6.5 Exemplo de arquivo gerado: seq_sync.p0. . . . . . . . . . . . . . . 57

7.1 Porcentagem de elementos eliminados para o critério Todas-arestas-s. . . . . . . . . 69

7.2 Porcentagem de elementos eliminados para o critério Todos-s-usos. . . . . . . . . 71

A.1 Exemplo de execução do crivo de Eratóstenes (Quinn, 2004) . . . . . . . . . . . . . 92

A.2 Exemplo de execução da ferramenta ValiPar. . . . . . . . . . . . . . . . . . . . 94 



\section{Lista de Tabelas}

4.1 Comparação entre os modelos de teste. . . . . . . . . . . . . . . . . . 38

7.1 Complexidade dos programas. . . . . . . . . . . . . . 63

7.2 Elementos requeridos para o critério Todas-arestas-s. . . . . . . . . . . . . 68

7.3 Elementos requeridos não-executáveis para o critério Todas-arestas-s. . . . . . . . . 69

7.4 Elementos requeridos para o critério Todos-s-usos. . . . . . . . . . . . . 70

7.5 Elementos requeridos não-executáveis para o critério Todos-s-usos. . . . . . . . . 71

7.6 Número de sequências executadas. . . . . . . . . . . . . . . . . . . . . . . . . . . . . 72

7.7 Cobertura para o critério Todas-arestas-s. . . . . . . . . . . . . 73

7.8 Cobertura para o critério Todos-s-usos. . . . . . . . . . . . . . . . 73

7.9 Evolução da cobertura para o programa jacobi . . . . . . . . . . . . . . . 74

7.10 Evolução da cobertura para o programa mmult . . . . . . . . . . . . . . 74 



\section{Lista de Programas}

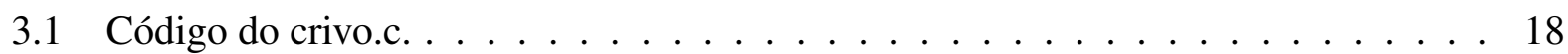

4.1 Código do crivo concorrente. . . . . . . . . . . . . . . . . 28

5.1 Trecho de código de exemplo. . . . . . . . . . . . . . . . . 45

6.1 Pseudocódigo do algoritmo do teste de alcançabilidade modificado. . . . . . . . . 54

A.1 Pseudocódigo do Crivo de Eratóstenes. . . . . . . . . . . . . . . . . . . . . 91 



\section{Lista de Siglas}

BPEL - Business Process Execution Language for Web Services

CPU - Central Processing Unit

CSP - Communicating Sequential Processes

GFC - Grafo de Fluxo de Controle

GFCP - Grafo de Fluxo de Controle Paralelo

IEEE - Institute of Electrical and Electronics Engineers

MEF - Máquina de Estados Finitos

MIMD - Multiple Instruction streams, Multiple Data streams

MISD - Multiple Instruction streams, Single Data stream

MPI - Message Passing Interface

MPMD - Multiple Program Multiple Data

PPFG - Parallel Program Flow Graph

PVM - Parallel Virtual Machine

RPC - Remote Procedure Call

SIMD - Single Instruction stream, Multiple Data streams

SISD - Single Instruction stream, Single Data stream

SPMD - Single Program Multiple Data

VV\&T - Verificação, Validação e Teste

WS-BPEL - Web Services Business Process Execution Language 


\section{CAPÍTULO \\ 1 \\ Introdução}

\subsection{Contextualização}

A computação paralela tem gerado um grande impacto em diversas áreas, de aplicações científicas como simulações computacionais a aplicações comerciais em mineração de dados e processamento de transações. A escolha da utilização de computação paralela nessas aplicações se justifica devido aos requisitos de performance dessas e ao custo-benefício do paralelismo (Grama et al., 2003). Uma falha em uma aplicação paralela pode representar altos custos, portanto, a sua verificação e validação é uma atividade fundamental.

A atividade de teste é crucial para a qualidade do software desenvolvido. Entretanto, essa tem sido apontada como uma das atividades mais onerosas no desenvolvimento de software, podendo consumir grande parte dos custos de desenvolvimento (Perry e Kaiser, 1990). Sem a utilização de ferramentas automatizadas, a atividade de teste tende a ser extremamente trabalhosa, propensa a erros e limitada a programas muito simples (Horgan e Mathur, 1992). Esses problemas se agravam quando são consideradas aplicações concorrentes.

Diferentemente dos programas sequenciais, programas concorrentes possuem comportamento não-determinístico, o que torna a atividade de teste ainda mais complexa. Múltiplas execuções de um programa concorrente com a mesma entrada podem executar diferentes sequências de sincronização, podendo produzir diferentes resultados. Esse comportamento é ocasionado devido à comunicação, sincronização e concorrência existentes entre os processos. Essas características diferem os programas concorrentes dos sequenciais e precisam ser consideradas durante a atividade de teste. Assim, é necessário adaptar os critérios de teste existentes para programas sequenciais a fim de tratar essas particularidades presentes em programas concorrentes. 
Este trabalho insere-se no contexto do projeto de Subsídios para o Teste Estrutural de Aplicações Distribuídas desenvolvido no período de 2008 a 2010, financiado pela FAPESP (processo n.2008/04614-5), Profa. Dra. Simone do Rocio Senger de Souza. Esse projeto visa identificar e propor alternativas para reduzir o custo de aplicação da atividade de teste no contexto de programas concorrentes. Neste contexto, este trabalho apresenta duas propostas: a primeira estática, descrita no Capítulo 5, focando na redução da quantidade de elementos requeridos, e a segunda dinâmica, descrita no Capítulo 6, utilizando o teste de alcançabilidade com o objetivo de aumentar a cobertura desses elementos.

\subsection{Motivação e objetivos}

Considerando o contexto apresentado, os principais pontos que motivam o desenvolvimento deste trabalho são os seguintes:

1. A necessidade de testar programas concorrentes é crucial para a qualidade do software desenvolvido.

2. A crescente importância da computação paralela, devido aos inúmeros domínios de aplicação existentes, bem como as novas propostas de processadores multicores (múltiplos núcleos), propostos por fabricantes de hardware como a Intel (Ramanathan, 2005; Held et al., 2006) e a IBM (Kahle et al., 2005).

3. A ferramenta ValiPar foi desenvolvida para o apoio ao teste de programas concorrentes, aplicando critérios de teste estrutural. Esta se encontra instanciada para PVM, MPI, BPEL e Pthreads. No entanto, a ValiPar ainda apresenta algumas restrições para o seu uso devido ao alto custo computacional.

A quantidade de elementos requeridos gerados pela ValiPar é um fator limitante na aplicação dos critérios de teste para programas concorrentes complexos. Os critérios relacionados a sincronizações adotam uma estratégia conservadora, ao considerar todas as possíveis arestas interprocesso, mesmo aquelas em que a comunicação não seja possível na prática. Essas sincronizações levam a um número elevado de elementos que precisam ser cobertos pelos testes, sendo que grande parte desses é não-executável (não existe caso de teste capaz de executar a sincronização). Portanto, há a necessidade de se investigar alternativas para reduzir esse custo de modo que o modelo e a ferramenta que o implementa possam ser empregados em programas complexos.

O principal objetivo deste trabalho de mestrado é explorar e caracterizar alternativas para reduzir o custo de aplicação dos testes em programas concorrentes. Com esse objetivo, foi realizado um estudo de um conjunto de modelos de teste focados na redução do custo do teste de programas concorrentes (apresentado na Seção 4.2) e, a partir desse, foram propostas duas abordagens, detalhadas nos Capítulos 5 e 6. 
A primeira proposta modifica a geração de elementos requeridos para os critérios Todasarestas-s e Todos-s-usos (implementada no módulo Vali-Elem), informações estáticas dos eventos send/receive a fim de possibilitar a detecção automática de elementos não-executáveis para esses critérios.

A segunda utiliza o teste de alcançabilidade proposto por Lei e Carver (2006) (implementado no módulo Vali-Sync), utilizando a cobertura de elementos requeridos como heurística para guiar a escolha de novas sequências de sincronizações. Esta abordagem tem por objetivo diminuir a quantidade de sequências executadas, garantindo que todas as sequências executadas contribuem para o aumento da cobertura dos elementos relacionados a sincronizações.

\subsection{Organização}

No Capítulo 2 são apresentados os conceitos de programação concorrente, as arquiteturas paralelas (segundo a taxonomia de Flynn (Flynn, 1972)), além de uma classificação de erros em programas concorrentes proposta por Krawczyk et al. (1994). No Capítulo 3 são apresentados os conceitos de teste de software e as técnicas são listadas, com uma ênfase maior para os critérios da técnica estrutural.

No Capítulo 4 são discutidos alguns trabalhos que exploram o teste aplicado a programas concorrentes, em especial aqueles que tratam de modelos de teste focados na redução do custo do teste de programas concorrentes. Neste capítulo é apresentada também a ferramenta ValiPar, que foi utilizada durante a realização deste trabalho de mestrado.

No Capítulo 5 é apresentada uma proposta de detecção automática de elementos não-executáveis relacionados a sincronizações, utilizando para isso informações estáticas dos eventos send/receive. No Capítulo 6 é apresentada uma proposta de utilização do teste de alcançabilidade no contexto de teste estrutural, utilizando-se informações de cobertura para diminuir o custo da aplicação do teste de alcançabilidade relacionado à grande quantidade de sequências executadas.

No Capítulo 7 são apresentados os experimentos realizados a fim de verificar a eficácia das duas abordagens propostas neste trabalho. O Capítulo 8 apresenta as considerações finais, as contribuições e sugestões de trabalhos futuros. 



\section{Programação concorrente}

\subsection{Considerações iniciais}

Neste capítulo são apresentados os conceitos de programação concorrente, arquiteturas paralelas, modelos de programas paralelos, assim como a classificação dos erros de programas concorrentes proposta por Krawczyk et al. (1994). Essa classificação dos erros é importante para se definir estratégias de teste no contexto de programas concorrentes (o teste de programas concorrentes é discutido no Capítulo 4).

Este capítulo está organizado da seguinte forma. Na Seção 2.2 são explicados os fundamentos da programação concorrente, como a definição de concorrência e paralelismo, granularidade, arquiteturas paralelas e modelos de programas paralelos. A Seção 2.3 apresenta os mecanismos necessários para se especificar a concorrência em um programa e algumas notações propostas para ativação, sincronização e comunicação de processos concorrentes. Na Seção 2.4 são mostrados os tipos de erros de programas concorrentes, conforme definidos por Krawczyk et al. (1994).

\subsection{Fundamentos básicos}

Computação paralela é o uso de computadores paralelos (várias unidades de processamento ou processadores que se comunicam entre si) para reduzir o tempo necessário para resolver um problema computacional (Quinn, 2004). Ela baseia-se no fato de que o processo de resolução de um problema pode ser dividido em tarefas menores, que podem ser realizadas simultaneamente através de algum tipo de coordenação. 
É importante notar a diferença de concorrência e paralelismo de processos, no contexto de programas concorrentes. Segundo Almasi e Gottlieb (1994), a concorrência ocorre quando, em um determinado instante, dois ou mais processos começaram a sua execução, mas não terminaram. Paralelismo ocorre em sistemas com mais de um processador, quando os processos estão executando ao mesmo tempo, em processadores distintos. Quando dois ou mais processos estão executando concorrentemente em um único processador, em um sistema multitarefa, ocorre o pseudoparalelismo, pois, estritamente falando, em qualquer instante de tempo, a CPU está executando só um processo, porém o usuário tem a impressão de que estes são executados simultaneamente devido à alternância destes na utilização da CPU. Assim, a definição de concorrência engloba tanto o conceito de paralelismo quanto o de pseudoparalelismo.

Um processo é um programa em execução, consistindo em um programa executável, seus dados, contador de instruções, registradores e todas as informações necessárias para a sua execução. O modelo de processo pode ser dividido em dois conceitos: agrupamento de recursos e execução. Separando esses, surge o conceito de thread (Tanenbaum, 2001). Uma thread é uma linha de execução dentro de um programa. Com essa separação, tem-se a possibilidade de múltiplas linhas de execução dentro de um mesmo processo (multithreading). O processo é responsável por agrupar os recursos (espaço de endereçamento, variáveis globais, lista de arquivos abertos, etc.), enquanto a thread possui os itens necessários para sua execução (contador de programa, registradores, pilha, etc.).

Para se obter um ganho de velocidade através do uso de concorrência, é necessário dividir a computação em tarefas ou processos que possam executar simultaneamente (Wilkinson e Allen, 1999). O tamanho dessas tarefas é indicado pela granularidade ou nível de concorrência. Em uma granularidade grossa, cada tarefa contém um grande número de instruções em relação à comunicação necessária para a execução. Em uma granularidade fina, a tarefa pode consistir de poucas instruções ou até mesmo apenas uma, para cada comunicação realizada. Uma granularidade média seria um meio termo entre as duas.

A granularidade relaciona-se diretamente com o número de processadores utilizados. Uma granularidade fina requer um número maior de processadores, enquanto uma granularidade mais grossa, comparativamente, precisa de menos. Em alguns casos, é desejável uma granularidade mais grossa para diminuir o custo com comunicação e criação de processos, porém isso diminui a concorrência. Assim, a granularidade deve ser escolhida de acordo com o problema a ser tratado e os processadores disponíveis. Em geral, é desejável que o projeto do programa concorrente possibilite que a granularidade seja modificada facilmente, ou seja, que se adapte às características do hardware e da carga de trabalho. Se isso ocorrer, o programa terá facilitada a sua escalabilidade, ou seja, a capacidade de apresentar bons e constantes desempenhos frente a variações na carga de trabalho e a variações no desempenho do hardware disponível. 


\subsubsection{Arquiteturas paralelas}

Com o avanço do processamento paralelo, surgiram diversas maneiras de se organizar o hardware, especialmente as interconexões entre os processadores e sua comunicação. Algumas classificações foram propostas para agrupar arquiteturas com características similares. Apesar de antiga, a taxonomia de Flynn (Flynn, 1972) é a mais frequentemente referenciada e é amplamente adotada. Essa se baseia no fluxo de instruções e de dados.

Essa classificação divide as arquiteturas em quatro categorias. São elas:

SISD (Single Instruction stream, Single Data stream): corresponde ao mono-processador tradicional (computador de von Neumann).

SIMD (Single Instruction stream, Multiple Data streams): vários processadores, cada um com sua própria memória, executam a mesma instrução. Esse modelo é adequado apenas para algumas tarefas altamente especializadas, caracterizadas pelo alto grau de regularidade.

MISD (Multiple Instruction streams, Single Data stream): envolve vários processadores executando diferentes instruções em um único conjunto de dados. Para muitos autores, nenhum computador existente encaixa-se nesta categoria (Stallings, 2005), enquanto outros acreditam que arquiteturas sistólicas (systolic arrays) encaixam-se nessa categoria (Quinn, 2004).

MIMD (Multiple Instruction streams, Multiple Data streams): vários processadores, executando diferentes conjuntos de instruções em diferentes conjuntos de dados.

Utilizando-se essa classificação, a maioria dos computadores paralelos existentes na atualidade é classificada como MIMD (Dongarra et al., 2005). A principal diferença entre eles se dá no acesso dos processadores à memória, podendo ser divididos em dois grupos: os com memória compartilhada e os com memória distribuída. As Figuras 2.1 e 2.2 (retiradas de Hausen (2005)) exemplificam arquiteturas com memória compartilhada e memória distribuída, respectivamente.

Memória compartilhada: Nas arquiteturas MIMD com memória compartilhada, também conhecidas como multiprocessadores, os processadores compartilham uma memória comum (memória única, ou várias memórias organizadas logicamente com um endereçamento comum a todos os processadores).

A comunicação e o sincronismo dos processos ocorrem através da leitura e escrita das variáveis compartilhadas no espaço de endereçamento compartilhado. Devido à concorrência entre os processos, a consistência dos dados torna-se um problema, sendo necessário utilizar mecanismos para garantir essa consistência.

Estas arquiteturas são fortemente acopladas, devido à alta interação entre os processadores, sendo indicadas em aplicações com granularidade mais fina. 


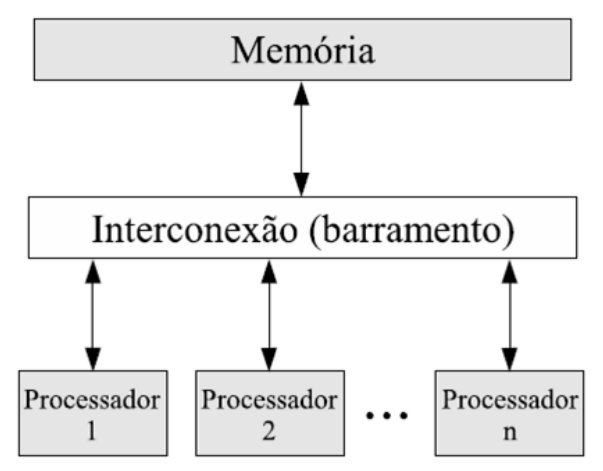

Figura 2.1: Arquitetura de um multiprocessador (memória compartilhada) (Hausen, 2005).

Memória distribuída: Nas arquiteturas MIMD com memória distribuída, ou multicomputadores, cada processador possui sua própria memória local, não tendo acesso à memória dos demais processadores. Assim, a comunicação, em última instância, deve ser feita através de passagem de mensagens.

Como o custo de acesso à memória local é menor do que o acesso a um dado remoto, a localidade dos dados se torna importante para o desempenho da aplicação. Assim, é desejável que haja pouca troca de mensagens, devido ao alto custo de latência dessa. Essas arquiteturas são indicadas para sistemas com granularidade média a grossa, onde o sistema possui um acoplamento fraco.

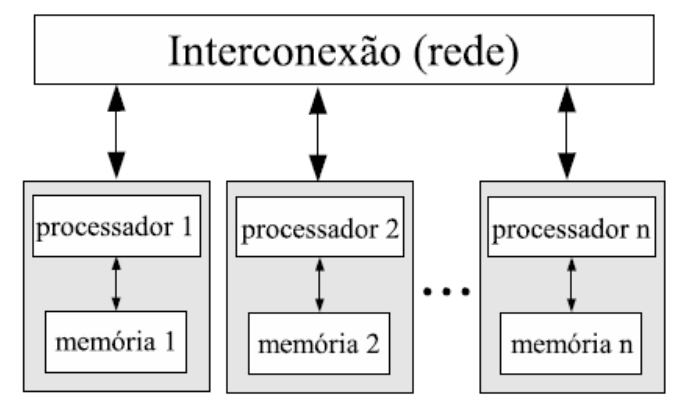

Figura 2.2: Arquitetura de um multicomputador (memória distribuída) (Hausen, 2005).

\subsubsection{Modelos de programas paralelos}

Existem diversos modelos para se organizar um programa paralelo, dependendo da arquitetura utilizada e das características do programa. A escolha do modelo geralmente é feita visando utilizar uma estratégia para diminuir a interação entre as tarefas. A seguir são apresentados alguns dos modelos mais utilizados:

Mestre-Escravo: No modelo mestre-escravo, um ou mais processos mestre alocam tarefas para os processos escravos (Grama et al., 2003). Esse modelo pode ser implementado tanto com distribuição de carga estática quanto dinâmica. 
Ao se utilizar esse modelo, o processo mestre pode se tornar um gargalo, caso as tarefas sejam muito pequenas ou os escravos sejam muito rápidos. Assim, deve-se escolher a granularidade de modo que o custo de atribuir tarefas e de sincronização seja menor que o custo de executar as tarefas.

Work Pool: No modelo work pool ou task pool é utilizado um mapeamento dinâmico das tarefas nos processos visando o balanceamento de carga, de modo que cada tarefa potencialmente pode ser executada por qualquer processo (Grama et al., 2003).

Pipeline: No modelo pipeline, um fluxo de dados passa por uma sequência de processos, cada um executando uma tarefa diferente (Grama et al., 2003). O pipeline pode ser visto como uma cadeia de produtores e consumidores. Cada processo inicia a execução de sua tarefa ao receber os dados do processo anterior na cadeia, e produz os dados para o processo seguinte. Os processos não necessariamente precisam ser organizados de forma linear; pode-se construir pipelines com estrutura multidimensional, árvores ou grafos direcionados.

SPMD: No modelo SPMD (Single Program Multiple Data), uma cópia do mesmo programa é executada em cada processador, com dados diferentes. Este modelo é amplamente usado por diversas plataformas paralelas, e requer suporte arquitetural mínimo (Grama et al., 2003).

Aplicações SPMD podem ser muito eficientes se os dados forem bem distribuídos entre os processos e o sistema for homogêneo. Se os processos possuírem carga de trabalho ou capacidades diferentes, é necessário um balanceamento de carga para adaptar a distribuição dos dados durante a execução (Silva e Buyya, 1999).

MPMD: No modelo MPMD (Multiple Program Multiple Data), cada processador tem seu próprio programa, executando sobre dados diferentes (Wilkinson e Allen, 1999).

Nada impede que alguns dos programas sejam cópias. Comumente somente dois programas fontes são utilizados, um para o processo mestre, e outro para os escravos. Um programa no modelo MPMD pode ser implementado utilizando SPMD, fazendo com que cada processo execute apenas certo trecho do programa (Wilkinson e Allen, 1999).

Híbrido: Em alguns casos, mais de um modelo pode ser aplicado para certo problema, resultando em um modelo híbrido. Um modelo híbrido pode ser composto por vários modelos aplicados em fases diferentes do algoritmo. Há ainda casos em que a formulação do algoritmo apresenta características de mais de um modelo (Grama et al., 2003). 


\subsection{Suporte ao desenvolvimento de programas concor- rentes}

Para se desenvolver um programa concorrente, além das instruções presentes em programas sequenciais, como instruções de desvio condicional ou estruturas de repetição, necessita-se de mecanismos para, por exemplo, especificar a ativação e término de processos concorrentes. Segundo Almasi e Gottlieb (1994), três fatores são essenciais para a execução concorrente: definir um conjunto de subtarefas a serem executadas concorrentemente, capacidade de iniciar e finalizar a execução das subtarefas e capacidade de coordenar e especificar a interação entre as subtarefas enquanto essas estiverem executando.

As operações fork e join foram definidas por Conway (1963), sendo uma das primeiras notações propostas para a ativação de processos concorrentes. Essa proposta apresenta a característica de não separar a definição de ativação dos processos da definição de sincronização (Andrews e Schneider, 1983). A execução da instrução fork $x$ por um processo $p$ faz com que um processo filho $q$ seja criado e inicie sua execução (concorrente à execução do processo pai) na instrução com rótulo $x$. A operação join $t$, end1, end 2 decrementa o valor da variável $t$ e verifica o seu valor. Se $t$ for igual a zero, a execução é desviada para end1; caso contrário, a execução é desviada para end2. Normalmente, o comando quit é utilizado em end2, para encerrar a execução do processo. O comando join é utilizado para a sincronização do processo pai com os filhos gerados. A Figura 2.3 exemplifica o uso do fork/join (exemplo retirado de Toscani et al. (2003)). A representação do programa no exemplo é feita utilizando um grafo de fluxo de processo, onde cada aresta representa a execução de um processo.

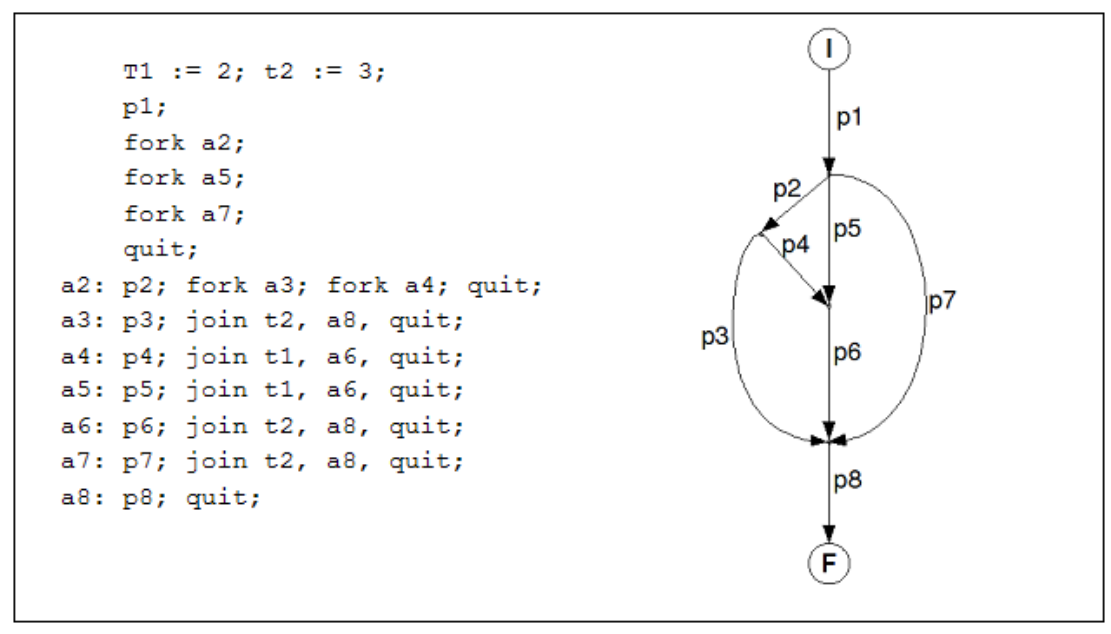

Figura 2.3: Exemplo da utilização do fork/join (Toscani et al., 2003).

As primitivas cobegin e coend (também denominadas como parbegin e parend), propostas por Dijkstra (1965), explicitam um conjunto de trechos de código para serem executados concorrentemente. Todos os comandos entre o cobegin e o coend são executados concorrentemente. A 
execução do comando cobegin/coend termina quando todos os processos terminam suas execuções.

A Figura 2.4 exemplifica o uso do cobegin/coend (exemplo retirado de Toscani et al. (2003)). Os comandos begin e end são utilizados para especificar trechos que devem ser executados sequencialmente.

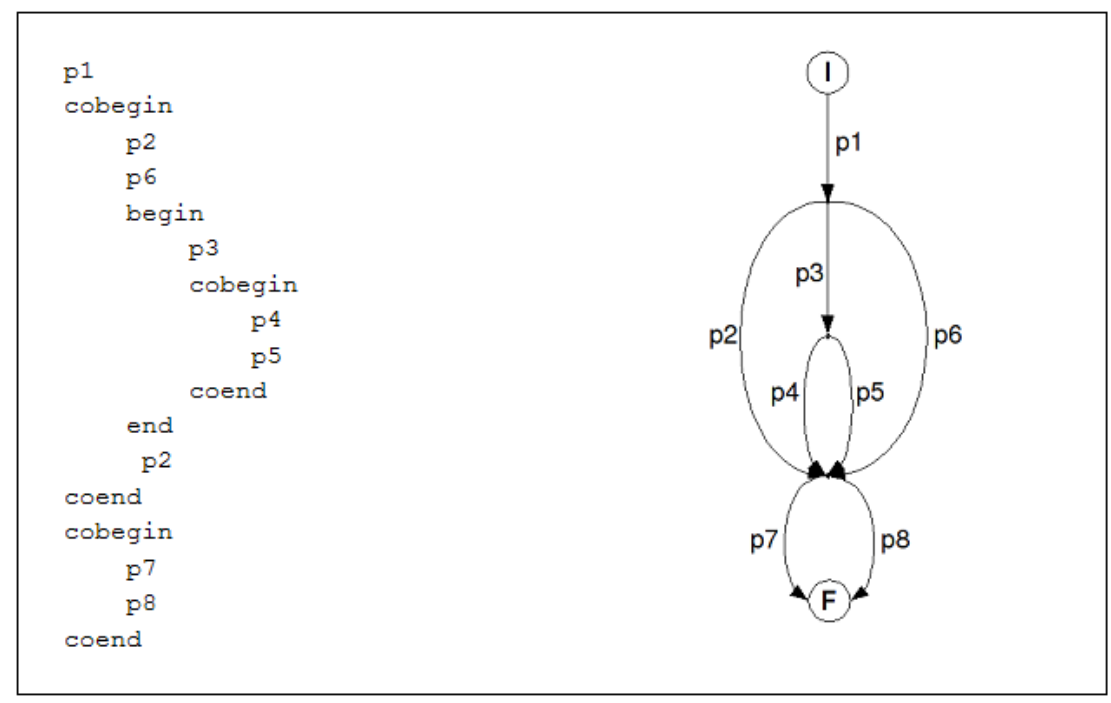

Figura 2.4: Exemplo da utilização do cobegin/coend (Toscani et al., 2003).

A primitiva doall é semelhante ao cobegin/coend, porém é utilizada para executar concorrentemente as diversas instâncias de um loop. Além disso, a quantidade de processos no doall é dinâmica, já que a quantidade de iterações pode vir a ser conhecida apenas em tempo de execução. No cobegin/coend, essa quantidade é estática.

Para se coordenar e especificar a interação entre os processos concorrentes, utiliza-se a comunicação e a sincronização entre eles. A comunicação permite que a execução de um processo interfira na execução de outro. A sincronização deve ser usada para possibilitar o controle na sequência da execução concorrente e para que o acesso simultâneo não torne inconsistentes os dados compartilhados. Como dito anteriormente, a comunicação pode ser feita pelo uso de variáveis compartilhadas (quando se tem memória compartilhada) ou pelo uso de passagem de mensagens (quando se tem memória distribuída).

Quando se utiliza memória compartilhada, a sincronização pode ser feita por mecanismos como busy-waiting (espera ocupada), semáforos ou monitores. No busy-waiting, o processo que deseja executar uma região crítica deve testar uma condição de entrada e, caso não tenha permissão de executar essa região, permanece em uma estrutura de repetição tentando obter a permissão. Uma região crítica é uma região que deve ser executada por apenas um processo de cada vez, por exemplo, um trecho do programa com uma variável compartilhada cujo acesso simultâneo pode gerar um estado inconsistente. Essa solução tem a desvantagem de utilizar tempo de processamento enquanto o processo espera para executar, além de possibilitar a entrada de mais de um processo 
na região crítica, caso não seja utilizado algum protocolo mais complexo que garanta a exclusão mútua.

O semáforo é um mecanismo que utiliza duas operações atômicas, down ( $\mathrm{P}$, ou wait) e up (V, ou signal), que atuam sobre uma variável compartilhada inteira e não negativa. A operação down verifica o valor dessa variável, bloqueando o processo caso a variável seja igual a zero, ou decrementando o valor da variável e permitindo o acesso à região crítica caso a variável seja maior que zero. A operação up é utilizada ao final da execução da região crítica, liberando-a.

O monitor é uma estrutura de alto nível, consistindo de uma estrutura de dados compartilhada, cujo acesso deve ser controlado, garantindo a exclusão mútua, e um conjunto de funções que tem acesso a essa estrutura.

Ao se utilizar memória distribuída, a passagem de mensagens pode ser implementada utilizando as primitivas send/receive. Essa comunicação pode ser síncrona, onde o comando send aguarda que o comando receive correspondente seja executado, ou assíncrona, utilizando-se um buffer para armazenar a mensagem até que o receive seja executado. A troca de mensagens pode ser feita também se utilizando chamada de procedimentos remotos (RPC). Nesta, um processo pode requisitar que um procedimento seja executado remotamente, ficando bloqueado até que o processo remoto termine a execução do procedimento, podendo retornar algum valor.

\subsubsection{Ferramentas}

Programas concorrentes podem ser implementados basicamente de três maneiras: utilizando compiladores que paralelizam o código sequencial, utilizando extensões de linguagens (através de bibliotecas) ou utilizando linguagens específicas para aplicações concorrentes, como CSP (Communicating Sequential Processes) ou Ada. Ferramentas e compiladores para paralelização automática no atual estado da arte aparentemente funcionam apenas para programas ou porções de programas altamente estruturados (Grama et al., 2003).

Dentre as extensões da linguagem $\mathrm{C}$, duas das mais usadas para o paradigma de passagem de mensagem são o PVM (Parallel Virtual Machine)(Geist et al., 1994) e o MPI (Message Passing Interface) (Snir et al., 1996). O MPI surgiu como uma tentativa de padronização dos ambientes de passagem de mensagem através de uma especificação para o desenvolvimento de aplicações concorrentes. Para o paradigma de memória compartilhada, pode-se citar como exemplo Pthreads (Lewis e Berg, 1998), que implementa o uso de threads em C, e o OpenMP (Open MultiProcessing) (Chandra et al., 2001), que dá suporte ao uso de memória compartilhada por meio de diretivas de compilação para especificar concorrência e variáveis compartilhadas.

\subsection{Erros mais comuns em programas concorrentes}

Krawczyk et al. (1994) definem dois tipos de erros de programas concorrentes, baseados na definição clássica de erros proposta por Howden (1976). Considere $p_{x}$ como um caminho em um 
programa $P, D\left(p_{x}\right)$ como o domínio de entrada de um caminho $p_{x}$, ou seja, o conjunto de todas as entradas que exercitam $p_{x}$, e $C\left(p_{x}\right)$ como a representação da computação de $p_{x}$.

Howden (1976) formaliza o conceito de desvio de um programa $P$ de sua versão correta $P^{\prime}$ assumindo um isomorfismo entre um programa $P\left(P=\left\{p_{i} \mid i=1,2, \ldots\right\}\right)$ e sua versão correta $P^{\prime}$ $\left(P^{\prime}=\left\{p_{i}^{\prime} \mid i=1,2, \ldots\right\}\right)$, e define:

1. Erro de computação (computation error): ocorre em $P$ quando para todo par de caminhos $\left(p_{i}, p_{i}^{\prime}\right)$ tal que $D\left(p_{i}\right)=D\left(p_{i}^{\prime}\right)$, existe um par $\left(p_{k}, p_{k}^{\prime}\right)$ no qual $C\left(p_{k}\right) \neq C\left(p_{k}^{\prime}\right)$.

2. Erro de domínio (domain error): ocorre em $P$ se para todo par de caminhos $\left(p_{i}, p_{i}^{\prime}\right)$ tal que $C\left(p_{i}\right)=C\left(p_{i}^{\prime}\right)$, existe um $\operatorname{par}\left(p_{k}, p_{k}^{\prime}\right)$ no qual $D\left(p_{k}\right) \neq D\left(p_{k}^{\prime}\right)$.

3. Erro de subcaso (subcase error): ocorre em $P$ se para todo par de caminhos $\left(p_{i}, p_{i}^{\prime}\right), C\left(p_{i}\right)=$ $C\left(p_{i}^{\prime}\right)$ e $D\left(p_{i}\right) \subset D\left(p_{i}^{\prime}\right)$ (este erro ocorre quando há um isomorfismo entre os caminhos de $P$ e um subconjunto dos caminhos de $P^{\prime}$ ).

Erros de computação ocorrem quando o programa possui alguma atribuição incorreta ou faltando ao longo do caminho. Erros de domínio ocorrem quando condições em comandos de controle de fluxo estão erradas ou são avaliadas incorretamente. Um erro de computação pode gerar um erro de domínio, caso o valor errado seja usado em uma condição. Um erro de subcaso ocorre em um caminho em que falta algum comando de controle.

Krawczyk et al. (1994) definem duas novas classes de erros, generalizando a classificação de erros de Howden para incluir erros de comunicação e sincronização em programas concorrentes.

4. Erro de observabilidade (observability error): ocorre em $P$ se para algum caminho $p_{i} \in P$ existe outro caminho $p_{j} \in P$ tal que $D\left(p_{i}\right)=D\left(p_{j}\right)$ e $C\left(p_{i}\right) \neq C\left(p_{j}\right)$.

Erros de observabilidade estão relacionados ao ambiente de teste, por isso não incluem em sua definição um caminho em $P^{\prime}$. Estes ocorrem quando o usuário não pode controlar o comportamento da execução do programa concorrente sendo testado. Esta classe de erros está relacionada com o fato de que pode existir mais de um caminho em $P$ para uma mesma entrada.

5. Erro de travamento (locking error): ocorre em $P$ se em um caminho $p \in P$, onde $p=$ $q 0 q 1 \ldots q j$, existe um nó $q i$ tal que o sub-caminho $p s=q 0 q 1 \ldots q i$ possui domínio não-vazio $D(p s)$, e todos os predicados avaliados a partir de $q i$ são falsos.

Erros de travamento não ocorrem em programas sequenciais, já que as estruturas de condição têm pelo menos dois arcos com predicados complementares. Esta classe de erro está relacionada com o fato de que as ações de um processo podem influenciar a habilidade de outro processo executar suas próprias ações. Assim, um caminho de $P$ pode iniciar sua execução, e mais tarde não conseguir prosseguir a partir de certo ponto. 


\subsection{Considerações finais}

Neste capítulo foram explicados os conceitos de programação concorrente, apresentado as definições de concorrência e paralelismo. Foi apresentada uma classificação de arquiteturas paralelas (segundo a taxonomia de Flynn (Flynn, 1972)), além da subdivisão da arquitetura MIMD em arquiteturas com memória compartilhada e distribuída. Foi explicada também a definição de erros em programas concorrentes proposta por Krawczyk et al. (1994) (baseada na definição clássica de erros proposta por Howden (1976)).

O capítulo seguinte explica os conceitos do teste de programas sequenciais, enquanto o Capítulo 4 discute o teste de software aplicado no contexto de programas concorrentes. 


\section{3}

\section{Teste de software}

\subsection{Considerações iniciais}

Neste capítulo são apresentados conceitos do teste de software tradicional (aplicado a programas sequenciais), com ênfase no teste estrutural. Esses conceitos são necessários ao se discutir o teste de programas concorrentes (o teste de programas concorrentes é discutido no Capítulo 4).

Este capítulo está organizado da seguinte forma. Na Seção 3.2 são explicados os conceitos do teste de software, como a definição do que são técnicas e critérios de teste, as fases do teste e uma breve descrição das técnicas de teste. Na Seção 3.3 os critérios de teste estrutural são discutidos com mais detalhes, sendo apresentados os critérios mais utilizados, uma comparação entre os critérios, e algumas ferramentas que dão apoio à aplicação do teste estrutural para programas sequenciais.

\subsection{Fundamentos do teste de software}

A Engenharia de Software, por meio da aplicação de técnicas, critérios, métodos e ferramentas, busca produzir software de alta qualidade a baixo custo (Pressman, 2005). Porém, apesar da aplicação desses, erros ainda podem ocorrer. Atividades agregadas sob o nome de Garantia de Qualidade de Software têm sido introduzidas ao longo de todo o processo de desenvolvimento, dentre elas atividades de VV\&T (Verificação, Validação e Teste). Essas atividades têm o objetivo de minimizar a ocorrência de erros e riscos associados. A verificação visa assegurar que o software, ou uma determinada função do mesmo, esteja sendo implementado corretamente. A validação, por 
sua vez, procura assegurar que o software sendo desenvolvido é o software correto, de acordo com os requisitos do usuário.

A atividade de teste de software é um processo em que o programa é executado com a intenção de encontrar erros, sendo considerado um elemento crítico de garantia de qualidade de software. É uma técnica de verificação e validação, e representa a última revisão de especificação, projeto e codificação (Myers et al., 2004; Pressman, 2005). Dentre as técnicas de verificação e validação, a atividade de teste é uma das mais utilizadas, constituindo-se em um dos elementos para fornecer evidências da confiabilidade do software em complemento a outras atividades como, por exemplo, o uso de revisões e de técnicas formais e rigorosas de especificação e de verificação (Maldonado, 1991).

Um bom caso de teste é aquele que tem uma elevada probabilidade de revelar algum erro ainda não descoberto. O ideal seria que, para um dado conjunto de casos de teste, todos os erros do programa fossem revelados. Porém, isto implicaria na geração de testes com todas as entradas possíveis para o programa. Esse teste exaustivo é impraticável, devido a restrições de custo e tempo. Assim, é necessário escolher um conjunto de casos de teste que revele o máximo de erros possível a um baixo custo, e que não seja grande a ponto de ser impraticável. Para isso, faz-se necessária a aplicação de critérios que indiquem como testar o software, quando parar os testes e que, se possível, forneçam uma medida objetiva do nível de confiança e qualidade alcançados com os testes realizados (DeMillo, 1980).

O padrão IEEE 610.12 (IEEE, 1990) diferencia os seguintes termos, empregados no contexto de teste de software: defeito (fault) - passo, processo ou definição de dados incorreta (instrução ou comando incorreto); engano (mistake) - ação humana que produz um resultado incorreto (uma ação incorreta tomada pelo programador); erro (error) - diferença entre o valor obtido e o valor esperado (resultado ou estado intermediário inesperado) - e falha (failure) - produção de uma saída incorreta em relação à especificação.

O teste de software pode ser dividido em quatro etapas (Maldonado, 1991; Pressman, 2005):

Planejamento de testes: nessa etapa é criado um plano de teste, que contém, por exemplo, objetivo do teste, cronogramas, ferramentas utilizadas e critérios para julgar quando uma fase dos testes foi completada.

Projeto de casos de teste: nessa etapa são utilizadas as técnicas de teste para especificar os casos de teste.

Execução: nessa etapa são aplicados os testes especificados nas etapas anteriores.

Avaliação dos resultados dos testes: nessa etapa os resultados são organizados e comparados com os resultados esperados.

Essas etapas são realizadas ao longo do processo de desenvolvimento do software e são aplicadas em três fases: teste de unidade, teste de integração e teste de sistema. O teste de unidade é 
aplicado na menor unidade do software, também chamada de módulo. Ele busca revelar erros de lógica e implementação dentro da unidade. Em um programa orientado a objeto, o módulo pode ser um método (Vincenzi, 2004) ou uma classe (Perry e Kaiser, 1990; Binder, 1999). O teste de integração visa encontrar erros de interface, de interação entre os módulos e é aplicado durante a fase de integração do software. Por último, o teste de sistema procura testar o sistema como um todo, verificando se os elementos do software funcionam adequadamente quando combinados, por meio de vários tipos de teste, como teste de recuperação, segurança, estresse e desempenho (Pressman, 2005).

\subsubsection{Técnicas de teste}

Um critério de teste serve para selecionar e avaliar casos de teste com o intuito de revelar a presença de defeitos, ou estabelecer um nível elevado de confiança na correção do produto quando erros não são revelados (Maldonado e Fabbri, 2001). Os critérios podem ser classificados em diferentes técnicas, dependendo das informações utilizadas para derivar os requisitos de teste. São elas:

Funcional: Também conhecida como caixa-preta. A geração dos casos de teste é feita a partir da especificação do programa, dos requisitos funcionais. O testador considera o programa como uma caixa-preta, não possuindo conhecimento sobre o comportamento interno e estrutura do programa (Myers et al., 2004). São exemplos dessa técnica: particionamento em classes de equivalência, análise de valor limite e grafo de causa e efeito.

Estrutural: Também conhecida como caixa-branca. É uma técnica em que o testador deriva os casos de teste por meio da lógica interna do programa, verificando os detalhes do código e solicitando a execução de partes ou de componentes elementares do programa (Myers et al., 2004). Em geral, os critérios da técnica estrutural utilizam uma representação do programa conhecida como grafo de fluxo de controle ou grafo de programa.

Baseada em erros: Utiliza informações sobre os tipos de erros mais comuns no processo de desenvolvimento de software para derivar os requisitos de teste. Dois exemplos de técnicas desse tipo são: (1) semeadura de erros, onde uma quantidade conhecida de erros artificiais é introduzida no programa, podendo-se estimar usando probabilidade a quantidade de erros reais ainda existentes após o teste, e (2) análise de mutantes (DeMillo, 1978), que avalia a adequação de um conjunto de casos de teste em revelar erros específicos.

Baseada em estados: Utiliza uma representação baseada em estados, por exemplo, uma Máquina de Estados Finitos (MEF), para modelar o comportamento do sistema ou unidade a ser testada. Exemplos de critérios baseados em MEFs são os critérios W (Chow, 1978), DS (Gönenç, 1970), UIO (Sabnani e Dahbura, 1988) e Wp (Fujiwara et al., 1991). 
Segundo Howden (1987), o teste pode ser classificado de duas maneiras: teste baseado em especificação (specification-based testing) e teste baseado em programa (program-based testing). Seguindo essa classificação, os critérios das técnicas funcional e baseada em estados são baseados em especificação e os das técnicas estrutural e baseada em erros são baseadas em programa.

É importante que as técnicas não sejam usadas isoladamente. O ideal é que elas sejam consideradas como complementares, utilizando-as de forma a explorar as vantagens de cada uma, levando a um teste de boa qualidade, eficaz em revelar a presença de erros a um baixo custo (Maldonado, 1991). Myers et al. (2004) recomendam que casos de teste sejam desenvolvidos usando técnicas de teste funcional e complementados com técnicas de teste estrutural.

\subsection{Critérios de teste estruturais}

Critérios estruturais baseiam-se na estrutura interna do programa, no código-fonte. É definido um conjunto de elementos de software que deve ser executado para que se atinja uma cobertura mínima do critério. Esses elementos são os componentes do programa requeridos pelo critério e que devem ser testados. A cobertura é a medida que avalia quantos elementos foram testados (Rapps e Weyuker, 1985; Maldonado, 1991).

Um programa $P$ pode ser decomposto em um conjunto de blocos disjuntos de comandos; a execução do primeiro comando de um bloco acarreta a execução de todos os outros comandos desse bloco. Assim, a representação de um programa $P$ como um GFC (Grafo de Fluxo de Controle) consiste em estabelecer uma correspondência entre nós e blocos e em indicar possíveis fluxos de controle entre blocos através dos arcos. Um grafo de fluxo de controle em um programa sequencial é, portanto, um grafo orientado, com um único nó de entrada e um único nó de saída, no qual cada vértice representa um bloco indivisível de comandos e cada aresta representa um possível desvio de um bloco para outro. A partir do grafo de programa podem ser escolhidos os elementos que devem ser executados, caracterizando assim o teste estrutural. O Programa 3.1 apresenta o código do crivo.c que, recebendo como entrada um inteiro $n$, calcula e imprime todos os primos menores ou iguais a $n$, utilizando o Crivo de Eratóstenes (veja no Apêndice A a descrição do algoritmo do Crivo de Eratóstenes). A Figura 3.1 apresenta o grafo de fluxo de controle referente à função main desse programa.

Programa 3.1: Código do crivo.c.

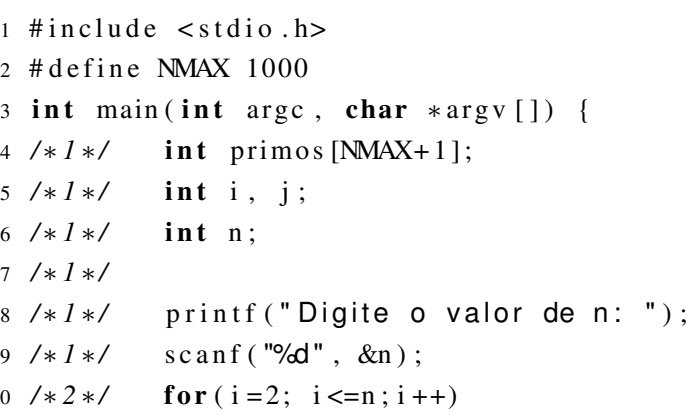




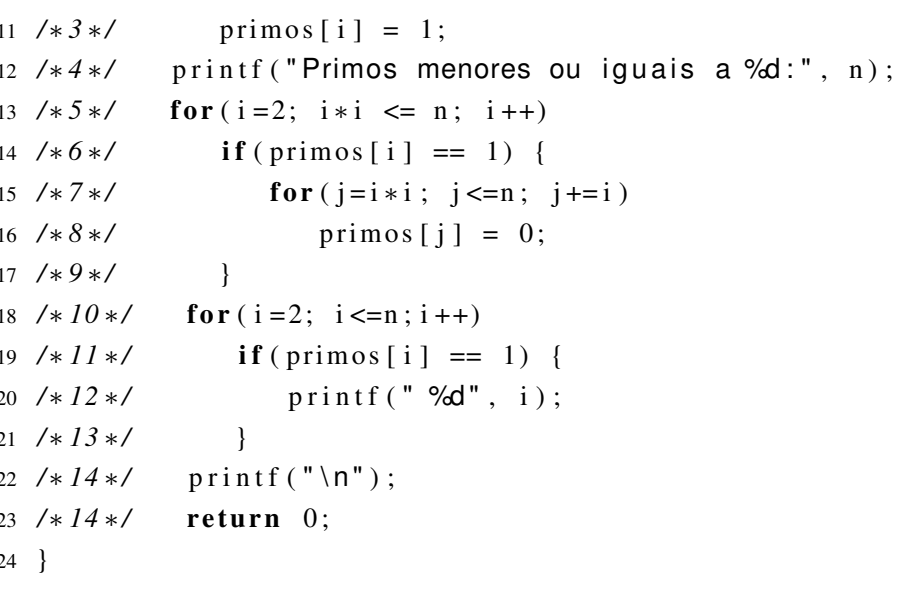

Os critérios estruturais são divididos em três classes: baseados na complexidade, baseados em fluxo de controle e baseados em fluxo de dados. Critérios baseados na complexidade utilizam informações sobre a complexidade do programa para derivar os requisitos de teste. Um critério bastante conhecido dessa classe é o critério de McCabe (McCabe, 1976), que utiliza a complexidade ciclomática (Pressman, 2005) do grafo de programa para derivar os requisitos de teste. Essencialmente, esse critério requer que um conjunto de caminhos linearmente independentes do grafo de programa seja executado (Pressman, 2005).

Os critérios baseados em fluxo de controle são aqueles que levam em conta apenas características do controle da execução e baseiam-se principalmente no GFC. Os critérios mais conhecidos dessa classe são os seguintes (Pressman, 2005):

Todos-nós: requer que os casos de teste executem pelo menos uma vez cada vértice do GFC, ou seja, requer que cada comando do programa seja executado pelo menos uma vez.

Todos-arcos: requer que os casos de teste executem pelo menos uma vez cada aresta do GFC, ou seja, requer que cada desvio de fluxo de controle do programa seja executado pelo menos uma vez.

Todos-caminhos: requer que todos os caminhos possíveis sejam executados no GFC. Esse critério geralmente é impraticável, devido ao grande número de elementos requeridos, o que o aproxima do teste exaustivo.

Os critérios baseados em fluxo de dados consideram as interações entre as definições de variáveis e os usos das mesmas no programa, a fim de determinar os requisitos de teste. São exemplos dessa classe os critérios de Rapps e Weyuker (1985) e os Critérios Potenciais-Usos (Maldonado, 1991).

Rapps e Weyuker (1985) propuseram o Grafo Def-Uso (Def-Use Graph) que consiste em uma extensão do grafo de programa. Nele são adicionadas informações a respeito do fluxo de dados do programa, caracterizando associações entre pontos do programa nos quais é atribuído um valor a 


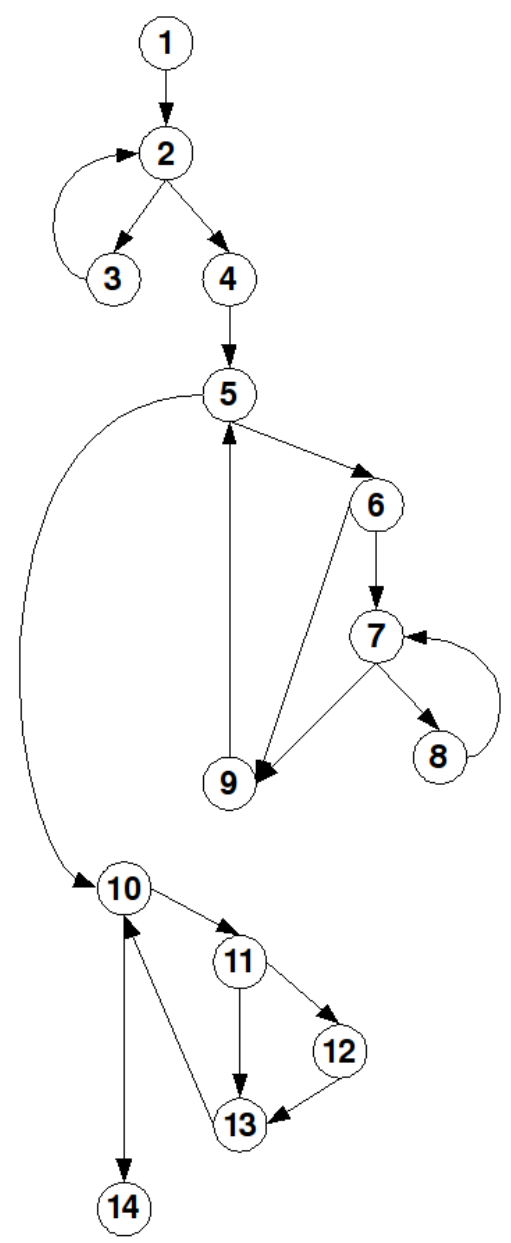

Figura 3.1: Grafo do crivo.c.

uma variável (chamados de definição da variável) e pontos em que esse valor é utilizado (chamados de referência ou uso da variável). Os requisitos de teste são determinados com base em tais associações. A Figura 3.2 ilustra o grafo Def-Uso do Programa 3.1.

Os usos são distinguidos em dois tipos: c-uso (uso computacional), que ocorre quando o valor da variável é usado em uma computação, e $p$-uso (uso predicativo), que é a referência ao valor de uma variável que afeta diretamente o fluxo de controle do programa. Os critérios mais conhecidos dentre propostos por Rapps e Weyuker (1985) são:

Todas-definições (all-defs): requer que cada definição de uma variável seja exercitada ao menos uma vez, seja por um c-uso ou um p-uso.

Todos-usos (all-uses): requer que todas as associações entre as definições de uma variável e seus usos posteriores (tanto c-uso quanto p-uso) sejam exercitadas, através de um caminho livre de definição, ou seja, um caminho onde essa variável não seja redefinida.

Todos-du-caminhos (all-du-paths): requer que todos os caminhos livres de definição entre as definições de uma variável e seus usos sejam exercitados. 
Os critérios Potenciais-Usos, propostos por (Maldonado, 1991), requerem associações independente da ocorrência de uma referência a uma variável. Se existir um caminho livre de definição entre uma definição de variável e um nó ou aresta, diz-se que existe um potencial-uso da variável. O principal critério dessa família é o Todos-Potenciais-Usos, que requer que toda associação entre uma definição de variável e um nó ou arco possível de ser alcançado por um caminho livre de definição seja exercitada ao menos uma vez.

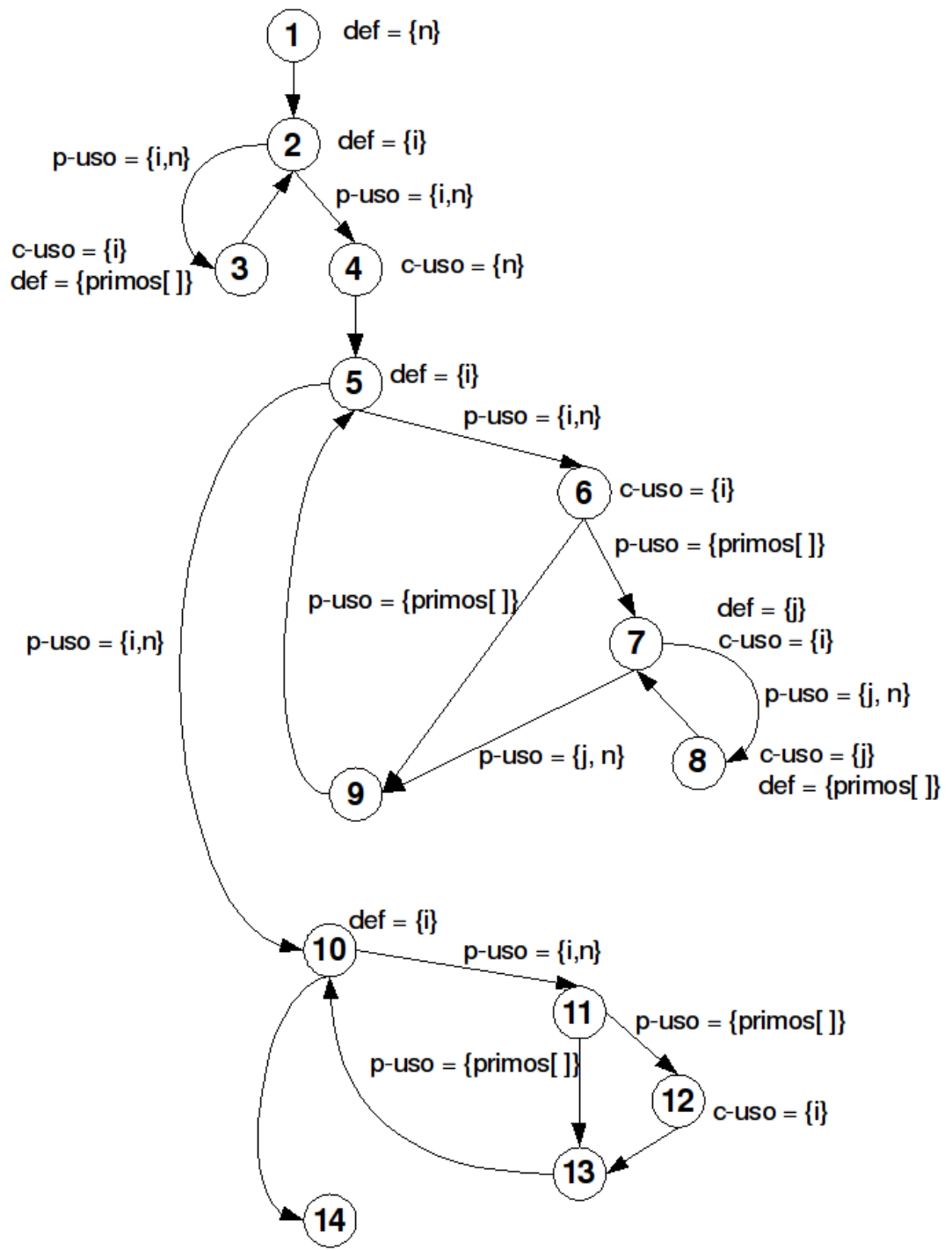

Figura 3.2: Grafo Def-Uso do crivo.c.

A técnica estrutural apresenta uma série de limitações e desvantagens. Um dos principais problemas é a impossibilidade, em geral, de se determinar automaticamente se um caminho é executável ou não. Um caminho é dito não executável se não existir dado de teste que cause a sua execução (Frankl e Weyuker, 1988). Não se conhece um algoritmo que, dado um caminho completo qualquer, decida se o caminho é executável e forneça o conjunto de valores que causam a execução desse caminho (Vergílio et al., 1993). Assim, é necessária a intervenção do testador para identificar caminhos não executáveis em um programa. Outra limitação é o da correção coincidente, 
ou seja, um programa incorreto pode apresentar, coincidentemente, um resultado correto para um dado de entrada. Além disso, existe o problema dos caminhos ausentes. Esse caminho poderia ser, por exemplo, uma funcionalidade que deveria ter sido implementada e, consequentemente, não será exercitado por nenhum caso de teste.

Apesar dessas limitações, esses critérios estabelecem de forma rigorosa os requisitos de teste a serem exercitados, em termos de caminhos, associações definição-uso ou outras estruturas do programa, fornecendo medidas objetivas sobre a adequação de um conjunto de teste para o teste de um dado programa $P$. Esse rigor na definição dos requisitos favorece a automatização desses critérios (Barbosa et al., 2005).

\subsubsection{Comparação entre critérios de teste}

A escolha dos critérios de teste a serem utilizados e a aplicação desses de maneira complementar não é uma tarefa fácil. Durante o planejamento dos testes é necessário escolher uma estratégia que seja eficaz em revelar erros e apresente baixo custo de aplicação. A realização de estudos teóricos e experimentais permite comparar os critérios de teste existentes, podendo ajudar na escolha de uma estratégia de teste viável.

Os estudos teóricos avaliam os critérios de teste utilizando principalmente a relação de inclusão e a complexidade dos critérios (Rapps e Weyuker, 1985; Ntafos, 1988; Weyuker, 1984). A relação de inclusão estabelece uma ordem parcial entre os critérios, caracterizando uma hierarquia entre eles. Um critério $C 1$ inclui um critério $C 2$ se, para qualquer programa $P$ e qualquer conjunto de casos de teste $T 1$ que é $C 1$-adequado (ou seja, $T 1$ cobre todos os elementos requeridos executáveis de $C 1$ ), $T 1$ é também $C 2$-adequado, e existir um programa $P$ e um conjunto $T 2$ que seja $C 2$ adequado e não seja $C 1$-adequado. A complexidade é definida como o número máximo de casos de testes ou de elementos requeridos por um critério, no pior caso.

Rapps e Weyuker (1985) apresentam a relação de inclusão entre os critérios de fluxo de dados. Maldonado (1991) estendeu essa hierarquia inserindo os critérios Potenciais-Usos (Figura 3.3). Pode-se notar, por exemplo, que o critério Todas-Arestas inclui o critério Todos-Nós, ou seja, um conjunto de casos de teste que satisfaz o critério Todas-Arestas também satisfaz o critério TodosNós. Quando não se pode estabelecer essa relação de inclusão entre dois critérios, como é o caso dos critérios Todos-p-Usos e Todas-Defs, diz-se que esses são incomparáveis.

Não existe uma correspondência direta entre a relação de inclusão e a capacidade de revelar erros, ou seja, o fato de um critério $C 1$ incluir um critério $C 2$ não quer dizer necessariamente que $C 1$ tem uma capacidade maior de revelar erros que $C 2$. Alguns autores têm abordado a questão da eficácia dos critérios de teste, definindo outras relações de inclusão entre eles, as quais procuram captar a capacidade em revelar erros (Frankl e Weyuker, 1993; Zhu, 1996; Weyuker e Jeng, 1991).

Os estudos experimentais avaliam os critérios de teste a partir dos seguintes fatores: custo, eficácia e dificuldade de satisfação (strength). O custo refere-se ao esforço necessário para a utilização do critério. Pode ser medido pelo número de casos de teste necessário para satisfazer o 
critério por outras métricas dependentes do critério como, por exemplo, o tempo gasto para identificar caminhos e associações não executáveis. A eficácia refere-se à capacidade de um critério em detectar um maior número de erros em relação a outro. Dificuldade de satisfação refere-se à probabilidade de satisfazer um critério tendo satisfeito outro (Wong, 1993).

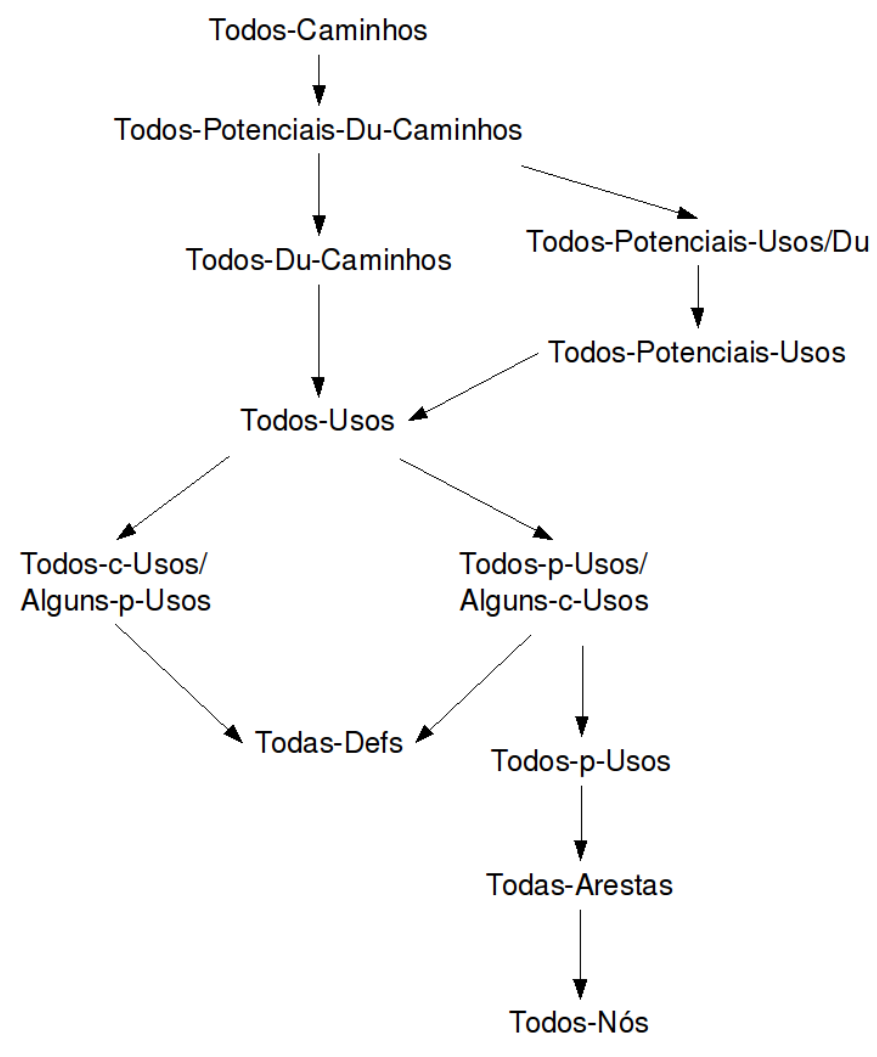

Figura 3.3: Relação de inclusão dos critérios de fluxo de dados, estendida com os critérios Potenciais-Usos (Maldonado et al., 2007).

\subsubsection{Ferramentas}

A aplicação das técnicas e critérios de teste sem a utilização de ferramentas automatizadas como mecanismos de apoio tende a ser extremamente trabalhosa, propensa a erros e limitada a programas muito simples (Horgan e Mathur, 1992; Grady, 1993). Assim, o desenvolvimento de ferramentas que automatizem a aplicação das técnicas e critérios associados é essencial para a qualidade e a produtividade dos testes. Além disso, a existência de ferramentas automatizadas viabiliza a realização de estudos empíricos, auxilia a condução dos testes de regressão e apoia o processo de ensino e aprendizado envolvendo a aplicação prática dos conceitos de teste (Barbosa et al., 2005). Instrumentação de código, geração de elementos requeridos, execução do programa, avaliação da cobertura e geração de casos de teste são atividades do processo de teste de software que necessitam de automatização.

Para apoio ao teste estrutural, existem diversas ferramentas produzidas pela comunidade científica. ASSET (Frankl e Weyuker, 1985) é uma das primeiras ferramentas de apoio aos critérios 
baseados em fluxo de dados para a linguagem Pascal. TACTIC (Ostrand e Weyuker, 1996) é outra ferramenta de apoio aos critérios baseados em fluxo de dados para a linguagem C. $\chi$ Suds (Agrawal et al., 1998) é um conjunto de ferramentas de apoio ao teste, análise e depuração de programas. Uma das ferramentas do $\chi$ Suds é a ATAC (Horgan e London, 1991), que apóia a aplicação de critérios de teste estrutural em programas escritos em $\mathrm{C}$ e C++. A POKE-TOOL (Chaim, 1991) apóia a aplicação dos critérios Potenciais-Usos e outros critérios estruturais em programas escritos em C. A POKE-TOOL trabalha de forma integrada com a ferramenta ViewGraph (Vilela et al., 1997) que possibilita a visualização do GFC. A ferramenta JaBUTi (Vincenzi et al., 2003; Vincenzi, 2004) é um ambiente completo para o entendimento e teste de programas e componentes Java. Uma extensão dessa ferramenta é a JaBUTi/AJ (Lemos, 2005), usada para o teste de unidade de programas Orientado a Aspectos.

\subsection{Considerações finais}

Neste capítulo foram explicados os conceitos relacionados ao teste de software, como a definição de técnicas e critérios de teste. O critério de teste estrutural foi explorado com mais detalhes, já que este foi utilizado nos trabalhos relacionados à ferramenta ValiPar (mais detalhes sobre a ferramenta na Seção 4.4). Estes conceitos são fundamentais para o estudo do teste de programas concorrentes, discutido no próximo capítulo. 
CAPítulo

4

\section{Teste de programas concorrentes}

\subsection{Considerações iniciais}

É possível aplicar o conhecimento existente sobre teste de software, adquirido durante a validação de programas sequenciais, para testar programas concorrentes. Os programas concorrentes possuem os mesmos problemas que programas sequenciais: corretitude, não-executabilidade, equivalência, dentre outros. Além desses, o teste aplicado a programas concorrentes apresenta dificuldades não encontradas em programas sequenciais (Yang, 1999; Yang e Pollock, 1997), devido a características que tornam a atividade de teste mais complexa, como: não-determinismo, concorrência, sincronização, comunicação, dentre outras (Wong et al., 2005; Vergilio et al., 2005).

Yang e Pollock (1997) discutem os desafios que precisam ser tratados ao se construir mecanismos para o teste de programas concorrentes. Esse trabalho foca em critérios estruturais para programas desenvolvidos no paradigma de memória compartilhada. Porém os desafios apresentados podem ser considerados para programas concorrentes em geral. Alguns desses desafios são:

1. Desenvolver técnicas de análise estática para analisar programas concorrentes.

2. Detectar situações não desejadas, como erros de sincronização, de comunicação, de fluxo de dados e de deadlock.

3. Reproduzir uma execução com a mesma entrada de teste e forçar a execução de um caminho na presença de não-determinismo.

4. Gerar uma representação do programa concorrente que capture informações pertinentes ao teste. 
5. Investigar a aplicação de critérios de teste sequenciais para programas concorrentes.

6. Projetar critérios de fluxo de dados para programas concorrentes, considerando troca de mensagens e variáveis compartilhadas.

Neste capítulo, são apresentados trabalhos relacionados ao teste estrutural aplicado a programas concorrentes, assim como trabalhos que tratam de modelos de teste que focam na redução do custo do teste de programas concorrentes. Este capítulo está organizado da seguinte forma. Na Seção 4.2 são apresentados modelos e critérios de teste para programas concorrentes. A Seção 4.3 apresenta algumas ferramentas desenvolvidas para o apoio do teste de programas concorrentes. $\mathrm{Na}$ Seção 4.4 a ferramenta ValiPar é discutida com mais detalhes.

\subsection{Modelos e critérios de teste}

A Subseção 4.2.1 cita alguns trabalhos relacionados no contexto de teste estrutural aplicado a programas concorrentes, incluindo os critérios e modelo propostos por Vergilio et al. (2005), implementados na ferramenta ValiPar e utilizados neste trabalho. A Subseção 4.2.3 apresenta dois trabalhos, Wong et al. (2005) e Seo et al. (2006), que focam na geração de sequências de teste, sendo que o primeiro utiliza grafo de alcançabilidade e o segundo aplica o teste de especificação utilizando statecharts. A Subseção 4.2.2 detalha o teste de alcançabilidade proposto em Lei e Carver (2006) e estendido em Lei et al. (2007). Uma comparação dessas propostas de teste é apresentada na Subseção 4.2.4.

\subsubsection{Critérios de teste estruturais}

Existem alguns trabalhos de pesquisa voltados à extensão de critérios estruturais para o contexto de aplicações concorrentes, como Taylor et al. (1992), Yang e Chung (1992), Yang et al. (1998), Yang (1999), Koppol et al. (2002) e Vergilio et al. (2005). A maioria desses trabalhos concentra-se em programas desenvolvidos no paradigma de memória compartilhada, com exceção de Vergilio et al. (2005).

No trabalho de Yang et al. (1998) é descrita a geração de casos de teste de acordo com o critério Todos-Du-Caminhos (All Du-Paths) para teste de programas concorrentes por memória compartilhada. O modelo utilizado nesse trabalho considera múltiplas threads que podem ser executadas simultaneamente, sendo que a comunicação é feita por variáveis compartilhadas. Esse modelo é chamado Parallel Program Flow Graph (PPFG) ou grafo de fluxo de programa paralelo. O PPFG tem como principal diferença para o GFC a criação de três tipos de arcos: arcos de fluxo de controle intra-thread, arcos de sincronização e arcos de criação de thread. Em um trabalho seguinte de Yang e Pollock (2003) é discutido o desenvolvimento de ferramentas para o teste de cobertura Todos-Usos de programas concorrentes, baseando-se no modelo PPFG. 
Ao se tratar de programas concorrentes desenvolvidos no paradigma de passagem de mensagens, novos aspectos precisam ser considerados. Por exemplo, uma associação entre a definição de uma variável e seu uso podem ocorrer em espaços de endereçamento diferentes. Vergilio et al. (2005) propõem uma família de critérios estruturais para o teste de programas concorrentes em ambientes de passagem de mensagens. Além disso, esse trabalho propõe um Grafo de Fluxo de Controle Paralelo (GFCP), o qual é formado pelos GFCs (Grafo de Fluxo de Controle) de cada processo. O GFCP inclui o conceito de nós de sincronização ao GFC, associados aos comandos send e receive, e de arestas de sincronização. Essa representação é baseada no PPFG, tendo como principal diferença que no GFCP são considerados processos concorrentes executando em diferentes espaços de memória.

O modelo GFCP possui, além dos usos computacional (c-uso) e predicativo (p-uso) de variáveis, o uso comunicacional ( $s$-uso). Esse uso ocorre quando há uma referência à variável em comandos de sincronização (send e receive), em arestas interprocessos (arestas de sincronização). A partir disso, podem-se caracterizar também associações s-uso, que ocorrem quando há um caminho livre de definição entre a definição e uso de uma variável, e estes ocorrem em processos diferentes, ou seja, o caminho possui um s-uso da variável.

A partir do GFCP, os seguintes critérios de fluxo de controle foram definidos: todos-nós, todasarestas, todos-nós-r e todos-nós-s, relacionados a nós com receives e sends, respectivamente, e todas-arestas-s, relacionado a todas as possíveis arestas de sincronização. Além desses, foram propostos critérios baseados em fluxo de dados, como: todos-c-usos, todos-p-usos, todos-s-usos, todos-s-c-usos e todos-s-p-usos.

Sarmanho et al. (2008) propõem critérios de teste para programas multithread baseados em semáforos. Esses critérios são baseados nos propostos por Vergilio et al. (2005) para o paradigma de passagem de mensagem. Em programas multithreads baseados em semáforos, a comunicação é implícita, utilizando-se variáveis compartilhadas, o que dificulta a identificação do par de sincronização. Assim, Sarmanho et al. (2008) define um método post mortem baseado em timestamps para estabelecer os pares de definição e uso de variáveis compartilhadas e, consequentemente, determinar quais arestas de sincronização entre as threads foram executadas.

O Programa 4.1 apresenta uma implementação do Crivo de Eratóstenes concorrente utilizando MPI. No Apêndice A são apresentados a descrição do algoritmo do Crivo de Eratóstenes e um exemplo de execução da ferramenta ValiPar para esse programa. A Figura 4.1 ilustra o GFCP associado a esse programa. Esse código é baseado na solução apresentada em Quinn (2004) ${ }^{1}$. O programa considera que a quantidade $p$ de processos é maior ou igual a $\sqrt{n}$ (onde, semelhantemente ao Programa 3.1, deseja-se obter os primos menores ou iguais a $n$ ) e, consequentemente, o primeiro processo $\left(p_{0}\right)$ é responsável por achar o próximo primo. O código referente à execução do processo $p_{0}$ é implementado pela função p0() (ilustrada no grafo pelos nós de cor branca), enquanto os demais processos executam a função pi() (ilustrada no grafo pelos nós de cor cinza).

\footnotetext{
${ }^{1}$ Código-fonte disponível em http://fac-staff.seattleu.edu/quinnm/web/education/ParallelProgramming/mpi/ chapter5/sieve1.c (acessado em 22/01/2011)
} 
As arestas de sincronização são representadas no GFCP pelas arestas tracejadas (por exemplo, a aresta que liga o nó 7 de $p_{0}$ ao nó 3 de $p_{i}$ representa a sincronização do MPI_Send da linha 64 com o MPI_Recv da linha 85 - nessa aresta ocorre um s-uso da variável prime).

Programa 4.1: Código do crivo concorrente.

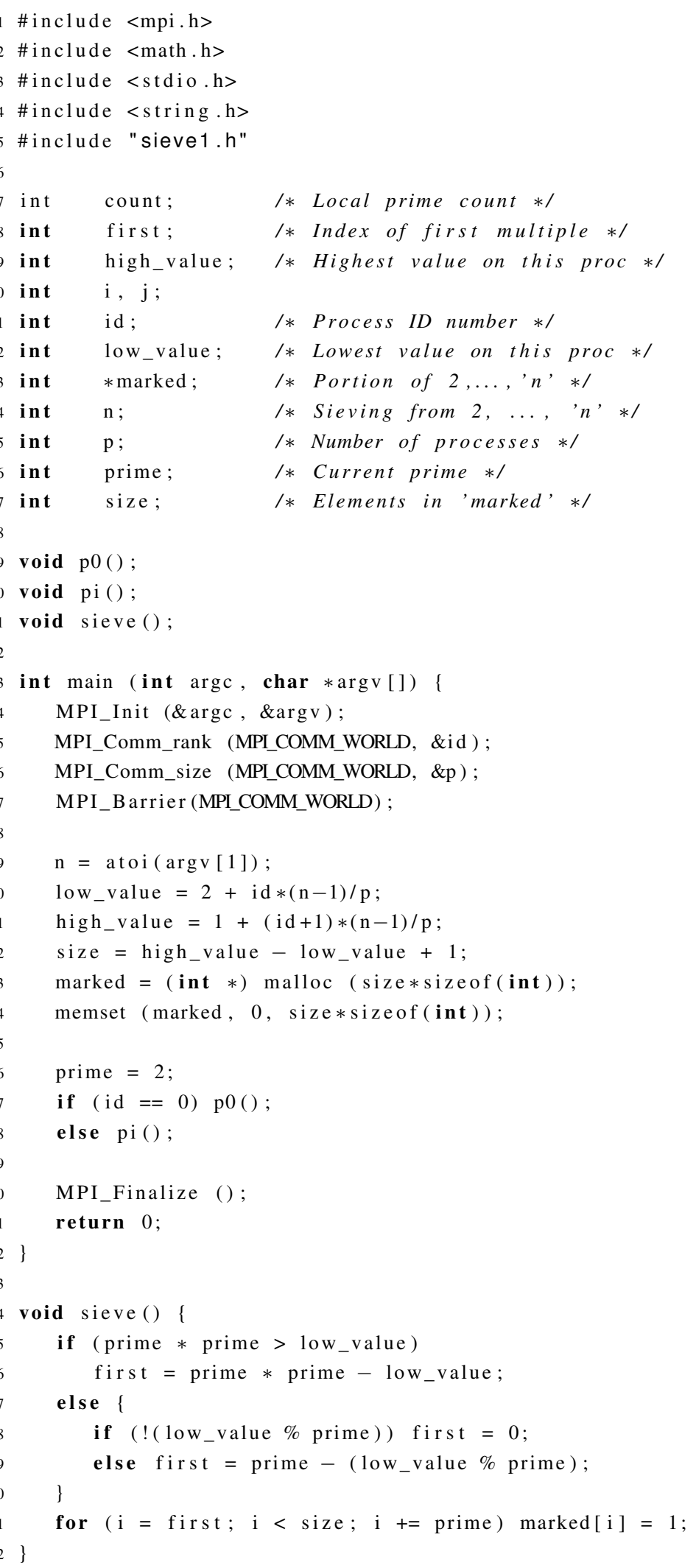




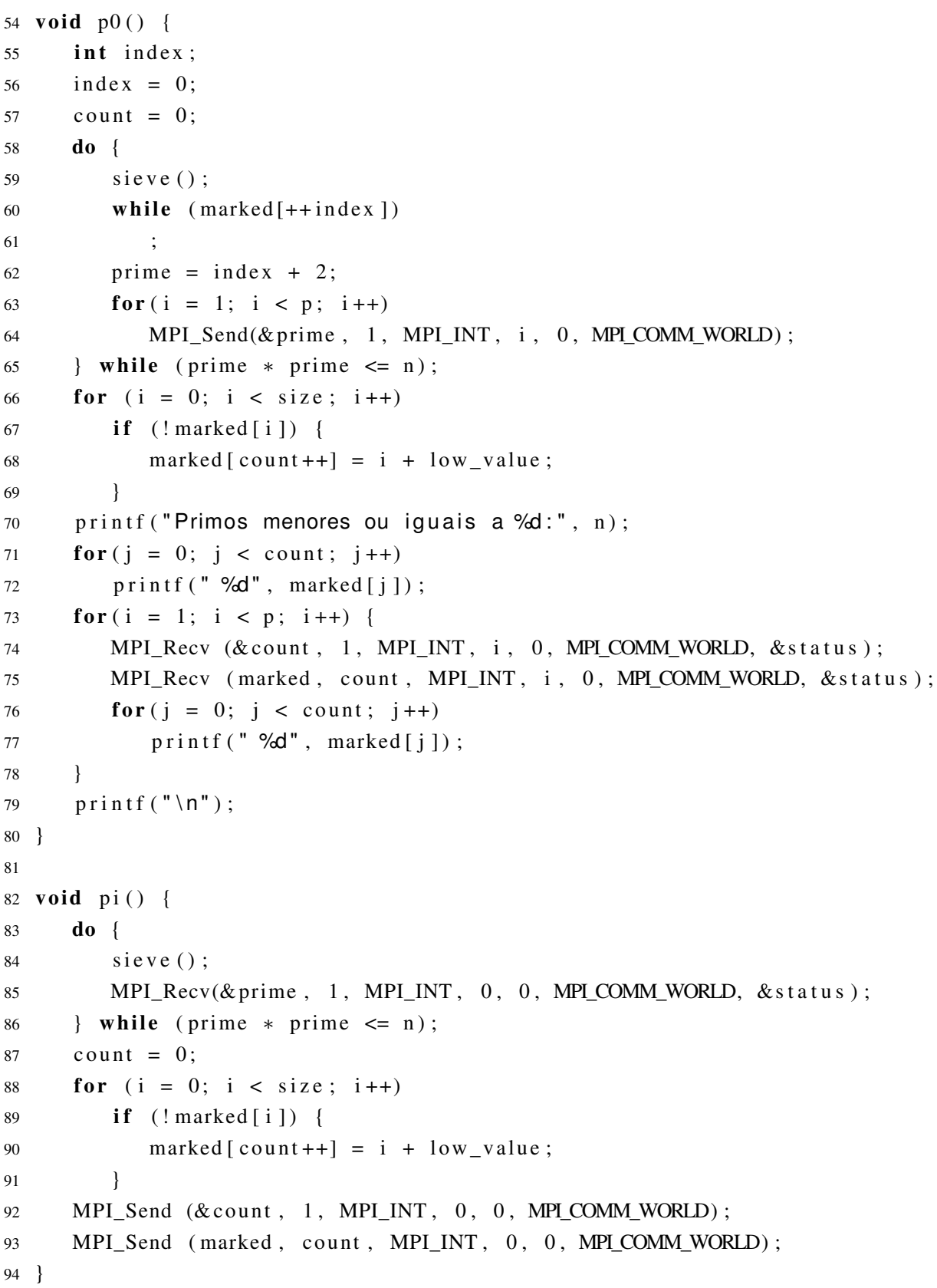

Um dos principais problemas a ser tratado no modelo GFCP são os elementos não-executáveis relacionados a sincronizações. O modelo requer a execução de todos os pares send-receive de modo a cobrir todas as sincronizações possíveis, porém muitas dessas são não-executáveis. Em geral, um par send-receive não é executável por duas razões: lógica do programa e sequência de execução. Em Endo (2008) é proposto um método para identificar pares que se enquadram nesse segundo caso. Nessa proposta, as redes de Petri são utilizadas como um modelo intermediário para identificar os arcos inter-processos não-executáveis. O método transforma o GFCP em uma rede de Petri. Para essa rede, é gerada sua árvore de cobertura. A partir dessa árvore de cobertura é possível obter informações sobre quais arcos não são executáveis. 


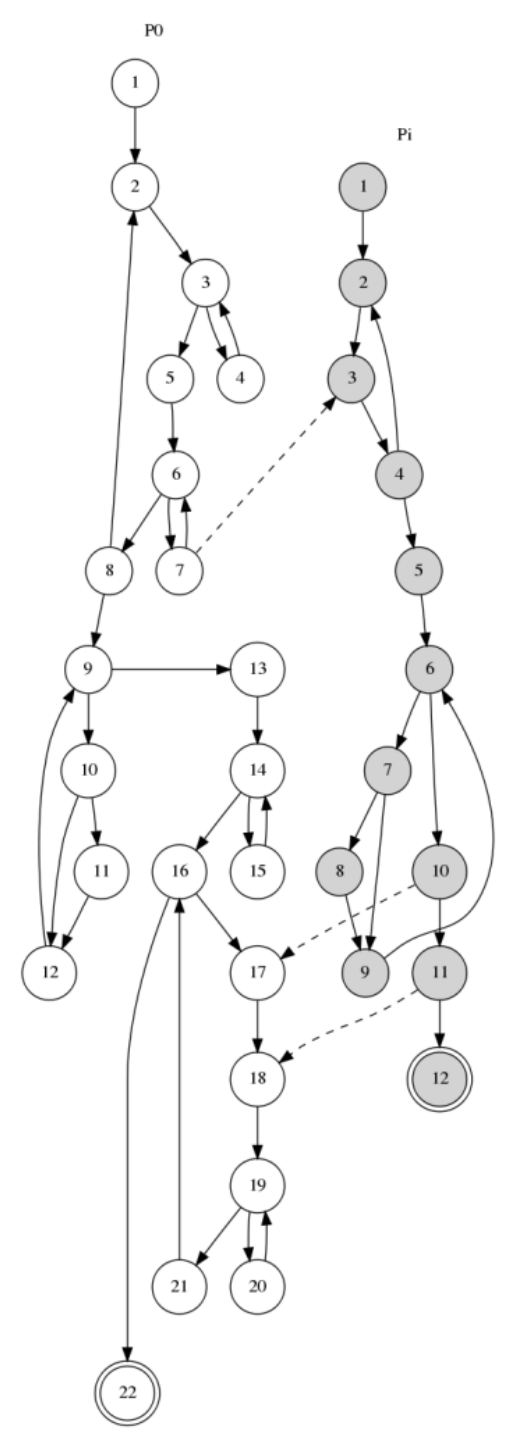

Figura 4.1: GFCP do crivo concorrente.

Dois algoritmos foram propostos por Endo (2008) para a transformação do GFCP em uma rede de Petri. A diferença entre os algoritmos é que no primeiro, algoritmo A, o send apresenta um comportamento não-bloqueante, enquanto no segundo, algoritmo $\mathrm{B}$, o send tem um comportamento bloqueante, ou seja, o token só passa para o próximo lugar caso a sincronização (arco inter-processos) ocorra. Cada nó $n_{i}$ do GCFP é mapeado para um lugar $p_{n_{i}}$ na rede de Petri, e cada arco intra-processo $\left(n_{i}, n_{j}\right)$ é mapeado para uma transição $t_{n_{i}, n_{j}}$. Além disso, lugares a mais são criados para cada evento send e receive (para cada nó $n_{i} \in N_{s}$, é criado um lugar $s_{n_{i}}$ e para cada nó $n_{j} \in N_{r}$, é criado um lugar $r_{n_{j}}$ ), assim como uma transição $s y n c_{n_{i}, n_{j}}$ para cada arco inter-processo $\left(n_{i}, n_{j}\right)$. O comportamento das sincronizações, ou seja, se essas são bloqueantes ou não-bloqueantes é definida através dos arcos entre os lugares e transições.

Após a construção da rede de Petri são identificados os arcos inter-processos que não são executáveis. Para isso, é criada uma árvore de cobertura da rede de Petri gerada. A árvore de cobertura é gerada a partir de uma marcação inicial, obtendo-se novas marcações para cada uma das 
transições habilitadas. Assim, gera-se uma árvore em que cada nó representa uma marcação, tendo como raiz a marcação inicial, e cada arco representa a transição habilitada que transformou uma marcação em outra. O algoritmo utilizado para a geração da árvore de cobertura é o apresentado em Murata (1989).

Dado um GFCP $g$, é gerada uma rede de Petri $P N_{g}$, usando um dos algoritmos propostos. A seguir, é criada a árvore de cobertura $C G_{P N_{g}}$. Para cada arco inter-processos $e=\left(n_{i}, n_{j}\right) \in E_{s}$ de $g$, se $s_{y n c_{i}, n_{j}}$ não aparece em $C G_{P N_{g}}$, então $e$ é não-executável. Nada pode-se afirmar sobre os arcos inter-processos que aparecem em $C G_{P N_{g}}$, apenas que a sequência de execução permite que eles sejam executados. Fatores como expressões condicionais e dados de entrada podem tornar esses arcos não-executáveis.

\subsubsection{Teste de alcançabilidade}

Lei e Carver (2006) apresentam o teste de alcançabilidade de programas concorrentes. Diferentemente das abordagens anteriores, o teste de alcançabilidade determina, durante a execução, quais sincronizações são possíveis de ocorrer em uma nova execução. O teste de alcançabilidade proposto utiliza a técnica de teste baseado em prefixo, que executa o teste deterministicamente até certo ponto e após esse ponto permite a execução não-determinística do programa. $\mathrm{O}$ teste de alcançabilidade utiliza um framework onde as sequências de sincronizações ( $S Y N$-sequences) são derivadas automaticamente e on-the-fly, sem construir nenhum modelo estático. O teste de alcançabilidade realiza uma execução não controlada, produzindo uma sequência de sincronizações $Q_{0}$. A partir de $Q_{0}$, identificam-se "condições de disputa" nos eventos receive, gerando variantes dessa sequência. As variantes são prefixos de $Q_{0}$ com uma ou mais sincronizações modificadas. Essas variantes são utilizadas para realizar execuções controladas baseadas em prefixo com a mesma entrada, exercitando as sincronizações da variante. Como as sequências são derivadas a partir de uma execução do programa, essa abordagem não apresenta o problema da não-executabilidade.

A Figura 4.2 apresenta um exemplo da geração de variantes realizada pelo teste de alcançabilidade proposto por Lei e Carver (2006). $Q_{0}$ é representada em um diagrama espaço-tempo, onde cada linha vertical representa uma thread e as demais setas representam mensagens entre eventos send e receive. $V_{1}, V_{2}$ e $V_{3}$ são variantes geradas a partir de $Q_{0}$, dando origem às sequências $Q_{1}$, $Q_{2}$ e $Q_{3}$, respectivamente. Como citado anteriormente, essas variantes são geradas a partir de uma execução do programa, portanto não ocorre o problema da não-executabilidade, ou seja, as variantes possuem somente sincronizações executáveis.

Definição: Uma sequência de sincronizações $Q$ exercitada por uma execução de um programa concorrente é definida pela tupla $\left(Q_{1}, Q_{2}, \ldots, Q_{n}, \phi\right)$, onde $Q_{i}$ é a sequência de eventos send e receive ocorridos em uma thread ou objeto de sincronização (semáforo ou monitor) e $\phi$ é o conjunto de pares de sincronização que ocorreram durante a execução. 


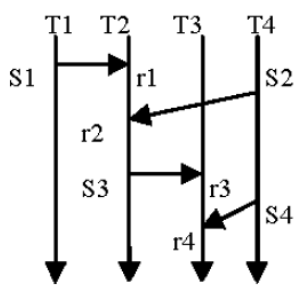

$\mathrm{Q}_{0}$

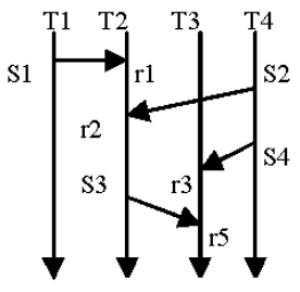

$\mathrm{V} 1 / \mathrm{Q}_{1}$

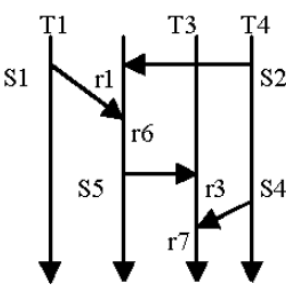

$\mathrm{V} 2 / \mathrm{Q}_{2}$

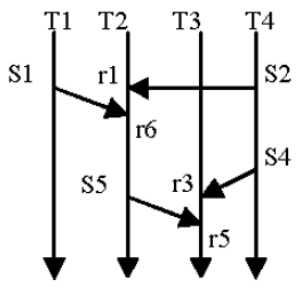

$\mathrm{V} 3 / \mathrm{Q}_{3}$

Figura 4.2: Geração de variantes no teste de alcançabilidade (Lei e Carver, 2006).

Os eventos send são descritos como uma tupla (Sender, Destination, Operation, $i$ ), onde Sender é a thread que executa o evento, Destination é a thread ou objeto de sincronização destino, Operation é o tipo de operação realizada ( $P, V$, send, receive, etc.), e $i$ é o índice do evento indicando que $s$ é o $i$-ésimo evento na thread. Os eventos receive são descritos pela tupla (Receiver, OpenList, i), onde Receiver é a thread ou objeto de sincronização onde ocorre o evento receive, OpenList é uma lista das threads que podem enviar para esse receive, utilizada para identificar condições de disputa, e $i$ é o índice do evento indicando que $r$ é o $i$-ésimo evento na thread.

Cada thread, assim como cada evento send e receive, é associada a um vetor com timestamps, utilizado para determinar a relação happened-before entre eventos. Um evento $e_{1}$ aconteceu antes de um evento $e_{2}$, denotado por $e_{1} \rightarrow e_{2}$, se e somente se: $(1)<e_{1}, e_{2}>$ é um par de sincronização, ou (2) $e_{1} \cdot t s\left[e_{1} . t i d\right] \leq e_{2} . t s\left[e_{1} . t i d\right]$ e $e_{1} \cdot t s\left[e_{2} . t i d\right]<e_{2} . t s\left[e_{2} . t i d\right]$, onde $e_{i} . t s[]$ e $e_{i} . t i d$ são o vetor de timestamps e o $i d$ da thread em que o evento ocorreu, respectivamente. Intuitivamente, $e_{1} \rightarrow e_{2}$ se $e_{1}$ pode afetar a execução de $e_{2}$. Note que existe uma diferença entre os eventos que ocorreram antes de um evento $e$, pois alguns podem ter influência na execução ou não deste. Um evento que ocorre antes na mesma thread pode influenciar na execução ou não de um evento receive (alterando o resultado de um if, por exemplo), porém o send que sincroniza com este não influencia. Assim, define-se o $c$-struct(e,Q), que é o prefixo de $Q$ que contém o evento $f$ imediatamente anterior a $e$ na mesma thread, e todos os eventos que aconteceram antes de $f$.

Definição: Seja $Q$ uma sequência de sincronizações. Seja $s$ um evento send e $r$ um evento receive pertencentes a $Q$ tal que $<s, r>$ é um par de sincronização. O conjunto de disputa de $r$ em $Q$, denotado por race_set $(r, Q)$, é o conjunto de eventos send em $Q$ para os quais existe uma condição de disputa com $s$ em relação a $r$, ou seja, eventos que poderiam sincronizar com $r$. Formalmente,

race_set $(r, Q)=\left\{s^{\prime} \in Q \mid\right.$ existe uma disputa entre s' e s com respeito a $\left.r\right\}$

Uma variante $V$ de uma sequência $Q$ é derivada mudando-se o send que sincroniza com um ou mais receive, devendo satisfazer as restrições de que se mudarmos o send que sincroniza com um evento $r$, este deve pertencer a race_set $(r, Q)$, e ao mudarmos o parceiro de $r$, todos os eventos $e_{i}$ tal que $r \in c$-struct $\left(e_{i}, Q\right)$ devem ser removidos. As variantes podem ser calculadas utilizando uma "tabela de disputa". Cada coluna representa um evento $r$, e cada linha representa uma variante. $\mathrm{O}$ 
valor $v$ em uma certa posição pode assumir os valores $v=-1$, indicando que $r$ foi removido de $V, v=0$, indicando que o send que sincroniza com $r$ não mudou ou $v>0$, indicando que $r$ irá sincronizar com o $v$-ésimo evento em race_set $(r, Q)$.

As variantes de uma sequência $Q$ são obtidas iterativamente, gerando-se todos os números de um sistema numérico. Cada coluna corresponde a um dígito, cuja base é o tamanho do race_set mais um. Ao mudarmos o valor para um certo evento $i$ de 0 para 1 , todo evento $j$ tal que $i \in$ $c \_s t r u c t(j)$, o valor da coluna de $j$ deve ser mudado para -1 , ou seja, todos os eventos que podem ser afetados pelo evento $i$ são removidos da variante. Ao mudarmos o valor para um certo evento $i$ de $\mid$ race_set $(i, Q) \mid$ para 0 , os eventos que possuíam valor -1 somente por causa de $i$ devem ter seu valor mudado para 0 .

As possíveis sequências de sincronizações de um programa concorrente $P$ com uma entrada $X$ podem ser representadas em um grafo $G$. Cada nó $n$ em $G$ representa uma sequência $\operatorname{seq}(n)$. Cada aresta representa uma variante. Uma aresta $e$ do nó $n$ para o nó $n^{\prime}$ representa uma variante $\operatorname{var}(e)$ de $\operatorname{seq}(n)$, e $\operatorname{seq}\left(n^{\prime}\right)$ pode ser exercitada fazendo uma execução com var $(e)$. Assim, o teste de alcançabilidade pode ser visto como o problema de gerar uma árvore de cobertura para o grafo G.

Uma aresta $e_{i}$ reconcilia uma diferença entre $\operatorname{seq}\left(n_{i}\right)$ e $\operatorname{seq}\left(n^{\prime}\right)$ se o send que sincroniza com $r$ em $\operatorname{seq}\left(n_{i}\right)$ é explicitamente modificado por $e_{i}$ para ser o mesmo de seq $\left(n^{\prime}\right)$. Para garantir que não haverá ciclos na árvore de cobertura, quando uma variante modifica explicitamente $\operatorname{send}(r, Q)$ de $s$ para $s^{\prime}$, esse par deve continuar sincronizado em toda sequência $Q^{\prime}$ exercitada posteriormente. Além disso, cada aresta $e_{i}$ deve reconciliar todas as diferenças entre $\operatorname{seq}\left(n_{i}\right)$ e $\operatorname{seq}\left(n^{\prime}\right)$. Caso uma variante pudesse modificar o valor de um receive, mas não o faz, garante-se que essa mudança não será realizada nas sequências geradas a partir dessa, garantindo assim que exista no máximo um caminho de um nó $n$ até um nó $n^{\prime}$.

A abordagem proposta em Lei e Carver (2006) gera todas as possíveis sequências de sincronizações a partir de uma execução, podendo vir a gerar uma quantidade muito grande de sequências. O trabalho de Lei et al. (2007) propõe a aplicação de uma estratégia combinatorial durante a geração das sequências, a fim de diminuir o número de sequências a serem exercitadas. A estratégia utilizada para a geração desse subconjunto de sequências é o teste de $t$-vias ( $t$-way testing). $\mathrm{O}$ teste de $t$-vias requer que todas as combinações de valores para quaisquer $t$ parâmetros sejam incluídos em algum caso de teste. O teste de $t$-vias parte do pressuposto de que nem todos os parâmetros contribuem para todos os erros, e que muitos erros podem ser descobertos considerando interações entre um pequeno número de parâmetros.

O algoritmo utilizado para o teste de $t$-vias é o IPO (In-Parameter-Order) (Tai e Lie, 2002). Esse algoritmo gera todas as combinações para os primeiros $t$ parâmetros, estende o conjunto gerado para $t+1$ parâmetros, e assim por diante, até que todos os $n$ parâmetros tenham sido utilizados. A quantidade de sequências geradas para o teste exaustivo é da ordem de $v^{n}$, enquanto no teste de $t$-vias o número de sequências geradas é da ordem de $v^{t} \log n$, onde $n$ é o número total de parâmetros, e $v$ são os possíveis valores para esses parâmetros. 


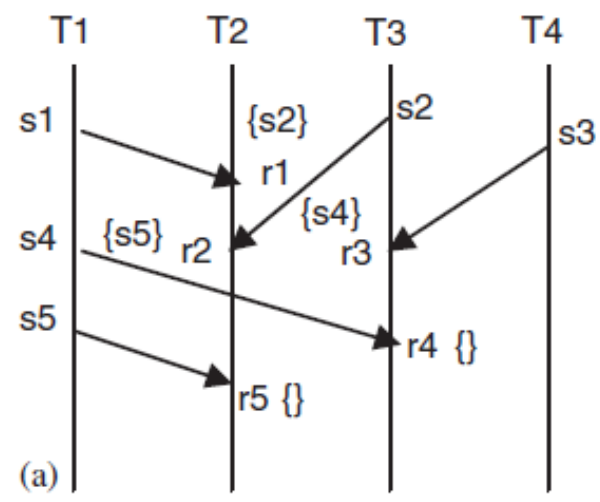

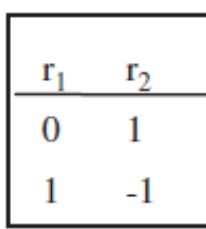

(b)

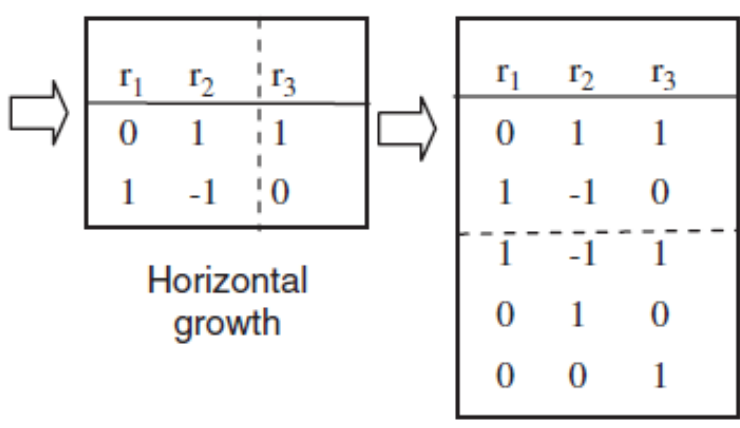

Vertical Growth

Figura 4.3: Exemplo de construção da tabela de disputa: (a) exemplo de sequência de sincronizações e (b) tabela de disputas sendo estendida através do crescimento horizontal e vertical (Lei et al., 2007).

O teste de alcançabilidade de $t$-vias modifica o algoritmo de Lei e Carver (2006) na função de geração das variantes (ConstructRaceTable). Os eventos receive são considerados como os parâmetros, e suas possíveis sincronizações como os valores. Para gerar a tabela com as sequências, os eventos receive são ordenados topologicamente. São geradas as sequências para os $t$ primeiros parâmetros, e esse conjunto é estendido para cobrir o parâmetro $t+1$ (e posteriormente os demais) seguindo dois passos: o crescimento horizontal e o crescimento vertical.

O crescimento horizontal consiste em estender cada linha já existente adicionando um valor para o novo evento receive. Utiliza uma estratégia gulosa, escolhendo o valor que cubra o maior número de combinações possíveis. O crescimento vertical cobre as demais combinações, modificando uma linha existente (caso seja possível), ou adicionando uma nova linha. A Figura 4.3 exemplifica a construção das variantes, utilizando o crescimento horizontal e vertical. A Figura 4.3(a) apresenta uma sequência de sincronizações de exemplo. Os valores entre chaves próximos a cada receive representam o race_set desse receive, ou seja, os eventos send que poderiam sincronizar com esse receive com a mesma entrada e a mesma sequência de sincronizações até esse ponto. A Figura 4.3(b) exemplifica a construção da tabela de disputa para essa sequência, para o teste de 2-vias. A primeira tabela apresenta todas as possíveis sequências considerando os dois primeiros eventos receive, $r_{1}$ e $r_{2}$. Como $r_{1}$ pode afetar a execução de $r_{2}$, quando o valor de $r_{1}$ na tabela é modificado para 1 , o valor de $r_{2}$ é modificado para -1 . A seguir, é realizado o crescimento horizontal e vertical, como descrito anteriormente. Na primeira sequência da segunda tabela, o valor 1 foi escolhido para $r_{3}$ pois este cobre duas combinações ainda não cobertas $\left(0\right.$ e 1 para $r_{1}$ e $r_{3}$, e 1 e 1 para $r_{2}$ e $r_{3}$ ). Caso o valor 0 fosse escolhido, somente uma combinação seria coberta (a combinação 0 e 0 para $r_{1}$ e $r_{3}$ já foi coberta pela sequência original).

Após a construção da tabela de variantes, o algoritmo segue como o original, utilizando as linhas geradas na tabela para derivar as sequências de sincronizações a serem executadas. Como a estratégia combinatorial não gera todas as combinações possíveis dos valores dos parâmetros, uma quantidade menor de variantes é executada, a fim de evitar o teste exaustivo da proposta original. 


\subsubsection{Geração de sequências de teste}

Uma abordagem para o teste determinístico de programas concorrentes é a geração de sequências de teste. O objetivo é gerar, a partir de um modelo do programa, um conjunto de sequências de sincronizações que consiga revelar falhas no programa, derivando os casos de teste a partir dessas sequências. A seguir, são apresentados dois trabalhos que tratam da geração eficiente de sequências de teste em diferentes contextos, o primeiro focando no teste estrutural de programas concorrentes e o segundo baseando-se no teste de especificação.

Uma abordagem para a geração de sequências de teste para o teste estrutural de programas concorrentes é a construção de um grafo de alcançabilidade (reachability graph - RG). Em um RG cada nó representa um estado que pode ser alcançado pelo programa e cada aresta representa uma transição entre dois estados alcançáveis. Logo, uma sequência de sincronizações pertencente a um caminho em um RG é executável. O RG apresenta como vantagem em relação ao GFC (grafo de fluxo de controle) o fato de não apresentar caminhos não-executáveis, porém com a desvantagem de que o tamanho do RG pode vir a ser muito maior que o GFC. Assim, são necessários métodos que consigam gerar sequências de teste que aumentem a cobertura de maneira eficiente. Wong et al. (2005) apresentam quatro métodos para a geração de sequências de teste, dois baseados em hot spot priorization, e dois baseados em ordenação topológica, visando satisfazer os critérios todos-nós e todas-arestas.

Os métodos baseados em hot spot priorization consistem em encontrar hot spots, ou seja, nós não cobertos com peso máximo. O primeiro método $\left(M_{1}\right)$ utiliza uma abordagem conservadora, enquanto o segundo método $\left(M_{2}\right)$ utiliza uma abordagem agressiva. O peso de um nó no método $M_{1}$ é o número de nós não cobertos no menor caminho da raiz do grafo até esse nó, enquanto no método $M_{2}$ é o número de nós não cobertos no maior caminho da raiz do grafo modificado (retirando-se os ciclos) até esse nó. Após o cálculo dos pesos de cada nó, o hot spot é encontrado, e é realizado um backtracking até a raiz, escolhendo os nós da sequência seguindo uma estratégia gulosa, ou seja, o nó não coberto com maior peso é escolhido para fazer parte do caminho. Esse caminho encontrado da raiz até o hot spot corresponde a uma sequência de teste. Os pesos dos nós são então calculados novamente, e o processo se repete até que todos os nós tenham sido cobertos.

Os métodos $M_{3}$ e $M_{4}$ realizam uma ordenação topológica dos nós (retirando os ciclos do grafo original), e a seguir essa lista de nós é invertida. A lista invertida é utilizada para gerar as sequências de teste. Esses métodos partem do pressuposto de que, como os nós estão ordenados topologicamente, realizar a cobertura dos nós dessa maneira tem uma boa chance de gerar uma sequência que cobre mais nós, aumentando a cobertura eficientemente. O método $M_{3}$ utiliza busca em largura para realizar a ordenação topológica, enquanto o método $M_{4}$ utiliza busca em profundidade. Somente uma ordenação topológica é realizada nos métodos $M_{3}$ e $M_{4}$, enquanto nos métodos $M_{1}$ e $M_{2}$ deve-se recalcular os hot spots a cada sequência gerada. 
Para gerar sequências de teste que satisfaçam o critério todas-arestas, é gerado um grafo dual onde cada nó deste representa uma aresta do grafo original, e cada aresta representa um nó do grafo original. Um pseudo-nó é adicionado no grafo como origem das arestas que representam a raiz do grafo original, e como destino das arestas que representam folhas do grafo original. Com essa conversão, os métodos utilizados para satisfazer o critério todos-nós podem ser utilizados para satisfazer o critério todas-arestas, aplicando-os no grafo dual gerado. A Figura 4.4 mostra um grafo de alcançabilidade e o grafo dual gerado a partir desse grafo.
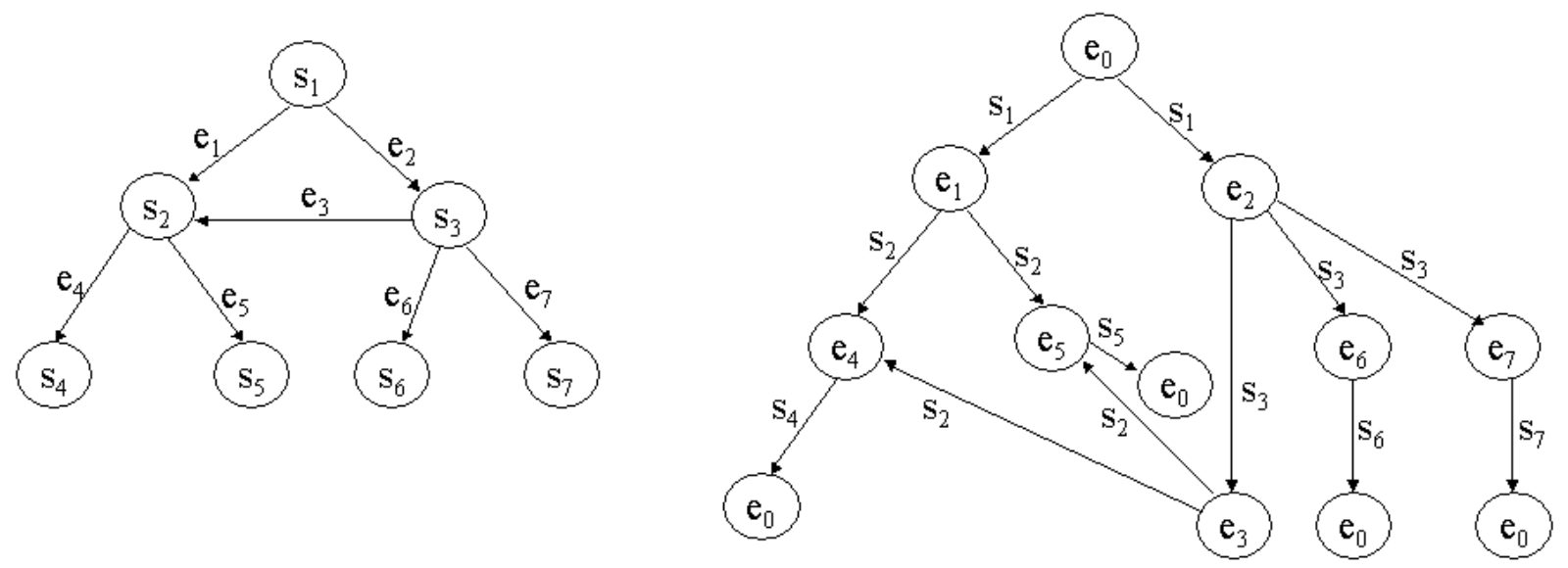

Figura 4.4: Exemplo de grafo de alcançabilidade e seu grafo dual (Wong et al., 2005).

A complexidade dos métodos $M_{1}$ e $M_{2}$ é de $\Theta(n V(V+E))$. O passo mais custoso é o cálculo dos pesos. $V+E$ é o tempo para computar o peso de cada nó (portanto, $\Theta(V(V+E))$ para calcular todos os pesos). $n$ é o número de sequências de teste geradas. A complexidade dos métodos $M_{3}$ e $M_{4}: \Theta\left(n^{\prime}(V+E)\right)$. O passo mais custoso é encontrar um caminho da raiz até o nó selecionado $(\Theta(V+E))$. $n^{\prime}$ é o número de sequências de teste geradas. A ordenação topológica tem custo $\Theta(V+E)$, porém só é realizada uma vez.

Wong et al. (2005) também apresentam um estudo de caso, utilizando grafos de alcançabilidade de cinco programas. Em geral, quanto maior o número de nós e arestas, maior o número de sequências geradas. Quando o grafo é pequeno, o número de sequências geradas é próximo para todos os métodos. Porém, conforme o grafo aumenta, a quantidade de sequências geradas pelos métodos $M_{1}$ e $M_{2}$ é menor que pelos outros dois. Uma razão para isso é que a cada sequência gerada um novo hot spot é identificado, enquanto em $M_{3}$ e $M_{4}$ a ordenação topológica é realizada somente no início.

O trabalho de Seo et al. (2006), diferentemente dos apresentados anteriormente, trata do teste baseado em especificação aplicado a programas concorrentes. O teste baseado em especificação executa o programa utilizando sequências geradas a partir da especificação desse, com o objetivo de verificar se todos os comportamentos presentes em sua especificação foram implementados. Como podem existir diversas sequências de teste para um mesmo comportamento, são geradas apenas sequências representativas, ou seja, uma sequência para cada possível comportamento do programa concorrente. As sequências são geradas a partir de um statechart. A especificação 
utilizando statecharts é uma extensão das máquinas de estados finitos, baseada em três elementos: hierarquia, concorrência e comunicação utilizando broadcast (Harel et al., 1987).

Como nem todos os eventos em uma thread afetam todas as outras threads, pode-se definir configurações abstratas do statechart. Assim, é definido um estado don't care, denotado por ‘*'. Um estado don't care em um componente do statechart é um estado especial que pode ser substituído por qualquer estado daquele componente. Uma configuração abstrata de um statechart é uma configuração que pode ter estados don't care em alguns dos componentes, enquanto uma configuração concreta deve ter estados especificados para todos os componentes. Com isso, define-se também um PMS (possible macro step), que são transições entre configurações abstratas. A definição de configurações abstratas e PMSs parte da observação de que eventos em uma thread normalmente afetam apenas um subconjunto dos componentes concorrentes.

Utilizando a técnica stubborn set (Valmari, 1991) pode-se gerar um grafo de alcançabilidade reduzido. A ideia básica é reduzir os estados no grafo àqueles alcançáveis através de transições dependentes, ou seja, ignorar transições independentes entre si. A partir desse grafo de alcançabilidade reduzido, são geradas sequências de PMS $w$, que são representativas em relação ao comportamento do programa concorrente. Para cada sequência $w_{i}$, é gerado um autômato para identificar sequências que estão na mesma "classe" da sequência $w_{i}$, ou seja, que representam o mesmo importamento que $w_{i}$. Assim, testando-se uma sequência de cada classe, pode-se cobrir todos os possíveis comportamentos do programa, sem precisar testar todas as possíveis sequências.

Os estudos realizados pelos autores demostram que a utilização de PMSs e do grafo de alcançabilidade reduzido consegue diminuir o número de sequências de teste que devem ser geradas, se comparado ao teste determinístico a partir do grafo de alcançabilidade completo. Os autômatos gerados são utilizados para controlar a execução do teste, para assim checar se o programa sendo testado implementa pelo menos uma das sequências aceitas por esse autômato. Assim, o número de execuções de teste necessárias passa a ser o número de autômatos gerados, e ainda assim testa todos os possíveis comportamentos do programa. Os autores não abordam a geração das sequências de teste para cobrir os PMSs gerados, e também não demonstram se estas contribuem de fato para o teste, ou seja, qual a eficácia dessas em revelar erros.

\subsubsection{Comparação entre os modelos de teste}

Como citado na Seção 1.2, o objetivo principal deste trabalho é a redução do custo de aplicação do teste de programas concorrentes. Sendo assim, foram estudados os trabalhos descritos anteriormente, que tratam do teste de programas concorrentes (Wong et al., 2005; Seo et al., 2006; Lei e Carver, 2006; Lei et al., 2007; Endo, 2008). O objetivo foi identificar ideias que pudessem ser aplicadas na ferramenta ValiPar, como um complemento ao teste estrutural utilizado atualmente, ou como uma alternativa a este. A Tabela 4.1 resume as características e desvantagens de cada proposta, relacionadas à utilização destas na ferramenta ValiPar. 
Tabela 4.1: Comparação entre os modelos de teste.

\begin{tabular}{|c|c|c|}
\hline Proposta & Vantagens & Desvantagens \\
\hline Wong et al. (2005) & $\begin{array}{l}\text { - Não apresenta o problema da não- } \\
\text { executabilidade. } \\
\text { - Gera sequências de teste visando a co- } \\
\text { bertura do RG. }\end{array}$ & $\begin{array}{l}\text { - Geração do grafo de alcançabilidade } \\
\text { é custosa. }\end{array}$ \\
\hline Seo et al. (2006) & $\begin{array}{l}\text { - Utiliza um grafo de alcançabilidade } \\
\text { reduzido. } \\
\text { - A definição do PMS (possible macro } \\
\text { step) permite a geração de sequências } \\
\text { representativas em relação ao compor- } \\
\text { tamento do programa concorrente. }\end{array}$ & $\begin{array}{l}\text { - Necessidade de gerar a especificação } \\
\text { em statecharts. } \\
\text { - Utilizado para o teste baseado em es- } \\
\text { pecificação, é necessário verificar se } \\
\text { pode ser utilizado para o teste estrutu- } \\
\text { ral. }\end{array}$ \\
\hline Lei e Carver (2006) & $\begin{array}{l}\text { - Utiliza um modelo dinâmico. } \\
\text { - Não apresenta o problema da não- } \\
\text { executabilidade. } \\
\text { - Gera novas sequências sem a necessi- } \\
\text { dade de guardar um histórico. }\end{array}$ & $\begin{array}{l}\text { - Gera todas as sequências possíveis, } \\
\text { ou seja, realiza um teste exaustivo. } \\
\text { - Não possui uma métrica como a co- } \\
\text { bertura para indicar que o programa foi } \\
\text { suficientemente testado. }\end{array}$ \\
\hline Lei et al. (2007) & $\begin{array}{l}\text { - Mesmas que a proposta de Lei e Car- } \\
\text { ver (2006), porém utiliza uma estra- } \\
\text { tégia combinatorial para minimizar o } \\
\text { custo. }\end{array}$ & $\begin{array}{l}\text { - Necessita de estudos que indiquem se } \\
\text { a estratégia utilizada não interfere na } \\
\text { capacidade de revelar erros nesse con- } \\
\text { texto. }\end{array}$ \\
\hline Endo (2008) & $\begin{array}{l}\text { - Trata da eliminação de sincronizações } \\
\text { não-executáveis no teste estrutural de } \\
\text { programas concorrentes. } \\
\text { - Utiliza um modelo formal (rede de } \\
\text { Petri). }\end{array}$ & $\begin{array}{l}\text { - Geração da árvore de cobertura é cus- } \\
\text { tosa. } \\
\text { - Mapeamento do GFCP para uma rede } \\
\text { de Petri precisa de melhorias para re- } \\
\text { presentar fielmente o comportamento } \\
\text { do programa. } \\
\text { - Não elimina toas as sincronizações } \\
\text { não-executáveis. }\end{array}$ \\
\hline
\end{tabular}

No trabalho de Wong et al. (2005), a utilização do grafo de alcançabilidade não apresenta o problema da não-executabilidade. Porém a geração do grafo tem uma complexidade alta, gerando um custo maior de tempo nessa etapa se comparado à geração do GFCP. Além disso, essa abordagem trata da geração de sequências de teste, sendo necessário ainda a partir dessas derivar casos de teste. Uma ideia que poderia ser aproveitada na ValiPar sem a necessidade de mudança da abordagem implementada atualmente é a utilização do conceito de hot-spots, identificando elementos requeridos que, sendo cobertos, ajudariam a cobrir um número maior de nós ainda não visitados do GFCP.

O artigo de Seo et al. (2006) apresenta uma estratégia para o teste baseado em especificação utilizando statecharts. Inicialmente, pensou-se em mapear o GFCP para uma representação em statecharts e então aplicar a abordagem proposta, porém os statecharts não representam eventos do tipo send/receive, sendo necessário utilizar a comunicação via broadcast. Além disso, é necessário gerar a especificação do programa utilizando o modelo statecharts, especificação essa que teria que ser feita manualmente. 
O teste de alcançabilidade proposto por Lei e Carver (2006) apresenta uma economia de espaço em relação a outros algoritmos de teste de alcançabilidade, já que não guarda as sequências geradas. As sequências são geradas dinamicamente a partir da execução original, e as restrições citadas acima garantem que não serão geradas sequências repetidas, mesmo sem guardar um histórico das sequências geradas anteriormente. Porém uma desvantagem é o fato de não possuir uma métrica como, por exemplo, cobertura, para indicar se o programa foi suficientemente testado. Além disso, a abordagem exige que toda combinação de sequência de sincronização seja executada, o que gera um custo elevado para programas mais complexos.

Em Lei et al. (2007), são apresentados experimentos utilizando a estratégia combinatorial para o teste de alcançabilidade, comparando os resultados com o teste de alcançabilidade proposto em Lei e Carver (2006). Os resultados indicam que o número de sequências de teste geradas diminuiu substancialmente em relação ao teste exaustivo, porém mais estudos são necessários para verificar a eficácia do teste de alcançabilidade de $t$-vias em revelar defeitos.

O método proposto em Endo (2008) tem como principal desvantagem seu custo, decorrente da geração da árvore de cobertura. A transformação do modelo GFCP para a rede de Petri e a análise da árvore de cobertura apresentam custos baixos. Já a geração da árvore de cobertura é um problema NP-completo (Lipton, 1975; Karp e Miller, 1969). Para diminuir esse custo, poderia-se criar algumas regras de redução, visto que o objetivo da análise da árvore é apenas verificar as transições referentes aos arcos inter-processos. A proposta de Endo (2008), utilizando redes de Petri, foi implementada na ValiPar e possui um objetivo em comum com este trabalho, pois trata da redução de elementos não-executáveis. Porém, melhorias no método proposto seriam necessárias, já que em alguns casos a rede de Petri gerada não representa fielmente o comportamento do programa original, acabando por não identificar arcos não-executáveis. Além disso, o custo elevado da geração da árvore de cobertura pode ser visto como um ponto contra a utilização dessa abordagem.

Uma característica que pode ser notada nas abordagens apresentadas é que a utilização destas para eliminar o problema da não-executabilidade normalmente vem associada a um aumento no custo da execução. Sendo assim, este trabalho procurou buscar um meio termo, diminuindo o número de elementos requeridos associados a sincronizações não-executáveis, sem obter um tempo de execução impraticável. Para isso, o módulo Vali-Sync (que implementa o teste de alcançabilidade proposto por Lei e Carver (2006)) foi modificado a fim de diminuir o número de sequências executadas, baseando-se em elementos requeridos associados a sincronizações não cobertas para isso. Além disso, a geração dos elementos requeridos foi modificada a fim de identificar parte dos elementos não-executáveis automaticamente, utilizando informações estáticas das sincronizações. Essas contribuições são descritas nos próximos capítulos. 


\subsection{Ferramentas de teste}

Diferentes iniciativas para verificação e validação de programas concorrentes podem ser encontradas em Taylor et al. (1992), Chung et al. (1996), Yang et al. (1998), Koppol et al. (2002), Edelstein et al. (2003), Yang e Pollock (2003) e Wong et al. (2005). A maioria desses trabalhos não apresenta uma ferramenta de apoio à atividade de teste. Algumas ferramentas podem ser encontradas, mas a maioria limita-se apenas à visualização, depuração ou controle de programas concorrentes, sem aplicar critérios de teste.

Della Pasta (Yang et al., 1998) foi uma das primeiras ferramentas de teste com análise de caminhos para programas com memória compartilhada. Um analisador estático gera os possíveis caminhos para cobrir associações entre as variáveis envolvidas na sincronização de tarefas. Outro exemplo de ferramenta é a STEPS (Krawczyk et al., 1998), uma ferramenta que permite o monitoramento através da análise simbólica de cenários de teste e execução controlada em programas PVM, além de suportar um critério de teste estrutural baseado em fluxo de controle com base nas sincronizações. A ferramenta ConTest (Edelstein et al., 2003) possibilita o teste estrutural para programas multithread em Java, além de implementar uma heurística para gerar testes com sincronizações diferentes para o mesmo caso de teste.

A ferramenta ValiPar é uma contribuição para o teste de programas concorrentes. Essa ferramenta encontra-se em desenvolvimento por pesquisadores dos grupos de Sistemas Distribuídos e de Engenharia de Software do ICMC.

\subsection{Ferramenta ValiPar}

A ferramenta ValiPar foi inicialmente desenvolvida para o teste no paradigma de passagem de mensagens, sendo instanciada para PVM, e posteriormente para MPI. A ferramenta implementa um conjunto de critérios de teste estrutural estabelecidos por Vergilio et al. (2005). A ferramenta ValiMPI fornece funções para criar sessões de teste, gerar e executar casos de teste, avaliar a cobertura dos testes em relação aos seguintes critérios: todos-nós, todos-nós-r, todos-nós-s, todasarestas, todas-arestas-s, todos-c-usos, todos-p-usos e todos-s-usos. Posteriormente, outras extensões do projeto abordaram a aplicação desses critérios para o paradigma de memória compartilhada (Sarmanho et al., 2008), e a utilização dos conceitos (modelos de teste e GFCP) no contexto de servidores web, especificados em WS-BPEL (Endo et al., 2007).

A ferramenta ValiPar é composta por quatro módulos: Vali-Inst, Vali-Exec, Vali-Elem e ValiEval. A comunicação entre os módulos é feita através de arquivos, como mostra a Figura 4.5. O módulo Vali-Inst é responsável por instrumentar o programa, adicionando comandos especiais que não mudam a semântica, mas registram informação de rastro (trace). A tarefa de instrumentação propriamente dita é feita pela IDeL (Simão et al., 2003). A IDeL, instanciada para a gramática da linguagem $\mathrm{C}$, recebe o programa fonte juntamente com a descrição semântica da instrumentação. 
Como resultado do Vali-Inst são gerados os seguintes itens: programa instrumentado, informações sobre o fluxo de dados e grafos de fluxo de controle. O módulo Vali-Elem utiliza as informações geradas pelo Vali-Inst e gera os elementos requeridos para os critérios de teste implementados pela ValiPar. Esses elementos requeridos representam as informações que precisam ser executadas (exercitadas/testadas) no código concorrente. O módulo Vali-Exec executa os dados de teste fornecidos pelo usuário tendo como base o programa instrumentado. Como resultado, tem-se a saída do teste e os caminhos executados no programa concorrente. Finalizando, o módulo Vali-Eval avalia a cobertura dos casos de teste em relação aos critérios de teste selecionados. Esse último módulo usa os caminhos executados para cada dado de teste para verificar quais elementos requeridos (para um critério de teste) são exercitados.

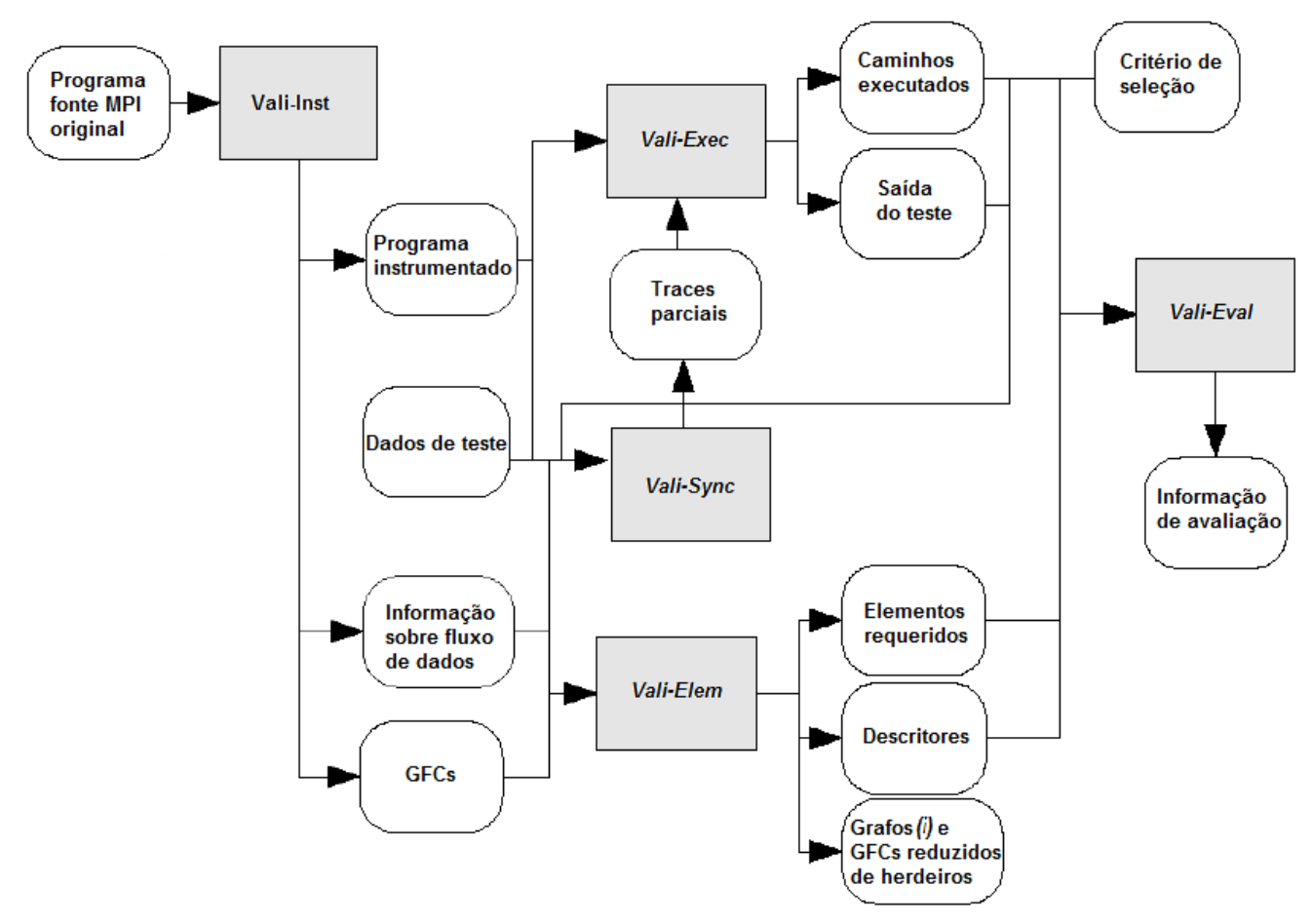

Figura 4.5: Arquitetura da ValiPar (Souza et al., 2008).

A ferramenta também permite execução controlada, para se conseguir uma execução determinística (replay), isto é, conseguir que duas execuções quaisquer de um programa com a mesma entrada executem a mesma sequência de instruções (Yang, 1999). A implementação da execução controlada na ferramenta foi baseada no trabalho de Tai et al. (1991) adaptado para passagem de mensagem. Essa funcionalidade visa auxiliar na correção de defeitos e no teste de regressão, bem como na geração de dados de teste para cobrir elementos requeridos que sejam difíceis de cobrir devido ao não-determinismo. Ela pode ser usada também na tentativa de forçar uma determinada sequência de sincronizações com o objetivo de aumentar a cobertura. A tentativa de forçar a execução de um elemento requerido não executável (Frankl e Weyuker, 1988) pode levar o programa a um estado de espera permanente. 
Posteriormente, um novo módulo foi implementado, o Vali-Sync (Camillo, 2008). Esse módulo implementa o teste de alcançabilidade proposto por Lei e Carver (2006). As variantes são geradas a partir da execução de um caso de teste, utilizando como entrada os arquivos de sincronizações executadas e traces gerados pelo módulo Vali-Exec. A partir dessas informações, as variantes possíveis são identificadas, seguindo o algoritmo proposto por Lei e Carver (2006). Para a execução das variantes, traces parciais são gerados, a fim de realizar a execução controlada dessas variantes. Esses traces parciais contêm as sincronizações que devem ser executadas deterministicamente. As demais sincronizações são executadas não-deterministicamente.

\subsection{Considerações finais}

Neste capítulo foram apresentados os desafios no teste de programas concorrentes, assim como alguns trabalhos que exploram essa área. Os trabalhos citados exploram a aplicação de critérios estruturais no contexto de programas concorrentes, sendo que a maioria deles concentra-se em programas que utilizam memória compartilhada. Além disso, foram citadas algumas ferramentas desenvolvidas para o apoio do teste de programas concorrentes, com uma explicação da ferramenta ValiPar, que foi utilizada durante a realização deste trabalho de mestrado.

Os trabalhos citados nesse capítulo foram estudados para identificar uma possível abordagem de redução de custo do teste de programas concorrentes. Após esse estudo, optou-se por basear esta abordagem no trabalho de Lei e Carver (2006), aplicando-se critérios de teste estrutural à proposta original a fim de diminuir o número de sequências executadas durante o teste de alcançabilidade. Esta proposta encontra-se descrita nos próximos capítulos. 


\section{Eliminação de elementos não-executáveis}

\subsection{Considerações iniciais}

Os critérios de teste estrutural propostos em Vergilio et al. (2005) que requerem arestas de sincronização adotam uma estratégia conservadora, ao considerar todas as possíveis arestas interprocesso, mesmo aquelas em que a comunicação não seja possível na prática. Esta estratégia foi adotada com o objetivo de revelar erros relacionados a comunicações faltantes, ou seja, sincronizações que de acordo com a especificação do programa deveriam ser executáveis porém não o são.

Os resultados do experimento conduzido em Souza et al. (2008) revelaram que muitos dos elementos não-executáveis gerados pela ferramenta ValiPar são relacionados aos critérios todasarestas-s e todos-s-usos, devido a essa abordagem conservadora, o que gera um esforço do testador para identificar quais desses elementos são executáveis. A estratégia aqui proposta tem por objetivo auxiliar na identificação de elementos não-executáveis relacionados a arestas de sincronização, utilizando para isso uma análise estática dos elementos.

Este capítulo está organizado da seguinte forma. A Seção 5.2 detalha a proposta de identificação de elementos não-executáveis para os critérios relacionados a arestas-s. A Seção 5.3 apresenta as modificações realizadas na ferramenta ValiMPI a fim de implementar a abordagem proposta neste capítulo. Por fim, a Seção 5.4 discute a abrangência da técnica proposta, assim como as suas limitações. 


\subsection{Identificação de elementos não-executáveis}

Um dos problemas do modelo GFCP é o grande número de elementos requeridos relacionados às arestas de sincronizações. Como não se pode determinar estaticamente quais pares send-receive irão sincronizar, devido a fatores dinâmicos como não-determinismo, fluxo de dados e de controle, a implementação dos critérios propostos por Vergilio et al. (2005) na ferramenta ValiPar considera como possíveis todos os pares send-receive. Porém, grande parte desses elementos requeridos é não-executável, ficando a cargo do testador identificar manualmente se os elementos não cobertos após a execução de um conjunto de casos de teste são não-executáveis. A quantidade de elementos requeridos gerados é um fator limitante na aplicação desses critérios de teste em programas concorrentes mais complexos, tornando o esforço de identificação de sincronizações não-executáveis muito custoso.

Apesar de ser impossível identificar durante a análise estática quais sincronizações podem efetivamente ocorrer em tempo de execução, informações obtidas estaticamente podem ser utilizadas para identificar alguns desses elementos não-executáveis. Por exemplo, se tivermos três processos $p_{0}, p_{1}$ e $p_{2}$, e no processo $p_{1}$ tivermos um receive que espera uma mensagem ponto-a-ponto de $p_{0}$ (o campo source do MPI_Recv possui o valor constante zero, ou seja, a mensagem tem como origem o processo $p_{0}$ ), podemos afirmar que um send do processo $p_{2}$ não irá sincronizar com esse receive. $\mathrm{O}$ mesmo não poderia ser afirmado caso a origem da mensagem desse receive fosse especificado através do uso de uma variável.

A melhoria proposta neste trabalho modifica a geração dos elementos requeridos do critério todas-arestas-s na ferramenta, critério esse que requer as arestas inter-processos (arestas de sincronização/comunicação). Como os critérios que consideram s-usos (usos comunicacionais) utilizam as arestas requeridas pelo critério todas-arestas-s, estes também são afetados por essa mudança. Atualmente, dos critérios que consideram s-usos, somente o critério todos-s-usos encontra-se implementado na ValiPar. Para a identificação de elementos não-executáveis, três campos das primitivas de comunicação MPI_Send e MPI_Recv são considerados: source/dest (origem/destino), tag e datatype (tipo de dados). Esses campos são utilizados quando seu valor é dado por uma constante numérica ou por uma constante definida através de uma macro, ou seja, quando o valor do campo é definido estaticamente. Uma possibilidade não explorada neste trabalho é a utilização de variáveis na identificação, quando o valor dessas puder ser determinado estaticamente, por exemplo, quando um valor constante é atribuído a uma variável (constante numérica ou macro) e existe um caminho livre de definição entre essa atribuição e um uso comunicacional da variável.

O Programa 5.1 apresenta um trecho de código utilizado para exemplificar os três casos em que uma aresta pode ser eliminada de acordo com a melhoria proposta. Neste exemplo, supõe-se que o programa é executado para quatro processos, um mestre $\left(p_{0}\right)$ e três escravos $\left(p_{1}, p_{2}\right.$ e $\left.p_{3}\right)$, ocorrendo duas rodadas de comunicação: a primeira com uma comunicação mestre/escravo, onde o processo mestre envia uma mensagem para cada escravo e espera uma resposta desses, e outra em anel, onde cada processo envia uma mensagem para o próximo processo, ou seja, para o processo com 
o rank imediatamente superior (por exemplo, $p_{1}$ envia uma mensagem para $p_{2}$ ), formando uma fila circular. Os nós do GFCP encontram-se como comentário no código.

Campo source/dest: A eliminação considerando o campo source/dest (origem/destino) ocorre quando, analisando-se uma aresta referente a um par send/receive, o destino do send for diferente do processo que executa o receive ou a origem do receive for diferente do processo que executa o send. Por exemplo, a aresta de sincronização que liga o nó 7 do processo $p_{2} \mathrm{e}$ o nó 2 de $p_{1}$ (aresta $\left(7^{2}, 2^{1}\right)$ ) pode ser identificada como não-executável pois o receive executado em $p_{1}$ espera uma mensagem de $p_{0}$, ou seja, o campo de origem neste receive contém o valor zero. O mesmo ocorre considerando-se o campo de destino na aresta que liga o nó 4 de $p_{2}$ ao nó 8 de $p_{3}$ (aresta $\left(4^{2}, 8^{3}\right)$ ).

Campo tag: A eliminação considerando o campo tag ocorre quando as tags da mensagem do send e do receive referentes à aresta de sincronização forem diferentes. As duas arestas utilizadas como exemplo anteriormente (arestas $\left(7^{2}, 2^{1}\right)$ e $\left(4^{2}, 8^{3}\right)$ ) poderiam ser classificadas como não-executáveis considerando-se que os campos tag do send e do receive são diferentes.

Campo datatype: A eliminação considerando o tipo de dados ocorre quando este for diferente no send e no receive da aresta de sincronização sendo analisada. Por exemplo, se considerássemos apenas origem/destino e tag da mensagem, a aresta do send no nó 4 de $p_{1}$ para o receive do nó 6 de $p_{0}$ (aresta $\left(4^{1}, 6^{0}\right)$ ) não poderia ser eliminada, pois este aceita mensagens de qualquer origem com qualquer tag, porém os tipos de dados diferem. O MPI permite a sincronização de um send e um receive com tipos de dados diferentes, portanto a eliminação considerando esse campo é uma heurística.

Programa 5.1: Trecho de código de exemplo.

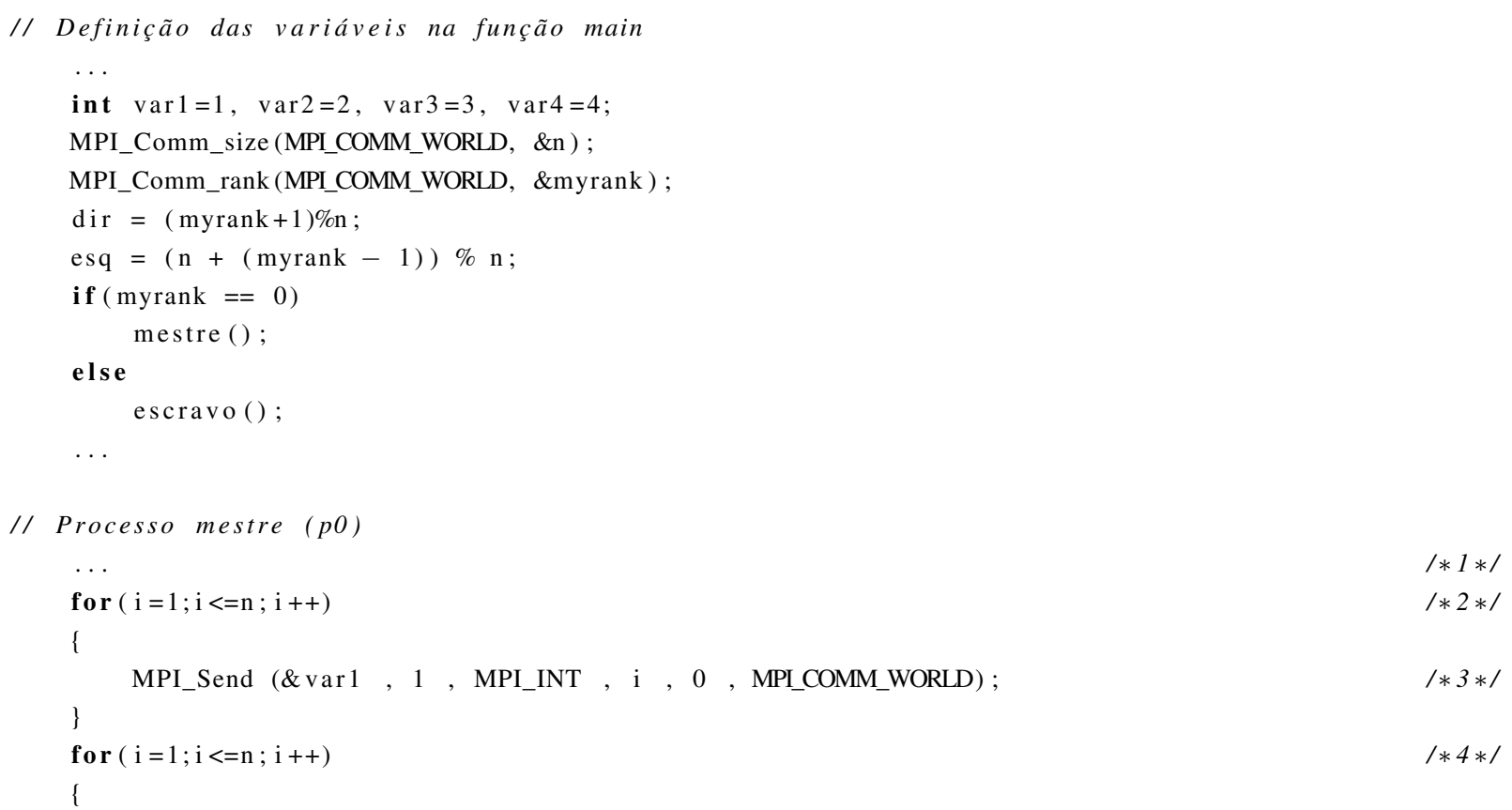




\subsection{Implementação da técnica na ValiMPI}

As arestas-S são criadas no módulo Vali-Elem. Inicialmente, o GFC de cada processo é carregado. Os arquivos que descrevem esses grafos são gerados pelo módulo Vali-Inst e possuem, além da descrição dos nós e arestas, informações da ocorrência de eventos de comunicação e definição e uso de variáveis. Para cada nó que possui um evento send no GFC de um processo, uma aresta de sincronização é adicionada para todo nó receive dos grafos dos demais processos, guardando-se esta aresta em uma lista no processo que executa o receive. Durante a geração dos elementos requeridos, as listas com as arestas de sincronização de cada processo são percorridas para a geração dos elementos requeridos do critério todas-arestas-s e todos-s-usos.

A identificação de arestas não-executáveis é feita no momento da criação dessas. Como citado anteriormente, os campos analisados são source/dest (origem/destino), tag e datatype (tipo de dados), quando definidos estaticamente. Sendo assim, uma aresta $\left(s^{i}, r^{j}\right)$, onde $s$ é um nó do processo $i$ que possui um evento send e $r$ é um nó do processo $j$ que possui um evento receive, é identificada como não-executável se uma das seguintes situações ocorrer: (1) o campo destino do evento send estiver definido estaticamente e for diferente de $j$ (processo que executa o receive sendo analisado); (2) o campo origem do evento receive estiver definido estaticamente e for diferente de $i$ (processo que executa o send sendo analisado); (3) os campos de tag estiverem definidos estaticamente em ambos os nós, e forem diferentes ou (4) o tipo de dados for diferente nos eventos send e receive. Como comentado anteriormente, o MPI permite a sincronização de um send e um receive com tipos de dados diferentes, portanto a utilização desse campo durante a identificação de elementos não-executáveis é opcional, sendo definido através de um parâmetro do Vali-Elem se este será considerado. 
Após a criação das arestas interprocessos, é realizada a geração dos elementos requeridos. Como já citado, as listas com as arestas de sincronização de cada processo são percorridas, para a geração dos arquivos que descrevem os elementos requeridos utilizados posteriormente no módulo Vali-Eval para verificar a cobertura alcançada com a execução dos casos de teste. Dois arquivos são gerados para cada critério, o primeiro contendo os elementos requeridos (arquivo com extensão .req) e o segundo contendo um descritor desse elemento (arquivo com extensão .aut). Um descritor é uma expressão regular que descreve um caminho que cobre um elemento requerido, sendo utilizado para verificar se o caminho percorrido durante uma execução cobre esse elemento. A Figura 5.1 mostra os elementos requeridos gerados para o Programa 5.1.

Os elementos requeridos são gerados somente para as arestas que não foram identificadas como não-executáveis. Para as demais, um terceiro arquivo (com a extensão .elim) é gerado, contendo as arestas identificadas como não-executáveis. Este arquivo não é considerado durante a análise de cobertura. Optou-se por guardar esses elementos não-executáveis ao invés de descartá-los pois estes podem ser interessantes durante o processo de teste, já que a eliminação de uma sincronização que deveria ocorrer de acordo com a especificação do programa pode indicar um erro na implementação desse programa. A Figura 5.2 mostra o arquivo com os elementos eliminados para o Programa 5.1. O campo utilizado para identificar um dado elemento como não-executável encontra-se especificado entre parênteses. Os campos são analisados na seguinte ordem: send (destino da mensagem), receive (origem da mensagem), tag e datatype.

ELEMENTOS REQUERIDOS PARA O CRITERIO TODAS AS ARESTAS S
1) $3-0 \quad 2-1$
2) $3-0 \quad 2-2$
3) $3-0 \quad 2-3$
4) $9-0$ 8-1
5) $9-0$ 8-2
6) $9-0 \quad 8-3$
7) $4-15-0$
8) $5-1$ 6-0
9) $7-1$ 5-0
10) $7-1$ 10-0
11) $7-18-2$
12) $7-18-3$
13) $4-2$ 5-0
14) $5-2$ 6-0
15) $7-2$ 5-0
16) $7-2 \quad 10-0$
17) $7-2 \quad 8-1$
18) $7-28-3$
19) $4-3$ 5-0
20) $5-3 \quad 6-0$
21) $7-3 \quad 5-0$
22) $7-3 \quad 10-0$
23) $7-3 \quad 8-1$
24) $7-3 \quad 8-2$

Figura 5.1: Exemplo de arquivo com os elementos requeridos para o critério todas-arestas-s. 
ELEMENTOS REQUERIDOS ELIMINADOS DO CRITERIO TODAS AS ARESTAS S

1) 3-0 8-1 ( Tag)

2) $3-0$ 8-2 ( Tag)

3) $3-0 \quad 8-3$ ( Tag)

4) $9-0$ 2-1 ( Tag $)$

5) $9-0 \quad 2-2$ ( Tag )

6) $9-0 \quad 2-3 \quad(\mathrm{Tag})$

7) 4-1 6-0 (Datatype)

8) $4-1 \quad 10-0 \quad(\mathrm{Tag})$

9) 4-1 2-2 (Send)

10) 4-1 8-2 (Send)

11) $4-1 \quad 2-3$ (Send)

12) $4-1 \quad 8-3$ (Send)

13) 5-1 5-0 (Datatype)

14) $5-1$ 10-0 ( Tag)

15) $5-1 \quad 2-2$ (Send)

16) 5-1 8-2 (Send)

17) 5-1 2-3 (Send)

18) 5-1 8-3 (Send)

19) 7-1 6-0 (Datatype)

20) 7-1 2-2 (Recv)

21) 7-1 2-3 (Recv)

22) 4-2 6-0 (Datatype)

23) 4-2 10-0 ( Tag)

24) $4-2 \quad 2-1$ (Send)

25) 4-2 8-1 (Send)

26) 4-2 2-3 (Send)

27) 4-2 8-3 (Send)

28) 5-2 5-0 (Datatype)

29) 5-2 10-0 ( Tag)

30) 5-2 2-1 (Send)

31) 5-2 8-1 (Send)

32) 5-2 2-3 (Send)

33) $5-2 \quad 8-3$ (Send)

34) 7-2 6-0 (Datatype)

35) 7-2 2-1 (Recv)

36) 7-2 2-3 (Recv)

37) 4-3 6-0 (Datatype)

38) 4-3 10-0 ( Tag)

39) 4-3 2-1 (Send)

40) $4-3 \quad 8-1$ (Send)

41) 4-3 2-2 (Send)

42) $4-3 \quad 8-3$ (Send)

43) 5-3 5-0 (Datatype)

44) 5-3 10-0 ( Tag)

45) 5-3 2-1 (Send)

46) 5-3 8-1 (Send)

47) $5-3 \quad 2-2$ ( Send)

48) 5-3 8-2 (Send)

49) $7-3$ 6-0 (Datatype)

50) 7-3 2-1 (Recv)

51) $7-3 \quad 2-2$ (Recv)

Figura 5.2: Exemplo de arquivo com os elementos eliminados para o critério todas-arestas-s.

\subsection{Abrangência desta técnica e suas limitações}

O objetivo da técnica aqui apresentada é diminuir o esforço do testador na tarefa de identificar elementos não-executáveis. Como explicado anteriormente, utilizam-se informações estáticas para a identificação de sincronizações que não podem ocorrer. Sendo assim, a eficácia dessa técnica é diretamente dependente da utilização, sempre que possível, de constantes na implementação da aplicação. Em programas que utilizam uma grande quantidade de variáveis nos campos analisados, a identificação de elementos não-executáveis pela técnica proposta acaba sendo comprometida. 
Uma possibilidade a ser investigada seria estender essa técnica para utilizar informações de fluxo de dados como, por exemplo, variáveis que são definidas com um valor constante, para aumentar a eficácia dessa técnica.

Outra limitação dessa técnica é que esta não considera a utilização de comunicadores diferentes e intercomunicadores. Assim, sincronizações que são não-executáveis devido ao comunicador utilizado não são identificadas. Porém, mesmo que o programa utilize mais de um comunicador ou intercomunicador, nenhum elemento executável será identificado erroneamente como não-executável. Supondo que um elemento seja identificado como não-executável considerando a existência de somente um comunicador, este seria também não-executável caso os eventos send e receive utilizassem comunicadores diferentes.

É importante ressaltar que a técnica auxilia a identificação automática de elementos nãoexecutáveis. Portanto, pode-se afirmar que todos os elementos identificados são relacionados a sincronizações não-executáveis, porém não se pode afirmar que os demais elementos são executáveis. Por exemplo, no Programa 5.1 o elemento referente à aresta $\left(7^{1}, 5^{0}\right)$ não é executável, porém este aparece na Figura 5.1. Outro exemplo é a aresta $\left(7^{2}, 10^{0}\right)$, que não pode ser identificada como não-executável pois não se sabe somente analisando o código qual o valor das variáveis esq e dir.

Apesar dessas limitações, os experimentos realizados neste projeto demonstram que a técnica estática de eliminação de elementos não-executáveis proposta permite reduções significativas na quantidade de elementos requeridos. Esta automatização tem como consequência direta a minimização dos custos da atividade de teste e a eventual redução da incidência de erros cometidos pelo testador durante a análise dos elementos requeridos.

\subsection{Considerações finais}

Este capítulo apresentou a abordagem proposta de detecção automática de elementos nãoexecutáveis relacionados a sincronizações. Foi apresentada também a modificação realizada no módulo Vali-Elem a fim de implementar esta técnica, assim como a abrangência desta e suas limitações.

O próximo capítulo apresenta a proposta de utilização de informações de cobertura durante o teste de alcançabilidade, no contexto do teste estrutural de programas concorrentes. Os experimentos realizados a fim de verificar a eficácia de ambas as técnicas e os resultados destes experimentos são apresentados no Capítulo 7. 



\section{Teste de alcançabilidade como apoio ao teste de cobertura}

\subsection{Considerações iniciais}

Como citado na Seção 3.2, testar todos os caminhos possíveis pode se tornar impraticável, devido a restrições de custo e tempo. Ao inserirmos o não-determinismo decorrente das sincronizações em programas concorrentes, este problema aumenta. Um critério menos custoso neste cenário é testar todas as arestas de sincronizações. Ao se utilizar a cobertura dos elementos requeridos do critério todas-arestas-s (citado na Subseção 4.2.1), que requer todas as arestas de sincronização, para restringir as sequências a serem exercitadas pelo teste de alcançabilidade, é possível reduzir consideravelmente o número de sequências, fazendo com que esse deixe de ser um teste exaustivo.

Em contrapartida, o teste de alcançabilidade auxilia o teste estrutural de programas concorrentes ao exercitar diferentes sequências de sincronizações a partir de uma mesma entrada de teste. Ao se realizarem execuções não-controladas, não é possível garantir quais sincronizações irão ocorrer. Logo, mesmo que uma sincronização seja executável para uma dada entrada, essa pode necessitar de diversas execuções para ser exercitada, ou mesmo nunca ser exercitada, devido ao não-determinismo. A utilização do teste de alcançabilidade nesse contexto auxilia nessa necessidade de execução controlada, exercitando diversas sequências de sincronizações para uma dada entrada, e exercitando elementos requeridos que poderiam necessitar de um grande esforço por parte do testador.

Este capítulo está organizado da seguinte forma. A Seção 6.2 detalha a proposta de utilização do teste de alcançabilidade para apoiar o teste estrutural, utilizando-se a cobertura de elementos 
requeridos para restringir a quantidade de sequências geradas. A Seção 6.3 apresenta as modificações realizadas na ferramenta ValiMPI a fim de implementar a abordagem proposta neste capítulo. Na Seção 6.4 é discutida a abrangência da técnica proposta, assim como as suas limitações.

\subsection{Abordagem proposta}

O teste de alcançabilidade proposto por Lei e Carver (2006) identifica, a partir de uma execução, todas as sequências de sincronizações que poderiam ser executadas com uma dada entrada (ver Subseção 4.2.2). O principal problema com essa abordagem é o número elevado de sequências geradas, pois o número de sequências possíveis cresce exponencialmente com o aumento da quantidade de pares de sincronizações.

A Figura 6.1 ilustra um exemplo de execução do teste de alcançabilidade. Um programa concorrente $C P$ consistindo de quatro threads ( $T 1, T 2, T 3$ e $T 4)$ que interagem entre si enviando e recebendo mensagens é apresentado na Figura 6.1(a). Uma operação pi.send(var) indica que a variável var será enviada para a thread Ti, enquanto uma operação pj.recv() indica que a origem da mensagem é a thread $T j$. A Figura 6.1(b) exemplifica a aplicação do teste de alcançabilidade para o programa $C P$. Inicialmente, $C P$ é executado não-deterministicamente, gerando a sequência $Q_{0}$. Essa sequência é representada na figura através de um diagrama de espaço-tempo, onde cada linha vertical representa uma thread e cada aresta orientada ligando duas linhas verticais representa uma mensagem enviada de um evento send para um evento receive.

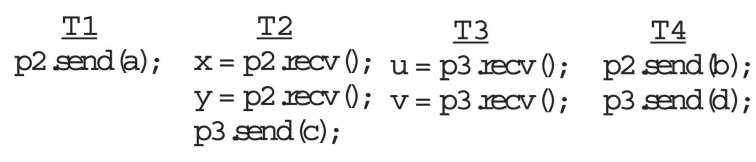

(a)

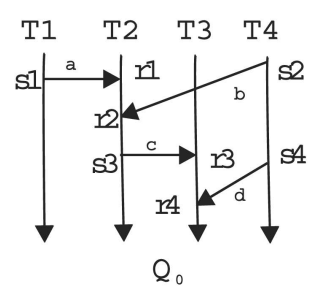

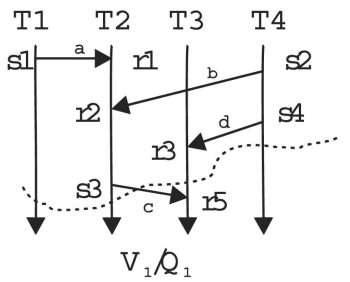

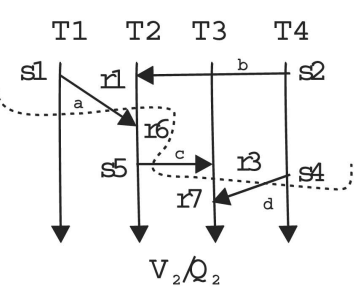

(b)

Figura 6.1: Geração de variantes no teste de alcançabilidade (Lei e Carver, 2006).

Após essa primeira execução, as condições de disputa em $Q_{0}$ são identificadas e utilizadas para derivar as variantes $V_{1}, V_{2}$ e $V_{3}$. As variantes são prefixos de $Q_{0}$ com uma ou mais condições de disputa alteradas, ou seja, com um ou mais pares de sincronização alterados. Cada variante é então utilizada para conduzir uma execução de teste baseada em prefixo, forçando os eventos e sincronizações presentes na variante a serem reexecutados e permitindo que o resto da execução do teste continue não-deterministicamente. 
O teste baseado em prefixo com as variantes $V_{1}, V_{2}$ e $V_{3}$ exercita as sequências $Q_{1}, Q_{2}$ e $Q_{3}$, respectivamente. A Figura 6.1(b) apresenta essas três sequências e as variantes que deram origem a elas. No diagrama, uma variante $V_{i}$ que dá origem à sequência $Q_{i}$ encontra-se acima da linha tracejada. Nenhuma nova variante pode ser derivada de $Q_{1}, Q_{2}$ e $Q_{3}$, já que todas as sequências possíveis para o programa $C P$ foram exercitadas, portanto o processo do teste de alcançabilidade para. No diagrama, um mesmo evento recebe números diferentes em algumas sequências, por exemplo, os eventos $r 2$ em $Q_{O}$ e $r 6$ em $Q_{2}$. Apesar de se referirem a uma mesma instrução no programa, esses são considerados eventos diferentes, devido à sequência de eventos de comunicação ocorridos até chegar a essa instrução ter mudado. A mudança na numeração serve para explicitar essa diferença.

O teste de alcançabilidade pode ser utilizado no contexto do teste estrutural de programas concorrentes, contribuindo com o aumento da cobertura dos critérios que tratam de sincronizações, já que este garante que todas as sequências de sincronizações possíveis para uma dada entrada são exercitadas. Com isso, diminui-se o esforço do testador em gerar casos de teste, já que um único caso de teste dá origem a diversas execuções, cobrindo assim uma quantidade maior de sincronizações. Por outro lado, com a utilização do teste de alcançabilidade, um novo custo é introduzido, relacionado ao grande número de sequências geradas. Assim, faz-se necessária uma estratégia para diminuir a quantidade de sequências geradas, a fim de reduzir esse custo.

Ao se analisarem as sequências geradas pelo teste de alcançabilidade sob a ótica do teste estrutural, ou seja, tendo como objetivo a cobertura de código, particularmente a cobertura de novas sincronizações, a execução de algumas dessas sequências pode tornar-se desnecessária. Isso pode ser visto no exemplo da Figura 6.1 analisando-se a sequência $Q_{3}$. Apesar de não ser igual a nenhuma das sequências executadas anteriormente, ao analisarem-se as sincronizações individualmente, todas já haviam sido executadas por alguma das outras sequências. Se, em um outro cenário, dois casos de teste exercitassem as sequências $Q_{0}$ e $Q_{3}$, todas as sincronizações possíveis teriam sido exercitadas. O ideal seria sempre conseguir testar todas as combinações possíveis de sincronizações, entretanto, para programas complexos o custo desse teste torna-se proibitivo e alternativas eficientes para reduzir esse custo são necessárias.

A estratégia aqui proposta consiste na utilização de informações sobre a cobertura de elementos requeridos para o critério todas-arestas-s, critério este que requer todas as sincronizações, a fim de diminuir o número de sequências exercitadas durante o teste de alcançabilidade. Essa redução na quantidade de sequências executadas é alcançada ao executar somente variantes que cubram novas sincronizações, descartando as demais variantes. Com isso, garante-se que todas as variantes executadas contribuem para o aumento da cobertura. Assim, o teste de alcançabilidade contribui para o teste estrutural provendo uma maneira de exercitar sincronizações ainda não cobertas, ao mesmo tempo em que a cobertura de elementos requeridos é utilizada para atenuar o problema da quantidade de sequências geradas durante o teste de alcançabilidade. 
O Programa 6.1 apresenta um algoritmo de alto nível do teste de alcançabilidade proposto por Lei e Carver (2006), com as modificações aqui propostas. As linhas que não fazem parte do algoritmo original estão identificadas através do caracter '+' no início da linha (linhas 3, 5, 10, 11 e 13). Não foi realizada nenhuma modificação no algoritmo de geração de variantes em si (linha 7 do Programa 6.1), mas sim na escolha da próxima variante a ser executada.

Programa 6.1: Pseudocódigo do algoritmo do teste de alcançabilidade modificado.

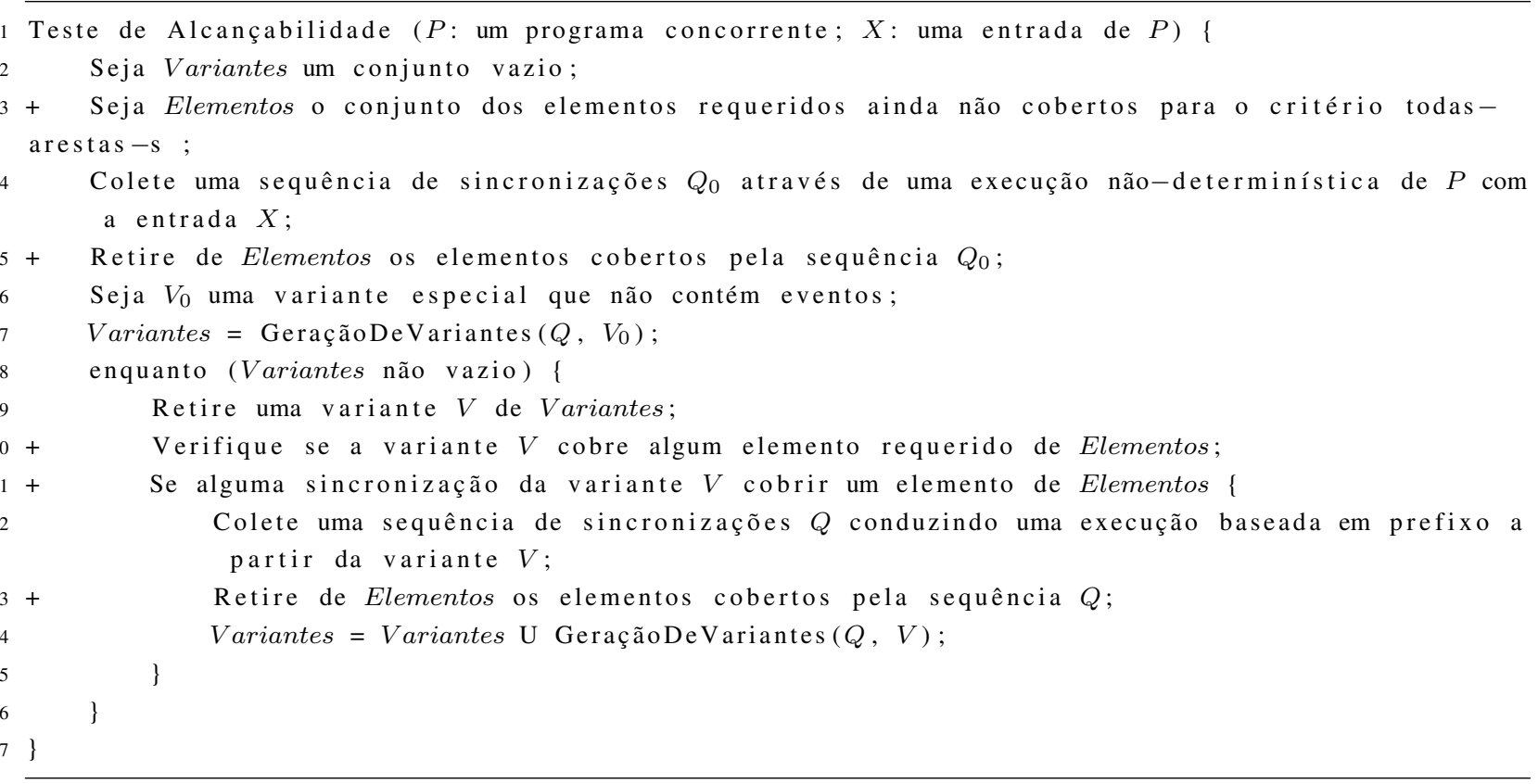

O algoritmo recebe como entrada um programa $P$ a ser analisado e uma entrada de testes válida $X$. A partir de uma execução não-determinística de $P$ com a entrada $X$, condições de disputa são identificadas, gerando variantes da sequência de sincronizações resultantes dessa execução (guardadas no conjunto Variantes). A partir das variantes desse conjunto, novas sequências de sincronizações são exercitadas, e para cada uma dessas novas sequências condições de disputa são identificadas, gerando novas variantes. Porém, diferentemente da proposta original de Lei e Carver (2006), no algoritmo do Programa 6.1, nem todas as variantes identificadas são executadas. Uma variante só é executada caso esta cubra uma sincronização ainda não coberta pelas execuções anteriores; caso contrário, a variante é descartada e a próxima variante do conjunto Variantes é analisada.

A verificação de que uma variante cobre uma nova sincronização é feita comparando as sincronizações presentes nesta com o conjunto Elementos, que contém todos os elementos requeridos do critério todas-arestas-s ainda não cobertos. Essa verificação é feita realizando-se uma busca sequencial no conjunto Elementos a fim de encontrar algum elemento requerido que seja coberto por uma sincronização presente nessa variante. A cada execução de uma nova variante, o conjunto Elementos é atualizado, retirando-se os elementos cobertos pela sequência resultante dessa execução. 


\subsection{Implementação da técnica na ValiMPI}

O módulo que implementa a proposta de Lei e Carver (2006) na ValiMPI é denominado ValiSync. O Vali-Sync teve sua versão inicial desenvolvida por Camillo (2008), com o intuito de avaliar o impacto da aplicação de testes temporais durante os testes de programas paralelos. Além da inclusão desse novo módulo, a execução controlada do módulo Vali-Exec foi modificada, a fim de possibilitar a execução baseada em prefixo, necessária durante o teste de alcançabilidade. Com a introdução do teste de alcançabilidade guiado por elementos requeridos, o módulo Vali-Sync passa a utilizar também o módulo Vali-Eval, durante a análise de cobertura, além dos elementos requeridos gerados pelo módulo Vali-Elem.

A execução da primeira sequência do teste de alcançabilidade é feita utilizando o módulo Vali-Exec. Esta execução é não-determinística, e produz como saída traces de execução para cada um dos processos (seguindo a nomenclatuda trace.<nome da função $>$. < <número do processo >), indicando quais nós do GCFP foram exercitados, assim como quais sincronizações ocorreram. Esses arquivos são armazenados em uma pasta, indicando qual o número do caso de teste (test_case<número do caso de teste $>$ ). Supondo que este seja o primeiro caso de teste, o nome da pasta seria test_case0001. A Figura 6.2 apresenta o GFCP do programa crivo. Esta é igual à Figura 4.1, e encontra-se repetida a fim de auxiliar na ilustração dos arquivos de trace.

A Figura 6.3 apresenta o arquivo de trace gerado para um dos processos escravos após uma execução do Programa 4.1 (Crivo de Eratóstenes). Cada nó exercitado $n_{a}^{b}$ é representado no arquivo de trace por um par $a-b$, onde $a$ é o índice do nó e $b$ representa o processo ao qual o nó $a$ pertence. Por exemplo, $2-1$ indica que o nó 2 do processo 1 foi exercitado. Uma sincronização $\left(a^{b}, c^{d}\right)$ é representada no arquivo de trace do processo receptor da mensagem (processo $d$ ) pela sequência $c-d \quad a-b \quad c-d$ e no trace do processo emissor da mensagem (processo $b$ ) pela sequência $a-b \quad 0-d a-b$. Note que no trace do processo emissor somente o número do processo receptor é indicado. O índice do nó receive não é especificado pois no caso de sends não-bloqueantes a determinação desta sincronização seria dificultada.

A partir dos dados gerados por essa execução, o módulo Vali-Sync calcula as variantes da sequência original utilizando o teste de alcançabilidade. As variantes são representadas como linhas da tabela de variantes (conforme explicado na Subseção 4.2.2) e armazenadas em um arquivo denominado syncQueue. Os dados de teste da sequência são então copiados para uma pasta denominada sync_queue00000, indicando que esta é a sequência $Q_{0}$. Um exemplo de um trecho do arquivo syncQueue pode ser visto na Figura 6.4. A sintaxe para cada linha do arquivo é a seguinte: <número da variante> <número da execução que originou essa variante> <quantidade de receives na tabela de variantes dessa execução> $<$ linha da tabela de variantes>

Logo, a primeira linha da figura indica que a variante 1 foi gerada a partir da sequência de sincronizações 0 com uma tabela de variantes de tamanho 2 e valores [ 01 ], ou seja, a primeira 


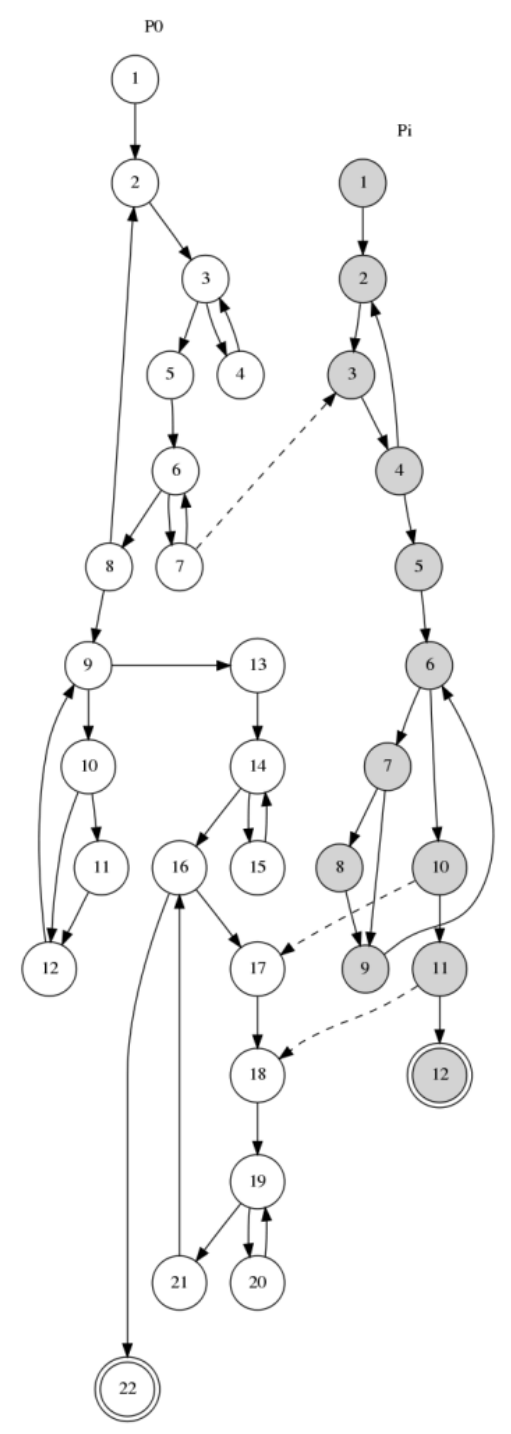

Figura 6.2: GFCP do crivo concorrente.

\begin{tabular}{lcclcclccc}
\hline $1-1$ & $2-1$ & $2-1$ & $8-0$ & $2-1$ & $3-1$ & $2-1$ & $2-1$ & $8-0$ & $2-1$ \\
$3-1$ & $2-1$ & $2-1$ & $8-0$ & $2-1$ & $3-1$ & $2-1$ & $2-1$ & $8-0$ & $2-1$ \\
$3-1$ & $4-1$ & $5-1$ & $6-1$ & $7-1$ & $10-1$ & $6-1$ & $7-1$ & $8-1$ & $9-1$ \\
$10-1$ & $6-1$ & $7-1$ & $10-1$ & $6-1$ & $7-1$ & $10-1$ & $6-1$ & $7-1$ & $10-1$ \\
$6-1$ & $7-1$ & $8-1$ & $9-1$ & $10-1$ & $6-1$ & $7-1$ & $10-1$ & $6-1$ & $7-1$ \\
$10-1$ & $6-1$ & $7-1$ & $10-1$ & $6-1$ & $7-1$ & $10-1$ & $6-1$ & $7-1$ & $10-1$ \\
$6-1$ & $7-1$ & $8-1$ & $9-1$ & $10-1$ & $6-1$ & $7-1$ & $10-1$ & $6-1$ & $7-1$ \\
$8-1$ & $9-1$ & $10-1$ & $6-1$ & $7-1$ & $10-1$ & $6-1$ & $7-1$ & $10-1$ & $6-1$ \\
$11-1$ & $0-0$ & $11-1$ & $12-1$ & $0-0$ & $12-1$ & $13-1$ & & & \\
\hline
\end{tabular}

Figura 6.3: Exemplo de arquivo gerado: trace.slave.p1.

sincronização não é alterada em relação à sequência original e a segunda sincronização muda, utilizando o primeiro send do conjunto de disputa (race set) para o evento receive.

Após a execução da sequência original, o módulo Vali-Eval é executado utilizando o critério todas-arestas-s, com o objetivo de verificar quais elementos foram cobertos para esse critério. Um arquivo auxiliar é utilizado para guardar somente os elementos ainda não cobertos do critério todas- 
arestas-s, ou seja, as sincronizações ainda não cobertas. Este arquivo é atualizado após a execução

de cada nova variante, a fim de retirar os elementos cobertos pela execução desta, tanto na parte determinística quanto na parte não-determinística da execução. Esse arquivo é posteriormente utilizado durante a análise das variantes a serem executadas.

Figura 6.4: Exemplo de arquivo gerado: syncQueue.

Após a geração das variantes, a primeira linha do arquivo SyncQueue é lida e retirada da fila. Esta linha é então utilizada para gerar traces parciais para cada um dos processos. Um trace parcial consiste em um prefixo do trace de execução original para esse caso de teste, porém com as sincronizações modificadas de acordo com a variante sendo analisada. Os traces parciais são utilizados durante a reexecução do caso de teste, contendo as sincronizações que devem ser executadas durante a parte determinística do teste. Essa reexecução é feita utilizando a versão modificada da execução controlada implementada no módulo Vali-Exec, permitindo que, após a execução das sincronizações contidas nos traces parciais, a execução prossiga não-deterministicamente.

A Figura 6.5 mostra um exemplo de um arquivo de trace parcial gerado para o processo $p_{0}$ do Programa 4.1. Cada linha do arquivo segue a sintaxe recv_no $<\mathrm{n}>$ :send_no $<\mathrm{m}>$ processo $<\mathrm{x}>$ com_a_tag $<\mathrm{t}>$, significando que o receive localizado no nó $n$ do processo referente ao arquivo sincroniza com o send localizado no nó $m$ do processo $x$, com a tag $t$. Antes de executar uma variante, os traces parciais são analisados, a fim de verificar se essa variante deve ser executada ou não. Uma variante só é executada se possuir alguma sincronização ainda não coberta por nenhuma das execuções realizadas anteriormente, a fim de garantir que todas as variantes executadas contribuam com o aumento da cobertura do critério todas-arestas-s. Assim, sempre que uma variante é retirada da fila, as sincronizações presentes nesta são analisadas. Essas sincronizações seriam exercitadas na parte determinística da execução da variante. Se a variante possuir alguma sincronização que exercite um elemento requerido ainda não coberto, esta variante é executada. Caso contrário, retira-se a próxima variante da fila, e a mesma análise é feita, até que se encontre alguma variante que atenda à condição.

\begin{tabular}{llllllll}
\hline recv_no & 23 & : send_no & 11 & processo & 1 & com_a_tag & 0 \\
recv_no & 27 & : send_no & 12 & processo & 1 & com_a_tag & 0 \\
recv_no & 28 & : send_no & 11 & processo & 2 & com_a_tag & 0 \\
recv_no & 32 & : send_no & 12 & processo & 2 & com_a_tag & 0 \\
recv_no & 33 & : send_no & 11 & processo & 3 & com_a_tag & 0 \\
recv_no & 37 & : send_no & 12 & processo & 3 & com_a_tag & 0
\end{tabular}

Figura 6.5: Exemplo de arquivo gerado: seq_sync.p0. 
Após a reexecução do caso de teste, uma nova sequência $Q_{1}$ é gerada. A partir dessa execução novas variantes são geradas e armazenadas no arquivo SyncQueue. Os dados de teste da sequência $Q_{1}$ são armazenados em uma pasta sync_queue00001, e o arquivo contendo as sincronizações não cobertas é atualizado. Uma nova linha de SyncQueue é retirada a fim de gerar uma variante. O algoritmo é repetido até que a fila de variantes armazenada no arquivo SyncQueue se torne vazia, ou seja, até que todas as variantes sejam executadas.

\subsection{Abrangência desta técnica e suas limitações}

O teste estrutural utiliza como métrica para indicar se um programa foi suficientemente testado a cobertura de elementos requeridos. A motivação para a utilização do teste de alcançabilidade nesse contexto é diminuir o esforço do testador de gerar novos casos de teste, já que, para atingir a mesma cobertura utilizando execução não controlada, poderia ser necessário um grande número de execuções. A utilização do teste de alcançabilidade adiciona um overhead em relação ao teste estrutural implementado na ferramenta ValiPar, porém a abordagem aqui proposta visa atenuar esse custo extra, garantindo que todas as sequências executadas contribuam para o aumento da cobertura. Logo, o custo da análise das variantes a serem executadas é justificado pela redução da quantidade de sequências de teste.

Pode-se notar a existência de sequências que não contribuem para o aumento de cobertura ao analisar a diferença no modo como os critérios propostos e o teste de alcançabilidade tratam os eventos send e receive. O teste de alcançabilidade considera cada evento send/receive como um novo evento, mesmo que a instrução já tenha sido executada anteriormente, como por exemplo, quando estes ocorrem em estruturas de repetição. Essa diferença pode ser vista utilizando-se como exemplo o evento receive da linha 22 do Programa 5.1 (nó $5^{0}$ ). Esse receive pode receber de três sends diferentes (nós $4^{1}, 4^{2}$ e $4^{3}$ ), o que gera um total de seis sequências de sincronização possíveis. Porém, todas as sequências cobrem os mesmos elementos requeridos $\left(\left(4^{1}, 5^{0}\right),\left(4^{2}, 5^{0}\right)\right.$ e $\left.\left(4^{3}, 5^{0}\right)\right)$, apesar das sequências serem diferentes. Ao utilizar o teste de alcançabilidade guiado por elementos requeridos, essas sequências não seriam executadas, já que as variantes não possuiríam nenhuma sincronização correspondente a algum elemento não coberto.

O teste de alcançabilidade, sem a utilização de elementos requeridos, não considera os demais casos de teste já executados. Para cada uma das entradas de teste utilizadas, todas as sequências possíveis são geradas. Assim, entradas de teste distintas podem possuir o mesmo conjunto de sequências de sincronizações possíveis, sequências essas que seriam executadas, mesmo que já tivessem sido exercitadas por algum caso de teste anteriormente executado. Ao se utilizar os elementos requeridos não-cobertos para selecionar as variantes a serem executadas, há uma redução na quantidade de sequências exercitadas também nesse caso. 
Note que durante o teste de alcançabilidade a análise de uma variante, para verificar se esta deve ser executada ou não, é realizada antes da execução desta variante. Assim, é possível que alguma sincronização ainda não coberta viesse a ocorrer na sequência resultante da execução dessa variante, na parte não-determinística da execução. Logo, pode-se afirmar somente que as variantes selecionadas certamente cobrirão pelo menos uma nova sincronização, porém não se pode afirmar que as variantes não selecionadas para execução não contribuiriam para o aumento da cobertura.

Ao realizar o teste estrutural, pode-se utilizar o teste de alcançabilidade em dois momentos: após a execução de todos os casos de teste, realizando o teste de alcançabilidade para cada um dos casos de teste ou executando o teste de alcançabilidade após a execução de cada caso de teste. No primeiro caso, o teste de alcançabilidade visa somente cobrir sequências de teste não cobertas durante a execução dos casos de teste não-deterministicamente. Porém, ao aplicar-se o teste de alcançabilidade durante a execução dos casos de teste, pode-se vir a diminuir a quantidade de casos de teste necessários para atingir a cobertura desejada.

\subsection{Considerações finais}

Este capítulo apresentou os detalhes da abordagem proposta de utilização do teste de alcançabilidade no contexto de teste estrutural, utilizando-se informações de cobertura para diminuir o custo da aplicação do teste de alcançabilidade relacionado à grande quantidade de sequências executadas. Foram apresentadas as modificações realizadas no teste de alcançabilidade implementado no módulo Vali-Sync a fim de utilizar a abordagem proposta, assim como a abrangência desta e suas limitações. O próximo capítulo apresenta os experimentos realizados tanto para a abordagem apresentada neste capítulo quanto para a proposta no Capítulo 5. 



\section{Resultados Obtidos}

\subsection{Considerações iniciais}

No Capítulo 5 foi proposta uma melhoria na geração de elementos requeridos implementada na ferramenta ValiMPI para os critérios que consideram arestas-s, ou seja, estão relacionados com as sincronizações inter-processos. Esta utiliza informações estáticas sobre os valores dos campos dos eventos send/receive para detectar elementos requeridos não-executáveis. Com o intuito de verificar a eficácia desta abordagem, os elementos requeridos gerados para os programas descritos na Seção 7.2 foram analisados a fim de verificar quais são executáveis, assim como quantificar a redução na quantidade de elementos requeridos decorrente da modificação proposta. Para esta primeira etapa dos experimentos, apenas os módulos Vali-Inst e Vali-Elem foram utilizados pois, como esta abordagem considera apenas informações estáticas dos programas, não é necessária a execução dos mesmos.

Em uma segunda etapa, um experimento foi conduzido comparando três cenários na ValiMPI. O primeiro cenário implementa o teste estrutural proposto para a ValiMPI. O segundo cenário adiciona o teste de alcançabilidade, implementado pelo módulo Vali-Sync (Camillo, 2008). O terceiro cenário utiliza critérios de cobertura para reduzir a quantidade de sequências geradas pelo Vali-Sync e guiar a escolha de novas sequências de sincronização, abordagem esta detalhada no Capítulo 6. Este experimento foi realizado com o objetivo de verificar o ganho de cobertura ao utilizar o teste de alcançabilidade na ValiMPI, assim como o número de sequências geradas e executadas para atingir essa cobertura. 
Os programas utilizados em ambas as etapas encontram-se descritos na Seção 7.2. A escolha dos programas é baseada na interação entre os processos nos programas, buscando exercitar diferentes padrões de comunicação, classificando a complexidade dessas interações. Uma breve descrição é apresentada para cada programa, assim como características de implementação, padrão de comunicação, número de processos utilizados, número de nós send/receive e arestas de sincronização.

Este capítulo está organizado da seguinte forma. Na Seção 7.2 são descritos os programas utilizados nos experimentos. A Seção 7.3 apresenta os cenários de teste utilizados durante os experimentos. Por último, na Seção 7.4 são analisados os resultados obtidos com a execução dos experimentos.

\subsection{Programas utilizados}

Os programas descritos a seguir foram utilizados para verificar o comportamento das modificações propostas na geração de elementos requeridos para os critérios relacionados a arestas de sincronização e na escolha de sequências de sincronizações a serem executadas durante o teste de alcançabilidade, propostas nos Capítulos 5 e 6, respectivamente. Para isso, procurouse utilizar programas com diferentes padrões de comunicação. Os algoritmos foram classificados considerando-se a complexidade da interação entre os processos, seguindo a seguinte classificação:

Simples: Os programas considerados simples possuem uma comunicação do tipo mestre-escravo, onde um processo mestre divide a atividade entre os processos escravos e espera o resultado computado por eles. As interações entre os escravos são previsíveis, ou seja, é possível saber com antecedência com quais processos, e em qual ordem, um determinado processo se comunicará.

Média: Nestes programas, a comunicação não ocorre somente no modelo mestre-escravo, ocorrendo também comunicação entre os escravos. Os valores são repassados mais de uma vez entre os processos, realizando-se várias rodadas de comunicação para que o resultado final seja obtido.

Complexa: Nos programas classificados como complexos, diferentes fases de comunicação são realizadas, ocorrendo uma maior interação entre os processos. A comunicação todos-paratodos é utilizada, aumentando assim o número de sincronizações. Com o aumento na interação entre os processos, há também uma maior ocorrência de não-determinismo.

A Tabela 7.1 apresenta os programas classificados por complexidade. O nome utilizado na tabela encontra-se entre parênteses na descrição dos programas apresentada a seguir. O programa crivo é baseado no algoritmo implementado por Quinn (2004). O programa quicksort é baseado na solução apresentada em (Grama et al., 2003). Este programa é uma modificação de um 
algoritmo selecionado dentre os programas implementados pelos alunos da disciplina SSC0143Programação Concorrente, do ano de 2009, ministrada pelo orientador deste trabalho - o autor desta dissertação participou como estagiário PAE desta disciplina neste semestre. Este algoritmo foi modificado para ler os dados de um arquivo ao invés de recebê-los via entrada padrão, no recebimento das amostras pelo processo mestre e nas fases de comunicação todos-para-todos (para a troca das partições) e de combinação (merge) dessas partições. Os demais programas foram escolhidos a partir dos programas utilizados por Hausen (2005) (gcd, mmult e filosofos) e Lopes (2009) (pairwise, reduction e jacobi), com base em sua complexidade, a fim de exercitar diferentes padrões de comunicação. Os algoritmos estão descritos à frente, nesta seção.

Tabela 7.1: Complexidade dos programas.

\begin{tabular}{|l|c|c|c|c|c|c|}
\hline Programas & Complexidade & Sends & Recvs & Sincronizações & Sinc. possíveis & Elementos requeridos \\
\hline crivo & simples & 7 & 9 & 9 & 21 & 51 \\
\hline gcd & simples & 7 & 7 & 6 & 10 & 30 \\
\hline mmult & simples & 15 & 27 & 27 & 45 & 297 \\
\hline filosofos & média & 11 & 10 & 18 & 18 & 19 \\
\hline pairwise & média & 16 & 16 & 16 & 12 & 12 \\
\hline reduction & média & 4 & 4 & 3 & 3 & 1092 \\
\hline qsort & complexa & 28 & 52 & 38 & 93 & 639 \\
\hline jacobi & complexa & 23 & 37 & 37 & 55 & \\
\hline
\end{tabular}

As execuções para todos os experimentos foram realizadas utilizando-se um número fixo de quatro processos, a fim de poder comparar as quantidades de elementos requeridos e sincronizações entre os programas, podendo assim ser observada a diferença de complexidade entre eles. A Tabela 7.1 apresenta a quantidade de sends e receives para cada programa ao considerar quatro processos, a quantidade de sincronizações que ocorrem em uma execução e a quantidade de sincronizações possíveis. As quantidades aqui listadas consideram a quantidade de nós send e receive, ou seja, caso um desses nós seja exercitado mais de uma vez durante a execução, estas duas ocorrências não serão consideradas como eventos distintos. $\mathrm{O}$ mesmo se aplica à quantidade de sincronizações. A quantidade de elementos requeridos apresentada é relacionada ao critério Todas-arestas-s, que requer todos os pares de sincronização possíveis, inclusive aqueles que não são executáveis. Analisando-se a diferença entre o total de elementos requeridos e o de sincronizações possíveis é possível notar o grande número de elementos requeridos não-executáveis relacionados a essas sincronizações.

\section{Crivo de Eratóstenes (crivo)}

Este programa implementa o Crivo de Eratóstenes, um algoritmo utilizado para se encontrar todos os primos menores que um certo número $n$. O Programa 4.1 apresenta o código-fonte deste algoritmo, baseado na solução descrita em Quinn (2004), e o Apêndice A contém a descrição do 
algoritmo do Crivo de Eratóstenes e um exemplo de execução da ferramenta ValiMPI para esse programa.

A versão utilizada durante os testes difere da apresentada no Programa 4.1 no momento em que os processos escravos enviam o seu resultado ao processo mestre. Na versão apresentada no Capítulo 4, o processo mestre recebe sempre a mensagem do processo referente à iteração atual (ver linhas 73, 74 e 75). Na versão utilizada nos testes, esse receive é não-determinínistico, utilizando como source a opção MPI_ANY_SOURCE. Essa modificação foi feita para permitir a ocorrência de uma condição de disputa nesse receive, além de possibilitar que o processo mestre comece a receber os resultados assim que algum escravo termine o processamento.

\section{Máximo Divisor Comum (gcd)}

Este programa paralelo calcula o máximo divisor comum (greatest common divisor - GCD) entre três números inteiros (Krawczyk et al., 1994), passados via linha de comando. Quatro processos paralelos são utilizadas neste experimento: um processo mestre que coordena os resultados dos três processos escravos, e cada escravo calcula o m.d.c. entre dois números. A comunicação é bloqueante e são utilizados receives não determinísticos.

\section{Multiplicação de matrizes (mmult)}

Este programa multiplica duas matrizes através da decomposição do domínio (Quinn, 2004). $\mathrm{O}$ processo mestre recebe como entrada as dimensões da matriz e valores em ponto flutuante, via entrada padrão. O problema pode ser escalável para $n$ processos. O processo mestre envia as partes das matrizes a serem multiplicadas aos escravos, que realizam a computação e devolvem o resultado ao processo mestre. A comunicação é bloqueante e determinística.

\section{Jantar dos filósofos (filosofos)}

Este programa simula o compartilhamento de recursos através do problema clássico do jantar dos filósofos (Dijkstra, 1971). Cinco filósofos concorrem pelo acesso aos garfos (recurso compartilhado). Como entrada é passado um inteiro, que representa a fome de cada filósofo. Cada filósofo é representado por um processo e um outro processo age como um repositório de garfos, mediando quando um filósofo consegue pegar os dois garfos necessários para comer. A comunicação é bloqueante e são utilizados receives não-determinísticos.

\section{Pairwise-interaction (pairwise)}

Neste programa, dado um conjunto de valores $\left\{X_{0}, X_{1}, \ldots, X_{n-1}\right\}$ cada processo $i$ é responsável por computar as interações $I\left(X_{i}, X_{j}\right), i \neq j$ (Foster, 1995). Caso as interações sejam simétricas, ou seja, $I\left(X_{i}, X_{j}\right)= \pm I\left(X_{j}, X_{i}\right)$, o cálculo pode ser realizado através de $n(n-1) / 2$ 
interações, utilizando-se $2 n-1$ canais de comunicação, onde cada canal de comunicação é um par origem-destino de mensagens diferente. Um exemplo de problema que requer este tipo de interação é o cálculo da força gravitacional agindo em cada corpo, para um sistema de $n$ corpos.

\section{Redução (reduction)}

Este programa implementa a operação de redução de dados distribuídos (implementada no MPI pela função MPI_Reduce ()$\left.^{1}\right)$, para as operações de adição, multiplicação, maior que e menor que. Cada processo contém um valor inteiro, e o operador é aplicado sucessivamente sobre os valores, dois a dois, até que todos os elementos sejam combinados e o resultado é armazenado em um único processo, obtendo-se, por exemplo, o valor do somatório dos valores.

\section{Quicksort (qsort)}

O quicksort é um algoritmo de divisão-e-conquista que ordena uma sequência de números dividindo-os recursivamente em subsequências menores (Grama et al., 2003). No algoritmo sequencial, durante a fase de divisão, um pivô é selecionado e os dados são particionados em duas subsequências tais que cada elemento da primeira subsequência é menor ou igual ao pivô e cada elemento da segunda subsequência é maior que o pivô. Durante a fase de conquista, as subsequências são ordenadas aplicando-se o quicksort recursivamente.

No algoritmo paralelo implementado são utilizados $p-1$ pivôs (onde $p$ é a quantidade de processos). Inicialmente, os dados a serem ordenados são divididos entre os processos e cada um dos processos ordena sua porção utilizando o quicksort sequencial e escolhe $p$ amostras, enviandoas para o processo mestre $\left(p_{0}\right)$. Estas amostras são ordenadas, e o processo mestre escolhe e envia aos demais processos $p-1$ pivôs a partir das amostras. Cada processo utiliza os pivôs para dividir seus dados em $p$ partições. Ocorre então uma comunicação todos para todos, onde cada processo $p_{i}$ recebe dos demais processos a $i$-ésima partição calculada nesse processo. Os processos combinam os dados recebidos (merge) e enviam os dados ordenados para o processo mestre, que exibe o resultado final. A comunicação entre os processos é não-determinística, com exceção da divisão dos dados e do envio do resultado final.

\section{Jacobi-Richardson (jacobi)}

Este programa calcula o determinante de uma matriz utilizando o método numérico de JacobiRichardson, também conhecido como Método dos Deslocamentos Simultâneos. Inicialmente é realizado um teste de convergência, testando se a matriz dos coeficientes é estritamente diagonalmente dominante. Se a matriz atender o critério de convergência, define-se a margem de erro máxima que o resultado terá. A partir de uma aproximação inicial da solução, o método calcula

\footnotetext{
${ }^{1}$ http://www.open-mpi.org/doc/v1.4/man3/MPI_Reduce.3.php (acessado em 15/01/2011)
} 
iterativamente sucessivas aproximações convergentes até que o critério de parada seja atingido, ou seja, até que se tenha uma solução que atenda a margem de erro.

Inicialmente, o processo mestre envia para cada um dos escravos uma parte da matriz, e estes enviam para o mestre o resultado do teste de convergência para a sua porção. Caso o teste indique que a matriz converge, a cada iteração do método os processos escravos calculam uma nova aproximação e enviam para o processo mestre os valores necessários para o cálculo do critério de parada. O processo mestre envia então aos escravos uma mensagem indicando se devem continuar e, caso o critério de parada não tenha sido atingido, os escravos trocam entre si os valores calculados, utilizados no cálculo da próxima aproximação, realizando uma comunicação todos-para-todos.

\subsection{Cenários e casos de teste}

A técnica proposta no Capítulo 5 de identificação de elementos requeridos não-executáveis considera apenas informações estáticas do programa, analisando os campos source, dest, tag e datatype, quando estes possuem um valor constante. A execução do programa em si não é necessária para avaliar esta técnica, já que a geração dos elementos requeridos, realizada pelo módulo ValiElem, independe do resultado da execução do programa. Assim, somente os módulos Vali-Inst e Vali-Elem foram executados para verificar a quantidade de elementos requeridos não-executáveis identificados.

A segunda contribuição deste trabalho, descrita no Capítulo 6, utiliza o teste de alcançabilidade a fim de gerar diferentes sequências de sincronizações a partir de uma entrada de teste. Esta abordagem auxilia o teste de cobertura, já que ao forçar a execução de diferentes sincronizações um conjunto menor de casos de teste pode vir a ser utilizado, pois uma mesma entrada pode cobrir um conjunto maior de elementos requeridos. Para analisar esta abordagem um experimento foi conduzido comparando a cobertura dos programas em três cenários, cada um considerando uma versão da ValiMPI.

No primeiro cenário foi considerado o teste estrutural implementado na ValiMPI original, sem a utilização do teste de alcançabilidade. Neste cenário foram considerados somente os critérios relacionados a sincronizações entre processos (Todas-arestas-s e Todos-s-usos). Os módulos utilizados foram: Vali-Inst, para realizar a instrumentação e geração dos GFCP, Vali-Elem, para gerar os elementos requeridos, Vali-Exec, para executar os programas e obter os traces de execução, e Vali-Eval, para avaliar a cobertura dos critérios analisados. No segundo cenário, foi utilizado o módulo Vali-Sync, que implementa o teste de alcançabilidade. No terceiro cenário, foi utilizado o módulo Vali-Sync modificado. Neste, além da utilização do teste de alcançabilidade para automatizar a execução de diferentes sequências de sincronizações, com o objetivo de aumentar a cobertura dos elementos relacionados a elas, informações sobre essa cobertura de elementos requeridos são utilizadas para diminuir o número de sequências executadas durante o teste de alcançabilidade. 
Conforme descrito na Seção 4.4, no módulo Vali-Sync as variantes são geradas a partir da execução de um caso de teste, utilizando como entrada os arquivos de sincronizações executadas e traces gerados pelo módulo Vali-Exec. Durante a execução do teste de alcançabilidade, em ambos os cenários, a mesma sequência original foi utilizada para a geração de variantes. As informações geradas pelo módulo Vali-Exec a partir das execuções dos programas no primeiro cenário foram utilizados como entrada para o módulo Vali-Sync nos demais cenários. Com isso, garante-se que a versão modificada do Vali-Sync, proposta neste trabalho, parte do mesmo conjunto inicial de variantes que o Vali-Sync sem a modificação, executada no segundo cenário.

Durante os experimentos realizados em Camillo (2008) para avaliar o módulo Vali-Sync, o conjunto de dados de teste utilizado foi o mesmo gerado por Hausen (2005), a fim de comparar os resultados obtidos. Para os programas utilizados nos experimentos aqui descritos, um subconjunto dessas entradas de teste foi utilizada, considerando apenas os casos de teste efetivos, ou seja, os casos de teste que cobriram algum elemento, considerando todos os critérios implementados na ValiMPI. Para os programas aqui analisados que não foram utilizados em Hausen (2005), o conjunto de dados de teste foi gerado aleatoriamente, com exceção do programa jacobi, onde foram utilizados os dados gerados por Souza et al. (2008).

É importante ressaltar que, durante o teste de alcançabilidade, as sequências geradas são dependentes da entrada de teste utilizada. Sendo assim, mesmo que se executem todas as sequências possíveis para um dado caso de teste, pode ser que ainda existam sequências de sincronizações não executadas, que só seriam exercitadas com uma entrada de teste diferente. Por exemplo, supondo que os valores 3,5,7 sejam utilizados como entrada para uma execução do programa gcd. Como os três valores são primos, o máximo divisor comum entre 3 e 5 será 1, assim como o máximo divisor comum entre 5 e 7 . Após o processo mestre receber o retorno dos processos $p_{1}$ e $p_{2}$, este não precisa que o processo $p_{3}$ calcule o m.d.c. para chegar ao resultado final. Nesse caso, mais casos de teste serão necessários para exercitar as sequências que possuem sincronizações com o receive em que o processo mestre recebe o resultado de $p_{3}$, já que, para a entrada do exemplo, este não é executado. Para os programas analisados, em geral os dados de entrada não influenciam em quais sincronizações podem ser executadas (com exceção do gcd e do jacobi), ou seja, estas são dependentes do número de processos utilizados e independentes da entrada. Sendo assim, a utilização de um subconjunto dos dados de teste gerados por Hausen (2005) não influi no resultado dos experimentos, já que estão sendo analisados critérios que utilizam sincronizações entre processos e a execução destas, para os programas utilizados, é independente da entrada.

O teste de alcançabilidade utilizado no terceiro cenário utiliza informações sobre a cobertura dos elementos requeridos para decidir quais sequências de sincronizações executar. Logo, a quantidade de sequências geradas para um dado caso de teste é influenciado pela cobertura obtida pelos casos de teste executados anteriormente. O teste de alcançabilidade pode ser aplicado em dois momentos: após a execução de todos os casos de teste, visando cobrir as sincronizações que não foram cobertas pela execução não-controlada para os dados de teste utilizados; ou após a execução de cada um dos casos de teste. Para os testes aqui realizados optou-se por essa segunda estratégia, 
aplicando-se o teste de alcançabilidade logo após a execução de um caso de teste, já que o objetivo deste trabalho é a redução de custo e, caso as entradas estivessem sendo geradas uma a uma, esta estratégia poderia diminuir a quantidade de casos de teste necessários para atingir a cobertura desejada. Como citado anteriormente, ao exercitar diferentes sequências de sincronizações uma mesma entrada pode cobrir um conjunto maior de elementos requeridos.

\subsection{Resultados}

\section{Eliminação de elementos não-executáveis}

As Tabelas 7.2 e 7.4 apresentam os resultados obtidos ao utilizar a modificação proposta no Capítulo 5 para os critérios Todas-arestas-s e Todos-s-usos, respectivamente. Essa modificação tem por objetivo a detecção, durante a execução do módulo Vali-Elem, de elementos requeridos não-executáveis para os critérios relacionados a arestas de sincronização. As tabelas apresentam inicialmente o total de elementos requeridos pelo Vali-Elem e, destes, quantos foram detectados como não-executáveis. A seguir, são analisados os elementos restantes. Foi realizada uma análise manual destes elementos para verificar quantos destes são executáveis e quantos são elementos não-executáveis que não puderam ser eliminados pela abordagem proposta. Por último, é apresentado o total de elementos não-executáveis para cada programa, ou seja, tanto os detectados automaticamente pela ferramenta quanto os que não foram classificados automaticamente como não-executáveis. As Tabelas 7.3 e 7.5 apresentam a porcentagem de elementos não-executáveis detectados automaticamente, em relação ao total de não-executáveis.

Tabela 7.2: Elementos requeridos para o critério Todas-arestas-s.

\begin{tabular}{|l|c|c|c|c|c|c|}
\hline & Total de elementos & Detecção automática & \multicolumn{3}{|c|}{ Elementos restantes } & \multicolumn{2}{|c|}{ Total de } \\
\cline { 4 - 6 } & requeridos & de não-executáveis & Restantes & Executáveis & Não-executáveis & não-executáveis \\
\hline crivo & 51 & $12(23,53 \%)$ & 39 & $21(41,18 \%)$ & $18(35,29 \%)$ & $30(58,82 \%)$ \\
\hline gcd & 30 & $16(53,33 \%)$ & 14 & $10(33,33 \%)$ & $4(13,33 \%)$ & $20(66,67 \%)$ \\
\hline mmult & 297 & $192(64,65 \%)$ & 105 & $45(15,15 \%)$ & $60(20,20 \%)$ & $252(84,85 \%)$ \\
\hline filosofos & 81 & $54(66,67 \%)$ & 27 & $18(22,22 \%)$ & $9(11,11 \%)$ & $63(77,78 \%)$ \\
\hline pairwise & 192 & $0(0,00 \%)$ & 192 & $16(8,33 \%)$ & $176(91,67 \%)$ & $176(91,67 \%)$ \\
\hline reduction & 12 & $0(0,00 \%)$ & 12 & $3(25,00 \%)$ & $9(75,00 \%)$ & $9(75,00 \%)$ \\
\hline qsort & 1092 & $921(84,34 \%)$ & 171 & $93(8,52 \%)$ & $78(7,14 \%)$ & $999(91,48 \%)$ \\
\hline jacobi & 639 & $572(89,51 \%)$ & 67 & $55(8,61 \%)$ & $12(1,88 \%)$ & $584(91,39 \%)$ \\
\hline
\end{tabular}

O gráfico mostrado na Figura 7.1 apresenta a porcentagem de elementos requeridos detectados como não-executáveis para o critério Todas-arestas-s em relação ao total de elementos requeridos gerados, além de, para os demais elementos, quantos porcento são realmente executáveis e quantos são não-executáveis. É possível notar uma grande disparidade entre o resultado obtidos para os programas. Como pode ser visto nesta Tabela 7.2, três programas possuem mais de $90 \%$ de elementos não-executáveis, jacobi $(91,39 \%)$, qsort $(91,48 \%)$ e pairwise $(91,67 \%)$. Os dois primeiros foram os que obtiveram a maior melhora dentre todos os programas, com $89,51 \%$ e $84,34 \%$ de elementos requeridos detectados automaticamente como não-executáveis. Se considerarmos somente 
o total de elementos não-executáveis (Tabela 7.3), 97, 95\% destes foram detectados automaticamente para o jacobi, enquanto para o qsort este valor foi de 92,19\%. Em contrapartida, para o programa pairwise, nenhum elemento não-executável foi detectado automaticamente, apesar da alta porcentagem de não-executabilidade.

Tabela 7.3: Elementos requeridos não-executáveis para o critério Todas-arestas-s.

\begin{tabular}{|l|c|c|c|c|}
\hline & $\begin{array}{c}\text { Total de elementos } \\
\text { não-executáveis }\end{array}$ & $\begin{array}{c}\text { Detecção automática } \\
\text { de não-executáveis }\end{array}$ & $\begin{array}{c}\text { Elementos } \\
\text { restantes }\end{array}$ & $\begin{array}{c}\text { Porcentagem de } \\
\text { não-executáveis }\end{array}$ \\
\hline crivo & 30 & $12(40,00 \%)$ & $18(60,00 \%)$ & $58,82 \%$ \\
\hline gcd & 20 & $16(80,00 \%)$ & $4(20,00 \%)$ & $66,67 \%$ \\
\hline mmult & 252 & $192(76,19 \%)$ & $60(23,81 \%)$ & $84,85 \%$ \\
\hline filosofos & 63 & $54(85,71 \%)$ & $9(14,29 \%)$ & $77,78 \%$ \\
\hline pairwise & 176 & $0(0,00 \%)$ & $176(100,00 \%)$ & $91,67 \%$ \\
\hline reduction & 9 & $0(0,00 \%)$ & $9(100,00 \%)$ & $75,00 \%$ \\
\hline qsort & 999 & $921(92,19 \%)$ & $78(7,81 \%)$ & $91,48 \%$ \\
\hline jacobi & 584 & $572(97,95 \%)$ & $12(2,05 \%)$ & $91,39 \%$ \\
\hline
\end{tabular}

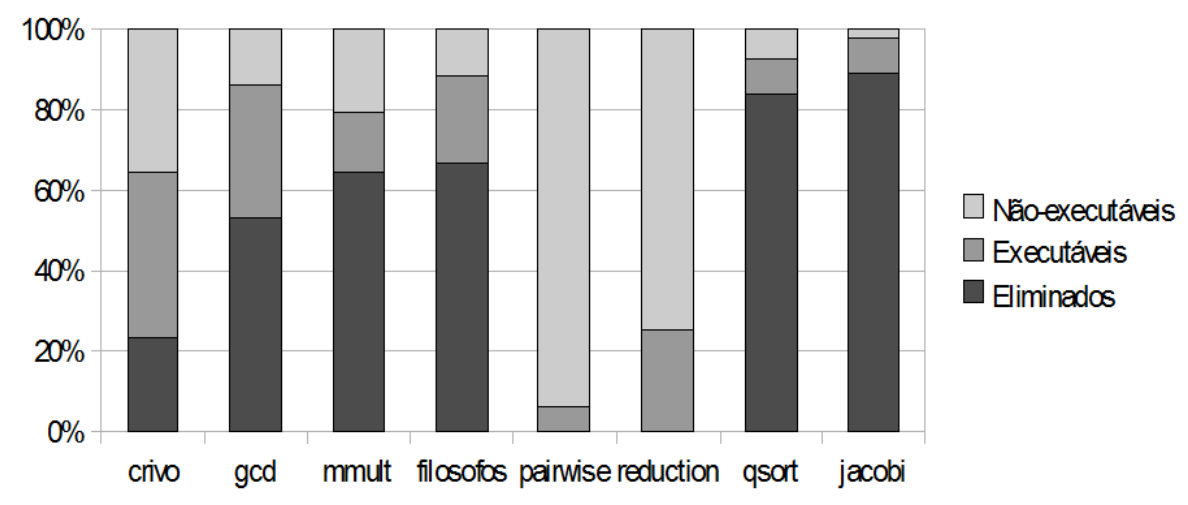

Figura 7.1: Porcentagem de elementos eliminados para o critério Todas-arestas-s.

O mesmo resultado obtido para o programa pairwise pode ser observado para o programa reduction, ambos classificados como tendo uma complexidade média. Para ambos os programas, os pares de comunicação são diferentes a cada iteração do algoritmo. Em cada rodada de comunicação, cada processo calcula, baseado na quantidade de processos e no número da iteração atual, com quais outros processos este deve se comunicar. Assim, como a origem e o destino das mensagens são definidos em tempo de execução e todas as mensagens utilizam a mesma tag, a abordagem de redução proposta não é capaz de identificar os elementos não-executáveis para esses programas. A quantidade de elementos não-executáveis para o programa pairwise é devido ao fato de, para o algoritmo implementado, as interações serem simétricas, resultando assim num total de $n(n-1) / 2$ interações entre os processos, onde $n$ é o número de processos, sendo que em cada interação 2 sincronizações são realizadas. Como o critério Todas-arestas-s requer todos os pares de sincronização possíveis, e cada processo possui 4 sends/receives, o total de elementos requeridos é de $16 n(n-1)$, ou seja, apenas 1/16 dos elementos são executáveis. Estes exemplos demonstram a limitação da proposta em relação ao padrão de codificação existente no algoritmo. 
Os programas jacobi e quicksort, apesar de terem um padrão de comunicação mais complexo que os demais, obtiveram uma alta taxa de detecção de elementos não-executáveis. O principal motivo para essa melhora é o fato destes utilizarem diferentes tags para as diversas fases de comunicação dos algoritmos. Apesar da quantidade de sends/receives ser maior que dos programas mais simples, boa parte dos elementos não-executáveis podem ser filtrados utilizandos-se a tag da mensagem, já que os eventos que deveriam sincronizar pertencem a fases distintas do algoritmo. Além disso, com exceção da divisão inicial dos dados e do envio do resultado final para o processo mestre, cujas mensagens possuem como origem/destino um valor estático, nas demais fases de comunicação (que utilizam variáveis nos campos source/dest) em geral ocorre comunicação todos-para-todos. Com isso, a quantidade de elementos não-executáveis dentre as sincronizações com uma mesma tag acaba sendo pequena.

Para os programas classificados como tendo uma complexidade simples, a abordagem apresentou uma boa porcentagem de detecção de elementos não-executáveis. Estes programas utilizam comunicação no padrão mestre-escravo, garantindo que para os pares de sincronização executáveis o campo origem (para as mensagens recebidas do processo mestre) ou destino (para as mensagens enviadas para o processo mestre) possuam um valor constante. Para o programa filosofos, apesar de ocorrer um número maior de mensagens enviadas durante a execução, a comunicação também é feita seguindo um padrão mestre-escravo. O processo responsável por gerenciar os garfos age como o mestre, e a comunicação é sempre realizada entre o mestre e os escravos, não ocorrendo comunicação direta entre os filósofos.

Apesar de ter uma porcentagem menor de elementos eliminados que os outros programas de complexidade simples, o programa crivo obteve resultados similares aos demais. Neste programa, ao enviar o resultado final, cada processo escravo envia duas mensagens, contendo o tamanho do vetor de primos calculados por este processo e o vetor em si. As sincronizações que não foram classificadas automaticamente como não-executáveis referem-se à sincronização do send que envia o vetor com o receive que espera o tamanho deste, e vice-versa. Estes poderiam ter sido eliminados caso fossem utilizadas tags para diferenciar as mensagens.

Tabela 7.4: Elementos requeridos para o critério Todos-s-usos.

\begin{tabular}{|l|c|c|c|c|c|c|}
\hline & \multirow{2}{*}{$\begin{array}{c}\text { Total de elementos } \\
\text { requeridos }\end{array}$} & \multirow{2}{*}{$\begin{array}{c}\text { Detecção automática } \\
\text { de não-executáveis }\end{array}$} & \multicolumn{3}{|c|}{ Elementos restantes } & \multicolumn{2}{c|}{ Total de } \\
\cline { 5 - 6 } & & $18(24,00 \%)$ & 57 & $30(40,00 \%)$ & $27(36,00 \%)$ & $45(60,00 \%)$ \\
\hline crivo & 75 & $32(48,48 \%)$ & 34 & $20(30,30 \%)$ & $14(21,21 \%)$ & $46(69,70 \%)$ \\
\hline gcd & 66 & $150(55,56 \%)$ & 120 & $38(14,07 \%)$ & $82(30,37 \%)$ & $232(85,93 \%)$ \\
\hline mmult & 270 & $54(60,00 \%)$ & 36 & $24(26,67 \%)$ & $12(13,33 \%)$ & $66(73,33 \%)$ \\
\hline filosofos & 90 & $0(0,00 \%)$ & 288 & $24(8,33 \%)$ & $264(91,67 \%)$ & $264(91,67 \%)$ \\
\hline pairwise & 288 & $0(0,00 \%)$ & 12 & $3(25,00 \%)$ & $9(75,00 \%)$ & $9(75,00 \%)$ \\
\hline reduction & 12 & $2352(88,69 \%)$ & 300 & $147(5,54 \%)$ & $153(5,77 \%)$ & $2505(94,46 \%)$ \\
\hline qsort & 2652 & $1147(91,47 \%)$ & 107 & $69(5,50 \%)$ & $38(3,03 \%)$ & $1185(94,50 \%)$ \\
\hline jacobi & 1254 & & & & Execután \\
\hline
\end{tabular}

A Figura 7.2 apresenta um gráfico com a porcentagem de elementos detectados automaticamente como não-executáveis para o critério Todos-s-usos, assim como, para os elementos restantes, a porcentagem de executáveis e não-executáveis. A Tabela 7.4 apresenta os resultados em 
relação ao total de elementos requeridos e a Tabela 7.5 apresenta a porcentagem dos elementos eliminados em relação ao total de elementos não-executáveis. Pode-se notar que os resultados para este critério foram próximos aos obtidos para o critério Todas-arestas-s, conforme esperado, já que o critério Todos-s-usos requer as mesmas arestas de sincronização que o critério Todas-arestas-s.

Tabela 7.5: Elementos requeridos não-executáveis para o critério Todos-s-usos.

\begin{tabular}{|l|c|c|c|c|}
\hline & $\begin{array}{c}\text { Total de elementos } \\
\text { não-executáveis }\end{array}$ & $\begin{array}{c}\text { Detecção automática } \\
\text { de não-executáveis }\end{array}$ & $\begin{array}{c}\text { Elementos } \\
\text { restantes }\end{array}$ & $\begin{array}{c}\text { Porcentagem de } \\
\text { não-executáveis }\end{array}$ \\
\hline crivo & 45 & $18(40,00 \%)$ & $27(60,00 \%)$ & $60,00 \%$ \\
\hline gcd & 46 & $32(69,57 \%)$ & $14(30,43 \%)$ & $69,70 \%$ \\
\hline mmult & 232 & $150(64,66 \%)$ & $82(35,34 \%)$ & $85,93 \%$ \\
\hline filosofos & 66 & $54(81,82 \%)$ & $12(18,18 \%)$ & $73,33 \%$ \\
\hline pairwise & 264 & $0(0,00 \%)$ & $264(100,00 \%)$ & $91,67 \%$ \\
\hline reduction & 9 & $0(0,00 \%)$ & $9(100,00 \%)$ & $75,00 \%$ \\
\hline qsort & 2505 & $2352(93,89 \%)$ & $153(6,11 \%)$ & $94,46 \%$ \\
\hline jacobi & 1185 & $1147(96,79 \%)$ & $38(3,21 \%)$ & $94,50 \%$ \\
\hline
\end{tabular}

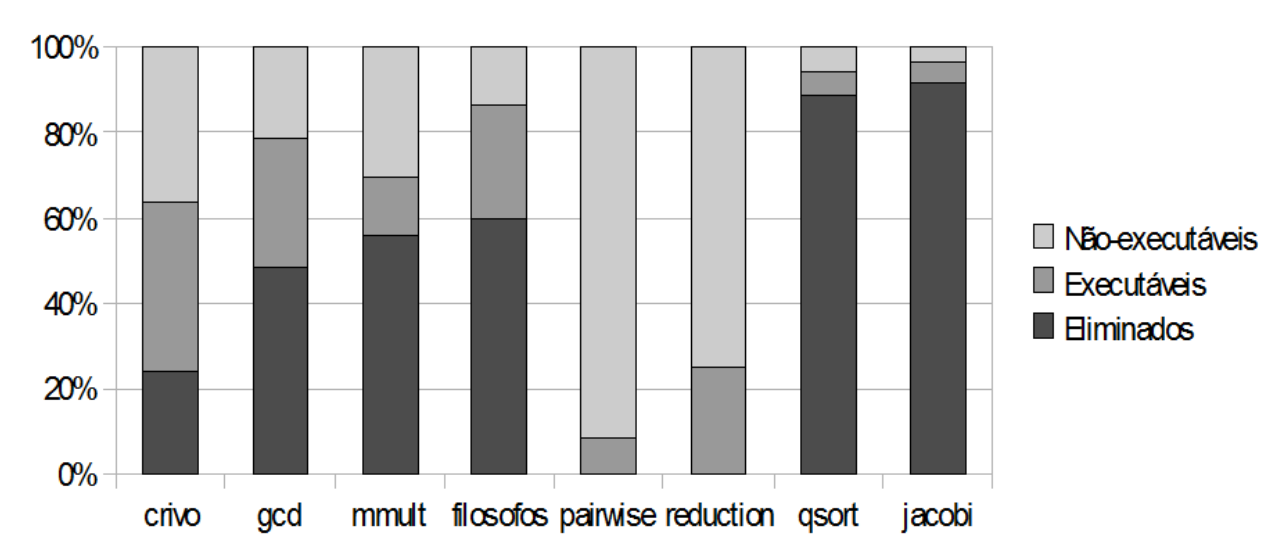

Figura 7.2: Porcentagem de elementos eliminados para o critério Todos-s-usos.

A partir da análise dos resultados obtidos para os critérios Todas-arestas-s e Todos-s-usos, pode-se observar que a técnica estática de eliminação de elementos não-executáveis proposta possibilita reduções significativas na quantidade de elementos requeridos relacionados a sincronizações. Conforme citado na Seção 5.4, a eficácia dessa técnica é diretamente dependente da utilização de valores constantes como parâmetro para os eventos send e receive, para os campos que definem a tag e a origem ou destino da mensagem. Em programas que utilizam uma grande quantidade de variáveis nos campos analisados, a identificação de elementos não-executáveis pela técnica proposta acaba sendo comprometida. Essa técnica pode ser estendida empregando-se informações de def-uso de variáveis (Rapps e Weyuker, 1985), onde pode-se detectar constantes atribuídas a variáveis utilizadas como parâmetro para as funções MPI_Send e MPI_Recv. 


\section{Teste de alcançabilidade como apoio ao teste de cobertura}

Conforme explicado na Seção 7.3, foram considerados três cenários a fim de verificar a abordagem proposta no Capítulo 6: o primeiro considerando apenas o teste estrutural implementado na ValiMPI original, sem a utilização do teste de alcançabilidade; o segundo cenário utilizando o módulo Vali-Sync, que implementa o teste de alcançabilidade; e o terceiro utilizando o módulo Vali-Sync modificado, que utiliza informações sobre os elementos requeridos para diminuir o número de sequências executadas durante o teste de alcançabilidade. Os elementos requeridos utilizados nesses experimentos foram gerados utilizando-se a versão modificada do módulo ValiElem, que implementa a detecção automática de elementos não-executáveis.

A Tabela 7.6 apresenta uma comparação do número de sequências de sincronizações exercitadas ao se aplicar o teste de alcançabilidade no segundo e terceiro cenários, utilizando-se o Vali-Sync original e o Vali-Sync com redução, respectivamente. A quantidade de sequências é apresentada considerando todos os casos de teste utilizados e também considerando somente os testes efetivos, ou seja, somente os casos de teste que possuam alguma sequência que tenha exercitado pelo menos um elemento ainda não coberto, considerando os critérios Todas-arestas-s e Todos-s-usos. Esta análise é feita pois o teste de alcançabilidade utilizado no segundo cenário gera todas as sequências de sincronizações possíveis para cada caso de teste, independentemente desta já ter sido exercitada por outros casos de teste. Como a abordagem aqui proposta executa apenas as variantes que exercitam algum elemento requerido ainda não coberto, a adição de casos de teste que exercitem apenas elementos já cobertos, ou seja, que não são efetivos para os critérios analisados, ocasiona um aumento na diferença do número de sequências para os dois cenários.

Tabela 7.6: Número de sequências executadas.

\begin{tabular}{|l|c|c|c|c|c|}
\hline & N. de casos & \multicolumn{2}{|c|}{ Todos os casos de teste } & \multicolumn{2}{c|}{ Somente testes efetivos } \\
\cline { 3 - 6 } & de teste & Vali-Sync & VS com Redução & Vali-Sync & VS com Redução \\
\hline crivo & 10 & 60 & 13 & 20 & 7 \\
\hline gcd & 13 & 24 & 14 & 14 & 9 \\
\hline mmult & 8 & 48 & 11 & 24 & 5 \\
\hline filosofos & 1 & 1680 & 2 & 1680 & 2 \\
\hline pairwise & 4 & 4 & 4 & 1 & 1 \\
\hline reduction & 4 & 4 & 4 & 1 & 1 \\
\hline qsort & 3 & 794 & 18 & 266 & 16 \\
\hline jacobi & 9 & 1710 & 13 & 377 & 11 \\
\hline
\end{tabular}

As Tabelas 7.7 e 7.8 apresentam a cobertura obtida para cada um dos três cenários para os critérios Todas-arestas-s e Todos-s-usos, respectivamente. É possível notar que há uma melhora na cobertura ao se aplicar a abordagem aqui proposta em relação à cobertura obtida sem a aplicação do teste de alcançabilidade. Porém, ao se comparar os resultados obtidos por essa abordagem com os do teste de alcançabilidade do segundo cenário, a cobertura atingida foi igual ou menor.

É importante notar que a utilização das informações sobre elementos cobertos para selecionar as variantes a serem executadas é uma heurística, garantindo que as variantes exercitadas serão efetivas. Assim, pode ser que uma variante não escolhida, ou alguma outra variante gerada a partir 
Tabela 7.7: Cobertura para o critério Todas-arestas-s.

\begin{tabular}{|l|c|c|c|}
\hline Programas & Sem Vali-Sync & Com Vali-Sync & Com elementos requeridos \\
\hline crivo & $43.59 \%$ & $53.85 \%$ & $48.72 \%$ \\
\hline gcd & $71.43 \%$ & $71.43 \%$ & $71.43 \%$ \\
\hline mmult & $40.00 \%$ & $42.86 \%$ & $40.00 \%$ \\
\hline filosofos & $66.67 \%$ & $66.67 \%$ & $66.67 \%$ \\
\hline pairwise & $8.33 \%$ & $8.33 \%$ & $8.33 \%$ \\
\hline reduction & $25.00 \%$ & $25.00 \%$ & $25.00 \%$ \\
\hline qsort & $28.07 \%$ & $53.80 \%$ & $48.54 \%$ \\
\hline jacobi & $85.07 \%$ & $85.07 \%$ & $85.07 \%$ \\
\hline
\end{tabular}

Tabela 7.8: Cobertura para o critério Todos-s-usos.

\begin{tabular}{|l|c|c|c|}
\hline Programas & Sem Vali-Sync & Com Vali-Sync & Com elementos requeridos \\
\hline crivo & $29.82 \%$ & $50.88 \%$ & $40.35 \%$ \\
\hline gcd & $47.06 \%$ & $55.88 \%$ & $50.00 \%$ \\
\hline mmult & $30.00 \%$ & $31.67 \%$ & $30.00 \%$ \\
\hline filosofos & $50.00 \%$ & $50.00 \%$ & $50.00 \%$ \\
\hline pairwise & $6.94 \%$ & $6.94 \%$ & $6.94 \%$ \\
\hline reduction & $25.00 \%$ & $25.00 \%$ & $25.00 \%$ \\
\hline qsort & $21.33 \%$ & $43.33 \%$ & $33.00 \%$ \\
\hline jacobi & $54.21 \%$ & $65.42 \%$ & $55.14 \%$ \\
\hline
\end{tabular}

desta, exercitasse um elemento não coberto na parte não controlada da execução. Essa situação pode ser visualizada através do seguinte exemplo: suponha um programa em que tenhamos quatro processos, um mestre e três escravos, e que cada escravo envia ao processo mestre uma mensagem $\left(s_{1}, s_{2}\right.$ e $s_{3}$, respectivamente). Os eventos receive no processo mestre $\left(r_{1}, r_{2}\right.$ e $\left.r_{3}\right)$ podem receber de qualquer processo. A partir de uma sequência original $Q_{0}=\left\{\left(s_{1}, r_{1}\right),\left(s_{2}, r_{2}\right),\left(s_{3}, r_{3}\right)\right\}$, as seguintes variantes seriam geradas:

$V_{1}=\left\{\left(s_{1}, r_{1}\right),\left(s_{3}, r_{2}\right)\right\}$

$V_{2}=\left\{\left(s_{2}, r_{1}\right)\right\}$

$V_{3}=\left\{\left(s_{3}, r_{1}\right)\right\}$

Todas as variantes exercitam alguma sincronização ainda não coberta, portanto as três seriam executadas. Supondo que a execução da variante $V_{2}$ desse origem à sequência $Q_{2}=\left\{\left(s_{2}, r_{1}\right)\right.$, $\left.\left(s_{1}, r_{2}\right),\left(s_{3}, r_{3}\right)\right\}$, a variante derivada a partir dessa execução, $V_{4}=\left\{\left(s_{2}, r_{1}\right),\left(s_{3}, r_{1}\right)\right\}$, não seria executada, já que as sincronizações que a compõe foram cobertas pelas sequências $Q_{1}$ e $Q_{2}$. Entretanto, caso a variante $V_{4}$ tivesse sido exercitada, esta cobriria a sincronização $\left(s_{1}, r_{3}\right)$, que ainda não havia sido coberta. $\mathrm{O}$ mesmo ocorreria caso a variante $V_{3}$ desse origem à sequência $Q_{3}=\left\{\left(s_{3}, r_{1}\right),\left(s_{1}, r_{2}\right),\left(s_{2}, r_{3}\right)\right\}$, e a sincronização $\left(s_{1}, r_{3}\right)$ não seria exercitada por nenhuma sequência executada.

As Tabelas 7.9 e 7.10 apresentam a cobertura para os programas jacobi e mmult após a execução de cada caso de teste, para o primeiro e o terceiro cenário (sem Vali-Sync e utilizando a ValiSync que implementa a abordagem proposta neste trabalho). Estas tabelas consideram a cobertura em relação ao total de elementos executáveis para os critérios Todas-arestas-s e Todos-s-usos. É 
possível notar que, mesmo em casos onde a cobertura é igual para os dois cenários, a abordagem aqui proposta atingiu esta cobertura com uma quantidade menor de casos de teste.

Tabela 7.9: Evolução da cobertura para o programa jacobi

\begin{tabular}{|l|c|c|c|c|}
\hline \multirow{2}{*}{$\begin{array}{l}\text { Casos } \\
\text { de teste }\end{array}$} & \multicolumn{2}{|c|}{ Todas-arestas-s } & \multicolumn{2}{c|}{ Todos-s-usos } \\
\cline { 2 - 5 } & Sem Vali-Sync & VS com Redução & Sem Vali-Sync & VS com Redução \\
\hline$t c 1$ & $19.30 \%$ & $19.30 \%$ & $8.70 \%$ & $8.70 \%$ \\
\hline$t c 2$ & $38.60 \%$ & $49.12 \%$ & $26.09 \%$ & $34.78 \%$ \\
\hline$t c 3$ & $82.46 \%$ & $94.74 \%$ & $60.87 \%$ & $71.01 \%$ \\
\hline$t c 4$ & $84.21 \%$ & $96.49 \%$ & $68.12 \%$ & $78.26 \%$ \\
\hline$t c 5$ & $94.74 \%$ & $100.00 \%$ & $78.26 \%$ & $82.61 \%$ \\
\hline$t c 6$ & $94.74 \%$ & $100.00 \%$ & $78.26 \%$ & $82.61 \%$ \\
\hline$t c 7$ & $94.74 \%$ & $100.00 \%$ & $78.26 \%$ & $82.61 \%$ \\
\hline$t c 8$ & $100.00 \%$ & $100.00 \%$ & $82.61 \%$ & $84.06 \%$ \\
\hline$t c 9$ & $100.00 \%$ & $100.00 \%$ & $84.06 \%$ & $85.51 \%$ \\
\hline
\end{tabular}

Tabela 7.10: Evolução da cobertura para o programa mmult

\begin{tabular}{|l|c|c|c|c|}
\hline \multirow{2}{*}{$\begin{array}{l}\text { Casos } \\
\text { de teste }\end{array}$} & \multicolumn{2}{|c|}{ Todas-arestas-s } & \multicolumn{2}{c|}{ Todos-s-usos } \\
\cline { 2 - 5 } & Sem Vali-Sync & VS com Redução & Sem Vali-Sync & VS com Redução \\
\hline$t c 1$ & $60.00 \%$ & $93.33 \%$ & $63.16 \%$ & $89.47 \%$ \\
\hline$t c 2$ & $60.00 \%$ & $93.33 \%$ & $68.42 \%$ & $94.74 \%$ \\
\hline$t c 3$ & $73.33 \%$ & $93.33 \%$ & $78.95 \%$ & $94.74 \%$ \\
\hline$t c 4$ & $86.67 \%$ & $93.33 \%$ & $89.47 \%$ & $94.74 \%$ \\
\hline$t c 5$ & $86.67 \%$ & $93.33 \%$ & $89.47 \%$ & $94.74 \%$ \\
\hline$t c 6$ & $86.67 \%$ & $93.33 \%$ & $89.47 \%$ & $94.74 \%$ \\
\hline$t c 7$ & $86.67 \%$ & $93.33 \%$ & $89.47 \%$ & $94.74 \%$ \\
\hline$t c 8$ & $93.33 \%$ & $93.33 \%$ & $94.74 \%$ & $94.74 \%$ \\
\hline
\end{tabular}

Analisando-se os dados obtidos durante os experimentos é possível notar que, apesar da cobertura não ter aumentado consideravelmente com a aplicação do teste de alcançabilidade, a quantidade de casos de teste necessária para obter essa cobertura foi minimizada. Tanto para o segundo quanto para o terceiro cenário, os elementos requeridos para os critérios analisados foram em geral cobertos por sequências derivadas da execução do primeiro caso de teste. Além disso, apesar de ter obtido uma cobertura menor que a do segundo cenário, ocorreu uma redução significativa na quantidade de sequências exercitadas pela abordagem aqui proposta. O teste se torna menos efetivo, porém com um ganho na quantidade de sequências executadas - o teste deixa de ser exaustivo, utilizando-se a heurística de executar as variantes baseado na cobertura de elementos requeridos.

Apesar do grande número de sequências distintas executadas pelo teste de alcançabilidade para os programas mais complexos, para alguns programas o aumento na cobertura não foi tão significativo, o que também foi notado nos testes realizados por Camillo (2008). Para o programa jacobi a cobertura para o critério Todas-arestas-s manteve-se a mesma ao se aplicar o teste de alcançabilidade, apesar de terem sido executadas 1710 sequências a partir dos nove casos de teste.

Como exemplificado na Seção 6.2, um motivo para esse resultado é a maneira como os critérios de testes estrutural analisados e o teste de alcançabilidade tratam a ordem em que as sincronizações ocorrem. Os critérios estruturais utilizados consideram apenas quais sincronizações foram 
realizadas, sem se preocupar com a ordem em que essas ocorrem. Por exemplo, quando um evento receive ocorre em uma estrutura de repetição, a cada iteração desse laço o teste de alcançabilidade considera que está ocorrendo um evento diferente, enquanto para o teste estrutural um mesmo nó do GFC está sendo executado repetidamente. Como consequência, se tivermos duas ou mais sequências em que a única diferença é a ordem em que essas sincronizações ocorrem, a cobertura permanece a mesma para o critério Todas-arestas-s.

\section{Erros encontrados}

A seguir são apresentados os erros encontrados durante a realização dos experimentos, mais especificamente durante a aplicação do teste de alcançabilidade. Estes encontram-se aqui documentados por se tratarem de erros que não haviam sido detectados durante a execução não controlada dos programas, sendo observados apenas durante o teste de alcançabilidade, evidenciando a necessidade de se exercitar diferentes sequências de sincronização. Além disso, alguns desses erros proporcionaram a descoberta de bugs no algoritmo implementado no módulo Vali-Sync, em geral devido a situações não previstas durante a implementação, que puderam ser corrigidos durante a realização deste trabalho.

\section{Erros relacionados à ferramenta}

O primeiro erro foi encontrado ao realizar testes com o programa do Crivo de Eratóstenes. A quantidade de variantes gerada estava correta, porém ao executar o teste de alcançabilidade para uma mesma sequência original, a cobertura estava variando. Notou-se também que a sequência executada para a primeira variante em alguns casos era idêntica à sequência original. Essa constatação levou à suspeita de que o erro seria na geração do trace parcial, já que a geração das variantes estava correta.

Analisando-se os traces parciais gerados, notou-se que somente a primeira sincronização estava sendo forçada para a primeira variante executada. Por exemplo, supondo uma execução com quatro processos (um mestre e três escravos), temos um total de dois sends para cada processo escravo (enviando a quantidade de valores e o vetor com esses valores) e seis receives no processo mestre. Conforme dito na Seção 7.2, para cada par de receives, o primeiro é não determinístico, e o segundo é dependente do processo que enviou a mensagem do primeiro. Assim, analisando-se somente os primeiros, poderíamos ter a seguinte sequência original $Q_{0}=\left\{\left(1^{1}, 1^{0}\right),\left(1^{2}, 3^{0}\right),\left(1^{3}, 5^{0}\right)\right\}$, o que geraria as seguintes variantes:

$$
\begin{aligned}
& V_{1}=\left\{\left(1^{1}, 1^{0}\right),\left(1^{3}, 3^{0}\right)\right\} \\
& V_{2}=\left\{\left(1^{2}, 1^{0}\right)\right\} \\
& V_{3}=\left\{\left(1^{3}, 1^{0}\right)\right\}
\end{aligned}
$$

Porém, durante a geração do trace parcial da primeira sequência, somente a primeira sincronização foi escrita, possibilitando assim que a sequência original ocorresse novamente. Ao realizar um teste com um programa com o mesmo padrão de comunicação, porém somente com os três 
receives não determinísticos, esse erro não ocorreu. Verificou-se então que o erro ocorria no algoritmo de geração dos traces parciais, ao analisar sincronizações que não possuíam uma condição de disputa. Por não tratar os casos em que estas ocorrem na porção a ser executada de modo controlado, ao analisar a sincronização $\left(2^{1}, 2^{0}\right)$ a geração do trace parcial parava, supondo que havia atingido a parte do trecho a ser executado não-deterministicamente, quando ainda haviam sincronizações a serem adicionadas no trace parcial. O código do Vali-Sync foi então modificado para forçar também as sincronizações com receives sem condição de disputa, quando estes ocorrem antes da sincronização que foi modificada para dar origem à variante.

Um problema no algoritmo da geração de variantes do módulo Vali-Sync foi identificado durante a execução dos experimentos com o programa que implementa o método de JacobiRichardson, mais especificamente durante a atribuição de timestamps. Ao analisar uma sequência para gerar as variantes, é criada uma lista de eventos ocorridos para cada processo. Esta lista é percorrida para calcular os timestamps de cada evento, a fim de determinar a relação happened-before entre eventos (conforme explicado na Subseção 4.2.2).

Nesse programa, durante o cálculo do critério de parada, cada processo envia para o processo $p_{0}$ o maior valor de $X$ calculado nessa iteração pelo escravo e a maior diferença em relação ao $X$ anterior. Cada um dos dois valores é enviado em uma mensagem, com tags diferentes. $\mathrm{O}$ processo $p_{0}$ escolhe o maior dentre os valores recebidos a fim de calcular $m_{r}$. Como $p_{0}$ necessita do máximo entre os valores, a ordem em que estes são recebidos não importa. Assim, supondo que tenhamos quatro processos e que os eventos send nos escravos ocorressem nos nós 5 e 6 , poderia ocorrer de $p_{0}$ sincronizar com os eventos send na seguinte ordem: $5^{2}, 6^{3}, 5^{3}, 6^{1}, 5^{1}$, $6^{2}$. Esta é uma sequência válida, já que o resultado é correto, porém, durante a atribuição de timestamps, o algoritmo implementado não prevê que dois sends enviados pelo mesmo processo possam sincronizar em uma ordem diferente da que foram enviados.

Durante a atribuição dos timestamps, quando o evento é um send, somente incrementa-se a posição do timestamp referente ao processo. Quando o evento é um receive, deve-se analisar o timestamp do evento send que sincroniza com ele também. Para isso, é necessário que os timestamps do começo da lista até o processo send desejado tenham sido calculados. Durante o cálculo do timestamp para o segundo receive, a lista de eventos do processo $p_{3}$ é percorrida, a fim de calcular o timestamp do evento send que sincronizou com ele.

Ao calcular o timestamp do próximo receive, essa lista é percorrida a partir do ponto em que havia parado anteriormente. Como o send que deveria sincronizar com este receive se encontra antes desse ponto na lista, os timestamps indicarão, erroneamente, que este receive sincronizou com o próximo evento send com a tag 5 , ou seja, com a mensagem enviada na próxima iteração do método de Jacobi-Richardson. Além disso, se enquanto a lista de $p_{3}$ estiver sendo percorrida para encontrar o próximo send com a tag 5 houver algum receive que receba uma mensagem do processo $p_{0}$, será necessário calcular o timestamp para esse send. Ao retornar o valor do timestamp para o receive de $p_{0}$, este será maior que o timestamp do evento send que ocorre após ele. 
A implementação da correção desse erro foi realizada pelo aluno de iniciação científica Rafael Regis do Prado, sob a orientação do Prof. Dr. Paulo Sérgio Lopes de Souza (orientador deste trabalho). Esta iniciação científica encontra-se em andamento.

\section{Erros relacionados à implementação dos programas}

Outro erro, dessa vez ocorrido no programa analisado, ocorreu durante os testes com o Quicksort. Nas primeiras execuções, não foi notado nenhum erro, porém ao executar o teste de alcançabilidade, observou-se a ocorrência de um problema de deadlock. Ao modificar o código para utilizar tags diferentes para as diferentes fases de comunicação do algoritmo - divisão dos dados, envio dos pivôs, troca das partições e envio do resultado final - o problema não foi mais detectado.

Analisando-se os traces gerados durante a execução dos testes, notou-se que o deadlock acontecia devido a um erro nas sincronizações: em alguns casos, um send não era recebido pelo receive correto, fazendo com que o programa travasse. Durante a fase de troca das partições, ocorre uma comunicação todos-para-todos, e os receives são não-determinísticos, podendo receber as mensagens em qualquer ordem. Depois que cada processo junta as partições recebidas, este envia para o mestre o resultado final. Supondo uma execução com quatro processos, o erro ocorria quando, por exemplo, o processo $p_{0}$, durante a troca das partições, recebe a partição 0 de $p_{1}, p_{2}$ e, antes de receber a partição de $p 3$, o processo $p_{1}$ terminar de ordenar os seus dados e enviar o resultado final. Como o receive em $p_{0}$ pode receber de qualquer processo e a tag de ambas as mensagens era a mesma, ocorrerá a sincronização, ocasionando o erro. A utilização de tags diferentes resolve o problema do deadlock, já que impossibilita uma mensagem com o resultado final de sincronizar com um receive que espera por uma partição.

\subsection{Considerações finais}

Neste capítulo foram apresentados os experimentos realizados para verificar a relevância das abordagens propostas nos Capítulos 5 e 6 . Foram apresentados os programas testados nos experimentos, os cenários utilizados para os experimentos das duas abordagens e os resultados destes experimentos. Ambos os experimentos apresentaram resultados satisfatórios, obtendo-se uma redução significativa na quantidade de elementos não-executáveis requeridos pelo módulo Vali-Elem e também na quantidade de sequências executadas pelo teste de alcançabilidade implementado no módulo Vali-Sync.

A análise manual dos elementos não-executáveis, antes da aplicação do teste de alcançabilidade, foi realizada somente para avaliar a detecção automática. O uso do teste de alcançabilidade não precisa que esses elementos sejam analisadas a priori, podendo inclusive ajudar a determinálas manualmente, diminuindo o custo dessa análise. Assim, as duas propostas podem ser vistas como complementares para reduzir o custo relacionado à análise da executabilidade dos elementos, sendo que a primeira detecta automaticamente parte dos elementos não-executáveis, enquanto 
a segunda, ao aumentar a cobertura com a aplicação do teste de alcançabilidade, reduz a quantidade de elementos a serem analisados manualmente.

No próximo capítulo são apresentadas as considerações finais, as contribuições deste trabalho, assim como os trabalhos futuros relacionados a este trabalho e à ferramenta ValiMPI como um todo. 


\subsection{Considerações Finais}

Este trabalho teve como principal objetivo reduzir o custo associado ao grande número de elementos requeridos gerados pelos critérios relacionados a sincronizações inter-processos. Nesse contexto, realizou-se um estudo de diversas abordagens de teste, apresentado na Seção 4.2, com o objetivo de identificar ideias que pudessem ser aplicadas na ferramenta ValiMPI, como um complemento ao teste estrutural utilizado atualmente, ou como uma alternativa a este. Após esse estudo, foram definidas duas propostas: a primeira estática, descrita no Capítulo 5, focando na redução da quantidade de elementos requeridos, e a segunda dinâmica, descrita no Capítulo 6, utilizando o teste de alcançabilidade com o objetivo de aumentar a cobertura desses elementos.

A primeira proposta apresentou uma modificação no módulo Vali-Elem a fim de identificar elementos requeridos não-executáveis para os critérios Todas-arestas-s e Todos-s-usos, relacionados a arestas de sincronização inter-processo. Esta técnica utiliza os valores dos campos source, dest, tag e datatype para identificar pares send/receive não-executáveis, quando estes valores são dados por constantes. A realização dos experimentos apresentados no capítulo anterior mostraram uma boa taxa de detecção de elementos não-executáveis, obtendo uma média de aproximadamente $60 \%$ de elementos identificados como não-executáveis para os programas analisados, em relação ao total de elementos não-executáveis. Essa técnica pode ser estendida empregando-se informações de def-uso de variáveis a fim de considerá-las quando estas forem utilizadas como parâmetro para as funções MPI_Send e MPI_Recv e o valor atribuído a essas variáveis seja constante. 
A segunda proposta estendeu o teste de alcançabilidade implementado no módulo Vali-Sync, reduzindo a quantidade de sequências de sincronizações executadas, ao utilizar a cobertura de sincronizações para escolher as variantes a serem executadas. Os resultados dos experimentos mostraram uma redução significativa na quantidade de sequências exercitadas pela abordagem proposta em relação ao teste de alcançabilidade original. Apesar da baixa melhora da cobertura em relação aos testes não controlados, esta pode ser obtida com um conjunto menor de sequências e casos de teste já que um mesmo caso de teste exercita diferentes sequências de sincronizações, o que antes necessitaria de várias execuções, e todas as sequências executadas contribuem para o aumento da cobertura.

\subsection{Contribuições}

Este trabalho tem duas contribuições principais, relacionadas às propostas apresentadas nos Capítulos 5 e 6. A primeira contribuição é relacionada à implementação dos critérios de teste estrutural propostos para programas concorrentes. Para os critérios relacionados a sincronizações inter-processos, todos os pares possíveis são requeridos, gerando um grande número de elementos não-executáveis. A automatização da detecção de elementos não-executáveis, utilizando informações estáticas, tem como contribuição diminuir o esforço do testador na tarefa de identificar elementos não-executáveis.

A segunda contribuição é relacionada a aplicação do teste de alcançabilidade no contexto do teste estrutural de programas concorrentes. O teste de alcançabilidade é aplicado aqui com o objetivo de aumentar a cobertura dos critérios relacionados a sincronizações. Com a utilização de informações sobre a cobertura dos elementos requeridos para selecionar as variantes a serem executadas pelo teste de alcançabilidade, diminui-se consideravelmente a quantidade de sequências de sincronizações executadas, o que era um fator limitante dessa abordagem, já que a geração de todas as sequências possíveis gera um teste exaustivo. Essa abordagem ajuda também na geração de casos de teste, já que, ao se garantir que todas as sequências geradas contribuem para o aumento da cobertura, um conjunto menor de casos de teste pode vir a ser necessário.

Ao realizar experimentos com programas diferentes dos utilizados em Camillo (2008), exercitando diferentes complexidades e padrões de comunicação, foi possível detectar e corrigir situações não previstas durante a implementação inicial do módulo Vali-Sync. Com isso, este trabalho contribuiu também melhorando a robustez deste módulo.

\subsection{Trabalhos futuros}

A seguir são apresentados os trabalhos futuros relacionados a este trabalho e à ferramenta ValiMPI:

- Criar uma IDel.C mais completa em relação à gramática da linguagem C. 
- Implementar os critérios: todas-defs, todas-defs/s, todos-s-c-usos e todos-s-p-usos.

- Adaptar os critérios para um número dinâmico ou desconhecido de processos paralelos

- Estender a proposta de detecção de elementos não-executáveis para utilizar informações de fluxo de dados como, por exemplo, variáveis que são definidas com um valor constante, para aumentar a eficácia dessa técnica.

- Adaptar a ferramenta a contextos de comunicação diferentes do contexto global (MPI_COMM_WORLD).

- Estender a proposta de detecção de elementos não-executáveis para a utilização de comunicadores diferentes e intercomunicadores.

- Avaliar a eficácia dos critérios de teste propostos. Esta avaliação está sendo realizado no trabalho de mestrado de Maria Adelina Silva Brito, sob orientação da Profa. Dra. Simone do Rocio Senger de Souza 



\section{Referências Bibliográficas}

Agrawal, H.; Alberi, J. L.; Horgan, J. R.; Li, J. J.; London, S.; Wong, W. E.; Ghosh, S.; WILDE, N. Mining system tests to aid software maintenance. IEEE Computer, v. 31, n. 7, pp. 64-73, 1998.

Almasi, G. S.; Gottlieb, A. Highly parallel computing. 2nd. ed. The Benjamin Cummings Publishing Company, 1994.

Andrews, G. R.; Schneider, F. B. Concepts and notations for concurrent programming. ACM Comput. Surv., v. 15, n. 1, pp. 3-43, 1983.

Barbosa, E. F.; Vincenzi, A. M. R.; Delamaro, M. E.; Maldonado, J. C. Teste estrutural e de mutação no contexto de programas OO. Belo Horizonte, MG: IV Escola Regional de Informática de Minas Gerais (ERI-MG 2005), texto didático, 2005.

BINDER, R. V. Testing object-oriented systems: Models, patterns, and tools, v. 1. Addison Wesley Longman, Inc., 1999.

CAmillo, M. S. Avaliação experimental do teste temporal na atividade de teste de programas paralelos, Trabalho de Conclusão de Curso, ICMC/USP, São Carlos, 2008.

CHAIM, M. L. Poke-tool - uma ferramenta para suporte ao teste estrutural de programas baseado em análise de fluxo de dados. Dissertação de Mestrado, DCA/FEEC/UNICAMP, Campinas, SP, 1991.

Chandra, R.; Dagum, L.; Kohr, D.; Maydan, D.; McDonald, J.; Menon, R. Parallel programming in OpenMP. San Francisco, CA, USA: Morgan Kaufmann Publishers Inc., 2001.

CHOw, T. S. Testing software design modeled by finite-state machines. IEEE Transactions on Software Engineering, v. 4, n. 3, pp. 178-187, 1978. 
Chung, A.; Sidhu, D.; Wang, Y.; Lin, W.; Kou, F. Task decomposition testing and metrics for concurrent programs. In: ISSRE'96 - International Symposium on Software Reliability Engineering, 1996, pp. 122-130.

Conway, M. A multiprocessor system design. In: Proc. AFIPS Fall Joint Computer Conference, Las Vegas, Nevada, 1963, pp. 139-146.

DeMillo, R. A. Software testing and evaluation. The Benjamim/Commings Publishing Company, Inc, 1978.

DEMillo, R. A. Mutation analysis as a tool for software quality assurance. In: COMPSAC80, Chicago, IL, 1980.

Dijkstra, E. W. Cooperating sequential processes, Technical Report EWD-123. Relatório Técnico, Technological University, Eindhoven, the Netherlands, 1965.

Dijkstra, E. W. Hierarchical ordering of sequential processes. Acta Informatica, v. 1, pp. 115138, 10.1007/BF00289519, 1971.

Disponível em: http://dx.doi.org/10.1007/BF00289519 (Acessado em 22/01/2011)

Dongarra, J.; Sterling, T.; Simon, H.; Strohmaier, E. High-performance computing: clusters, constellations, mpps, and future directions. Computing in Science \& Engineering, v. 7, n. 2, pp. 51-59, 2005.

Edelstein, O.; Farchi, E.; Goldin, E.; Nir, Y.; Ratsaby, G.; UR, S. Framework for testing multi-threaded java programs. Concurrency and Computation: Practice \& Experience, v. 15 , n. 3-5, pp. 485-499, 2003.

Endo, A. T. Teste de composição de Web services: uma estratégia baseada em um modelo de teste de programas paralelos. Dissertação de mestrado, ICMC/USP, São Carlos, SP, 2008.

Endo, A. T.; SimÃo, A. S.; SOUZA, S. R. S.; SOUZA, P. S. L. Aplicação do modelo PCFG no teste de composição de Web services. In: Brazilian Workshop on Systematic and Automated Software Testing (SAST 2007) - co-located with XXI Simpósio Brasileiro de Engenharia de Software, Porto Alegre, RS: Sociedade Brasileira de Computação, 2007, pp. 13-20.

FLYNn, M. J. Some computer organizations and their effectiveness. IEEE Trans. onComputers, v. C-21, pp. 948-960, 1972.

FOSTER, I. Designing and building parallel programs: Concepts and tools for parallel software engineering. Boston, MA, USA: Addison-Wesley Longman Publishing Co., Inc., 1995.

Frankl, P.; Weyuker, E. A data flow testing tool. In: Proceedings of IEEE Softfair II Conference on Software Development Tools, Techniques, and Alternatives, 1985, pp. 46-53. 
Frankl, P.; Weyuker, E. An applicable family of data flow testing criteria. Software Engineering, IEEE Transactions on, v. 14, n. 10, pp. 1483-1498, 1988.

Fujiwara, S.; Bochmann, G. V.; Khendek, F.; Amalou, M.; Ghedamsi, A. Test selection based on finite state models. IEEE Transactions on Software Engineering, v. 17, n. 6, pp. 591-603, 1991.

Geist, A.; Beguelin, A.; Dongarra, J.; MancheK, R.; JAing, W.; Sunderam, V. PVM: A users' guide and tutorial for networked parallel computing. 1994.

GönEnÇ, G. A method for the design of fault detection experiments. IEEE Trans. Comput., v. 19 , n. 6 , pp. 551-558, 1970.

Grady, R. B. Practical results from measuring software quality. Commun. ACM, v. 36, n. 11, pp. 62-68, 1993.

Grama, A.; KARYPIS, G.; KumAR, V.; GUPTA, A. Introduction to parallel computing. 2nd. ed. Addison Wesley, 2003.

Harel, D.; Pnueli, A.; Schmidt, J. P.; Sherman, R. On the formal semantics of statecharts. In: Proceedings of the 2nd IEEE Symposium on Logic in Computer Science, IEEE Press, 1987, pp. 54-64.

Hausen, A. C. ValimPI: Uma ferramenta de teste estrutural para programas paralelos em ambiente de passagem de mensagem. Dissertação de Mestrado, Dinf/UFPR, 2005.

Held, J.; Bautista, J.; Koehl, S. From a few cores to many: A tera-scale computing research overview. White Paper - Research at Intel, 2006.

Horgan, J. R.; London, S. A. Data flow coverage and the C language. In: Symposium Software Testing, Analysis, and Verification, 1991, pp. 87-97.

Horgan, J. R.; Mathur, A. P. Assessing testing tools in research and education. IEEE Transactions on Software Engineering, v. 9, n. 3, pp. 61-69, 1992.

Howden, W. E. Reliability of the path analysis testing strategy. IEEE Transactions on Software Engineering, v. 2, n. 3, pp. 208-215, 1976.

Howden, W. E. Software engineering and technology: Functional program testing and analysis. New York: McGrall-Hill Book Co, 1987.

IEEE IEEE standard glossary of Software Engineering terminology. Padrão 620.12, IEEE, 1990.

Kahle, J. A.; Day, M. N.; Hofstee, H. P.; Johns, C. R.; Maeurer, T. R.; Shippy, D. Introduction to the cell multiprocessor. IBM J. Res. Dev., v. 49, n. 4/5, pp. 589-604, 2005. 
Karp, R. M.; Miller, R. E. Parallel program schemata. J. Comput. Syst. Sci., v. 3, n. 2, pp. 147-195, 1969.

Koppol, P. V.; CARver, R. H.; TAI, K.-C. Incremental integration testing of concurrent programs. IEEE Trans. Softw. Eng., v. 28, n. 6, pp. 607-623, 2002.

KrawczyK, H.; Kuzora, P.; Neyman, M.; Proficz, J.; Wiszniewski, B. STEPS - a tool for testing PVM programs. In: Proceedings of the 3rd SEIHPC Workshop, Madrid, Spain, 1998.

KRAWCZYK, H.; WisZNIEWSKI, B.; MORK, P. Classification of software defects in parallel programs. Relatório Técnico, Faculty of Electronics, Technical University of Gdansk, Poland, 1994.

LEI, Y.; CARVER, R. H. Reachability testing of concurrent programs. IEEE Trans. Softw. Eng., v. 32, n. 6, pp. 382-403, 2006.

LEI, Y.; CARVER, R. H.; KACKER, R.; KUnG, D. A combinatorial testing strategy for concurrent programs. Softw. Test. Verif. Reliab., v. 17, n. 4, pp. 207-225, 2007.

Lemos, O. A. L. Teste de programas orientado a aspectos: uma abordagem estrutural para AspectJ. Dissertação de Mestrado, ICMC/USP, São Carlos, SP, 2005.

LEWIS, B.; BeRG, D. J. Multithreaded programming with Pthreads. Upper Saddle River, NJ, USA: Prentice Hall, 1998.

LIPTON, R. The reachability problem and the boundedness problem for Petri nets are exponentialspace hard. In: Conference on Petri Nets and Related Methods, M.I.T., 1975.

LOPES, B. L. Apoio à avaliação do teste de programas concorrentes: uma contribuição com benchmarks, Trabalho de Conclusão de Curso, ICMC/USP, São Carlos, 2009.

Maldonado, J. C. Critérios potenciais usos: Uma contribuição ao teste estrutural de software. Tese de Doutorado, DCA/FEE/UNICAMP, Campinas, SP, 1991.

Maldonado, J. C.; Delamaro, M. C.; Jino, M. Introdução ao teste de software. Editora Campus, 2007.

Maldonado, J. C.; FAbBri, S. C. P. F. Teste de software. In: Qualidade de software: Teoria e prática, cap. 3, São Paulo: Prentice Hall, pp. 73-84, 2001.

MCCABE, T. A complexity measure. IEEE Transactions on Software Engineering, v. 2, n. 4, pp. 308-320, 1976. 
Murata, T. Petri nets: Properties, analysis and applications. Proceedings of the IEEE, v. 77, n. 4, pp. 541-580, 1989.

Disponível em: http://dx.doi.org/10.1109/5.24143 (Acessado em 22/01/2011)

Myers, G. J.; SAndler, C.; BAdgett, T.; Thomas, T. M. The art of software testing. John Wiley \& Sons, Inc., Hoboken, New Jersey, 2004.

NTAFos, S. C. A comparison of some structural testing strategies. IEEE Transactions on Software Engineering, v. 14, n. 6, pp. 868-873, 1988.

OSTRAnD, T. J.; WeyUKeR, E. J. Data flow based test adequacy analysis for languages with pointers. In: Symposium on Software Testing, 1996, pp. 74-86.

Perry, D. E.; KAISER, G. E. Adequate testing and object-oriented programming. J. Object Oriented Program., v. 2, n. 5, pp. 13-19, 1990.

Pressman, R. S. Software engineering: A practitioner's approach. 6th. ed. New York: McGraw-Hill, 2005.

QuInN, M. J. Parallel Programming in C with MPI and OpenMP. Dubuque, Iowa: McGrawHill Education Group, 2004.

RAmANATHAN, R. Intel multi-core processors: Leading the next digital revolution. Intel Magazine, 2005.

RAPPS, S.; WEYUKER, E. J. Selecting software test data using data flow information. IEEE Transactions on Software Engineering, v. 11, n. 4, pp. 367-375, 1985.

Sabnani, K.; Dahbura, A. A protocol test generation procedure. Comput. Netw. ISDN Syst., v. 15, n. 4 , pp. 285-297, 1988.

Sarmanho, F. S.; Souza, P. S.; SouzA, S. R.; Simão, A. S. Structural testing for semaphore-based multithread programs. In: ICCS '08: Proceedings of the 8th international conference on Computational Science, Part I, Berlin, Heidelberg: Springer-Verlag, 2008, pp. 337-346.

SEO, H.-S.; Chung, I. S.; Kwon, Y. R. Generating test sequences from statecharts for concurrent program testing. IEICE - Trans. Inf. Syst., v. E89-D, n. 4, pp. 1459-1469, 2006.

SILVA, L. M.; BUYYA, R. Parallel programming models and paradigms. In: BUYYA, R., ed. High Performance Cluster Computing: Programming and Applications, v. 2, cap. 1, Upper Saddle River, NJ, USA: Prentice Hall, pp. 4-27, 1999.

Simão, A. S.; SouZA, S. R. L.; Maldonado, J. C. A family of coverage testing criteria for coloured petri nets. In: XVII Simpósio Brasileiro de Engenharia de Software, Manaus, AM, 2003, pp. 209-224. 
Snir, M.; Otto, S.; Steven, H.; Walker, D.; DongarraJ, J. MPI: The complete reference. Relatório Técnico, The MIT Press, Massachussets, 1996.

Souza, S. R. S.; Vergilio, S. R.; Souza, P. S. L.; Simão, A. S.; Hausen, A. C. Structural testing criteria for message-passing parallel programs. Concurrency and Computation: Practice \& Experience, v. 20, n. 16, pp. 1893-1916, 2008.

Stallings, W. Operating systems: Internals and design principles. 5th. ed. Upper Saddle River, N.J: Pearson/Prentice Hall, 2005.

TAI, K.-C.; CARVER, R. H.; OBAid, E. E. Debugging concurrent Ada programs by deterministic execution. IEEE Trans. Softw. Eng., v. 17, n. 1, pp. 45-63, 1991.

TAI, K. C.; LIE, Y. A test generation strategy for pairwise testing. IEEE Trans. Softw. Eng., v. 28, n. 1, pp. 109-111, 2002.

Tanenbaum, A. S. Modern operating systems. Upper Saddle River, NJ, USA: Prentice Hall PTR, 2001.

TAylor, R. N.; Levine, D. L.; Kelly, C. D. Structural testing of concurrent programs. IEEE Transactions on Software Engineering, v. 18, n. 3, pp. 206-215, 1992.

Toscani, S. S.; Oliveira, R. S.; CARISsimi, A. S. Sistemas operacionais e programação concorrente. Porto Alegre, RS: Ed. Sagra-Luzzato, 2003.

VAlmaRI, A. Stubborn sets for reduced state space generation. In: Proceedings of the 10th International Conference on Applications and Theory of Petri Nets, London, UK: SpringerVerlag, 1991, pp. 491-515.

Vergilio, S. R.; SouzA, S. R. S.; SouzA, P. S. L. Coverage testing criteria for messagepassing parallel programs. In: LATW2005 - 6th IEEE Latin-AmericanTestWorkshop, Salvador, Ba, 2005, pp. 161-166.

Vergílio, S. R.; Maldonado, J. C.; Jino, M. Uma estratégia para geração de dados de teste. In: Anais do VII Simpósio Brasileiro de Engenharia de Software, Rio de Janeiro, RJ, 1993, pp. 307-319.

Vilela, P. R.; Maldonado, J. C.; Jino, M. Program graph visualization. Software Practice \& Experience, v. 27, n. 11, pp. 1245-1262, 1997.

VinCENZI, A. M. R. Orientação a objeto: Definição e análise de recursos de teste e validação. Tese de Doutorado, ICMC/USP, São Carlos, SP, 2004.

Vincenzi, A. M. R.; Wong, W. E.; Delamaro, M. E.; Maldonado, J. C. JaBUTi: A coverage analysis tool for Java programs. In: XVII SBES - Simpósio Brasileiro de Engenharia de Software, Manaus, AM, Brasil, 2003, pp. 79-84. 
Weyuker, E. J. The complexity of data flow citeria for test data selection. Information Processing Letters, v. 19, n. 2, pp. 103-109, 1984.

Wilkinson, B.; Allen, M. Parallel programming: techniques and applications using networked workstations and parallel computers. Upper Saddle River, NJ, USA: Prentice Hall, 1999.

WONG, W.; LEI, Y.; MA, X. Effective generation of test sequences for structural testing of concurrent programs. In: ICECCS '05: Proceedings of the 10th IEEE International Conference on Engineering of Complex Computer Systems, Washington, DC, USA: IEEE Computer Society, 2005, pp. 539-548.

YAng, C.; Souter, A. L.; Pollock, L. L. All-du-path coverage for parallel programs. In: International Symposium on Software Testing and Analysis, 1998, pp. 153-162.

YANG, C.-S. D. Program-based structured testing of shared memory parallel programs. Tese de Doutorado, University of Delaware, 1999.

YANG, C.-S. D.; Pollock, L. L. The challenges in automated testing of multithreaded programs. In: In Proceedings of the 14th International Conference on Testing Computer Software, 1997, pp. 157-166.

YANG, C.-S. D.; Pollock, L. L. All-uses testing of shared memory parallel programs. Software Testing, Verification and Reliability (STVR), v. 13, n. 1, pp. 3-24, 2003.

YANG, R. D.; Chung, C. Path analysis testing of concurrent programs. Information and Software Technology, v. 34, n. 1, pp. 43-56, 1992. 

APÊNDICE

\section{$A$}

Crivo de Eratóstenes

O Crivo de Eratóstenes é um algoritmo utilizado para se encontrar todos os primos menores que um certo número $n$. Esse crivo foi desenvolvido pelo matemático grego Eratóstenes (Cyrene circa 284 BC - Alexandria circa 192 BC). O Crivo de Eratóstenes é impraticável para testar a primalidade de números muito grandes (com centenas de dígitos), pois a complexidade do tempo do algoritmo é $\Theta(n \ln \ln n)$, e $n$ cresce exponencialmente com o número de dígitos (Quinn, 2004). Porém, versões modificadas do crivo são utilizadas em algoritmos de fatoração mais eficientes.

O Programa A.1 apresenta o pseudocódigo do Crivo de Eratóstenes, e a Figura A.1 ilustra uma execução do crivo para $n=60$. Nessa figura, a cor de fundo branca representa valores não marcados, a cor cinza-claro representa valores marcados, e a cor cinza-escuro representa os valores múltiplos do primo atual (múltiplos de $k$ ).

Programa A.1: Pseudocódigo do Crivo de Eratóstenes.

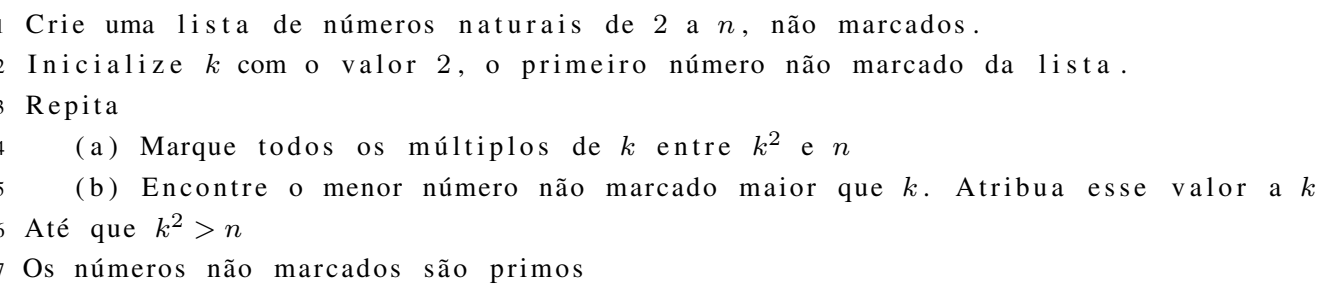

A execução do exemplo inicia com uma lista de naturais de 2 a 60 , não marcados, e $k=2$. Na primeira iteração do laço iniciado na linha 3, são marcados todos os múltiplos de 2 entre 4 e 60 , inclusive (Figura A.1(a)). Em seguida, é necessário procurar o menor número não marcado que seja maior que 2. O próximo valor não marcado é o 3, logo são marcados todos os seus múltiplos entre 9 e 60 (Figura A.1(b)). O mesmo é feito para os valores 5 e 7 (Figuras A.1(c) e A.1(d)). Como o próximo valor de $k$ é 11 (e $\left.11^{2}>60\right)$, tem-se que os números não marcados são primos. 


\begin{tabular}{|c|c|c|c|c|c|c|c|c|c|c|c|c|c|c|c|c|c|c|c|}
\hline & 2 & 3 & 4 & 5 & 6 & 7 & 8 & 9 & 10 & 11 & 12 & 13 & 14 & 15 & 16 & 17 & 18 & 19 & 20 \\
\hline 21 & 22 & 23 & 24 & 25 & 26 & 27 & 28 & 29 & 30 & 31 & 32 & 33 & 34 & 35 & 36 & 37 & 38 & 39 & 40 \\
\hline 41 & 42 & 43 & 44 & 45 & 46 & 47 & 48 & 49 & 50 & 51 & 52 & 53 & 54 & 55 & 56 & 57 & 58 & 59 & 60 \\
\hline
\end{tabular}

(a) $k=2$

\begin{tabular}{|c|c|c|c|c|c|c|c|c|c|c|c|c|c|c|c|c|c|c|c|}
\cline { 2 - 17 } \multicolumn{1}{c|}{} & 2 & 3 & 4 & 5 & 6 & 7 & 8 & 9 & 10 & 11 & 12 & 13 & 14 & 15 & 16 & 17 & 18 & 19 & 20 \\
\hline 21 & 22 & 23 & 24 & 25 & 26 & 27 & 28 & 29 & 30 & 31 & 32 & 33 & 34 & 35 & 36 & 37 & 38 & 39 & 40 \\
\hline 41 & 42 & 43 & 44 & 45 & 46 & 47 & 48 & 49 & 50 & 51 & 52 & 53 & 54 & 55 & 56 & 57 & 58 & 59 & 60 \\
\hline
\end{tabular}

(b) $k=3$

\begin{tabular}{|c|c|c|c|c|c|c|c|c|c|c|c|c|c|c|c|c|c|c|c|}
\cline { 2 - 16 } \multicolumn{1}{c|}{} & 2 & 3 & 4 & 5 & 6 & 7 & 8 & 9 & 10 & 11 & 12 & 13 & 14 & 15 & 16 & 17 & 18 & 19 & 20 \\
\hline 21 & 22 & 23 & 24 & 25 & 26 & 27 & 28 & 29 & 30 & 31 & 32 & 33 & 34 & 35 & 36 & 37 & 38 & 39 & 40 \\
\hline 41 & 42 & 43 & 44 & 45 & 46 & 47 & 48 & 49 & 50 & 51 & 52 & 53 & 54 & 55 & 56 & 57 & 58 & 59 & 60 \\
\hline
\end{tabular}

(c) $k=5$

\begin{tabular}{|c|c|c|c|c|c|c|c|c|c|c|c|c|c|c|c|c|c|c|c|}
\cline { 2 - 15 } \multicolumn{1}{c|}{} & 2 & 3 & 4 & 5 & 6 & 7 & 8 & 9 & 10 & 11 & 12 & 13 & 14 & 15 & 16 & 17 & 18 & 19 & 20 \\
\hline 21 & 22 & 23 & 24 & 25 & 26 & 27 & 28 & 29 & 30 & 31 & 32 & 33 & 34 & 35 & 36 & 37 & 38 & 39 & 40 \\
\hline 41 & 42 & 43 & 44 & 45 & 46 & 47 & 48 & 49 & 50 & 51 & 52 & 53 & 54 & 55 & 56 & 57 & 58 & 59 & 60 \\
\hline
\end{tabular}

(d) $k=7$

Figura A.1: Exemplo de execução do crivo de Eratóstenes (Quinn, 2004).

Quinn (2004) apresenta uma implementação de exemplo do Crivo de Eratóstenes concorrente. Essa é feita utilizando-se uma decomposição por blocos de dados, o que torna possível tornar concorrente o laço que marca os múltiplos do primo atual. Cada processo fica responsável por uma faixa de valores contíguos, devendo marcar os múltiplos do primo atual em sua faixa de valores. A interação entre os processos é feita através de passagem de mensagens (utilizando-se para isso o MPI). Quinn (2004) cita a possibilidade de uma divisão intercalada dos dados (discutindo suas vantagens e desvantagens), e apresenta também algumas melhorias que podem ser utilizadas para diminuir o tempo de execução, além da análise da complexidade de tempo e o tempo obtido em experimentos com essas implementações (como esse programa é utilizado nesta mini-dissertação apenas para exemplificar o teste de programas concorrentes, preferiu-se utilizar a implementação sem essas modificações).

As sincronizações no exemplo do Programa 4.1 utilizam as funções MPI_Send (linhas 64, 92 e 93) e MPI_Recv (linhas 74, 75 e 85). Como o MPI é um padrão, a implementação da função pode variar de uma implementação para outra (são exemplos de implementações do MPI o MPICH, o LAM/MPI e o Open MPI). Supõe-se aqui que essas primitivas são assíncronas (não-bloqueantes, utilizando buffer). O número de processos a serem utilizados é informado como argumento ao se iniciar a execução do programa (a função MPI_Comm_size retorna o número de processos).

Ao se utilizar critérios de teste estruturais, uma análise estática do código-fonte é feita para gerar o GFC e os elementos requeridos a partir desse. Por isso, ao se realizar o teste utilizando 
a ferramenta ValiPar, o módulo ValiElem precisa ser informado da quantidade de processos a ser utilizados na execução dos testes para poder gerar os elementos requeridos .

A quantidade de processadores utilizados para executar os processos não é conhecida pelo programa, sendo especificada ao se iniciar a execução. Porém, essa quantidade não interfere no teste, já que a ferramenta não tem o objetivo de avaliar o desempenho do programa, e sim a presença de erros. Logo, pode-se realizar os testes em um único processador sem perda de generalidade.

Executando-se a ferramenta ValiPar para o Programa 4.1, apesar de ser um programa simples, pode-se verificar o problema da geração de um grande número de elementos requeridos não executáveis. Fazendo-se um teste com quatro processos, o número de elementos requeridos para o critério todas-arestas-s é de 27, sendo que destes 18 são não executáveis (ou seja, a cobertura máxima possível é de aproximadamente 33,3\%). Para o critério todos-s-usos, 30 dos 39 elementos requeridos são não executáveis (cobertura máxima de aproximadamente 23,08\%). Caso esse mesmo código fosse estruturado como o apresentado por Quinn (2004) (utilizando-se estruturas de condição - if-else - para diferenciar os trechos a serem executados pelo processo 0 dos demais processos), o número de elementos não executáveis seria ainda maior (por exemplo, para o critério todas-arestas-s, com quatro processos, 108 elementos requeridos foram gerados, sendo que somente as mesmas nove sincronizações são executáveis).

A Figura A.2 mostra um exemplo de execução da ferramenta ValiMPI utilizando o Programa 4.1, com quatro processos, aplicando-se o critério todas-arestas-s. As linhas iniciadas com o caracter ' $>$ ' indicam as chamadas aos módulos da ferramenta. As demais linhas são produzidas como saída da ferramenta. A variável de ambiente \$VALIMPI_ROOT aponta para o diretório raiz da ferramenta. A sintaxe de chamada dos módulos pode ser encontrada em Hausen (2005). 


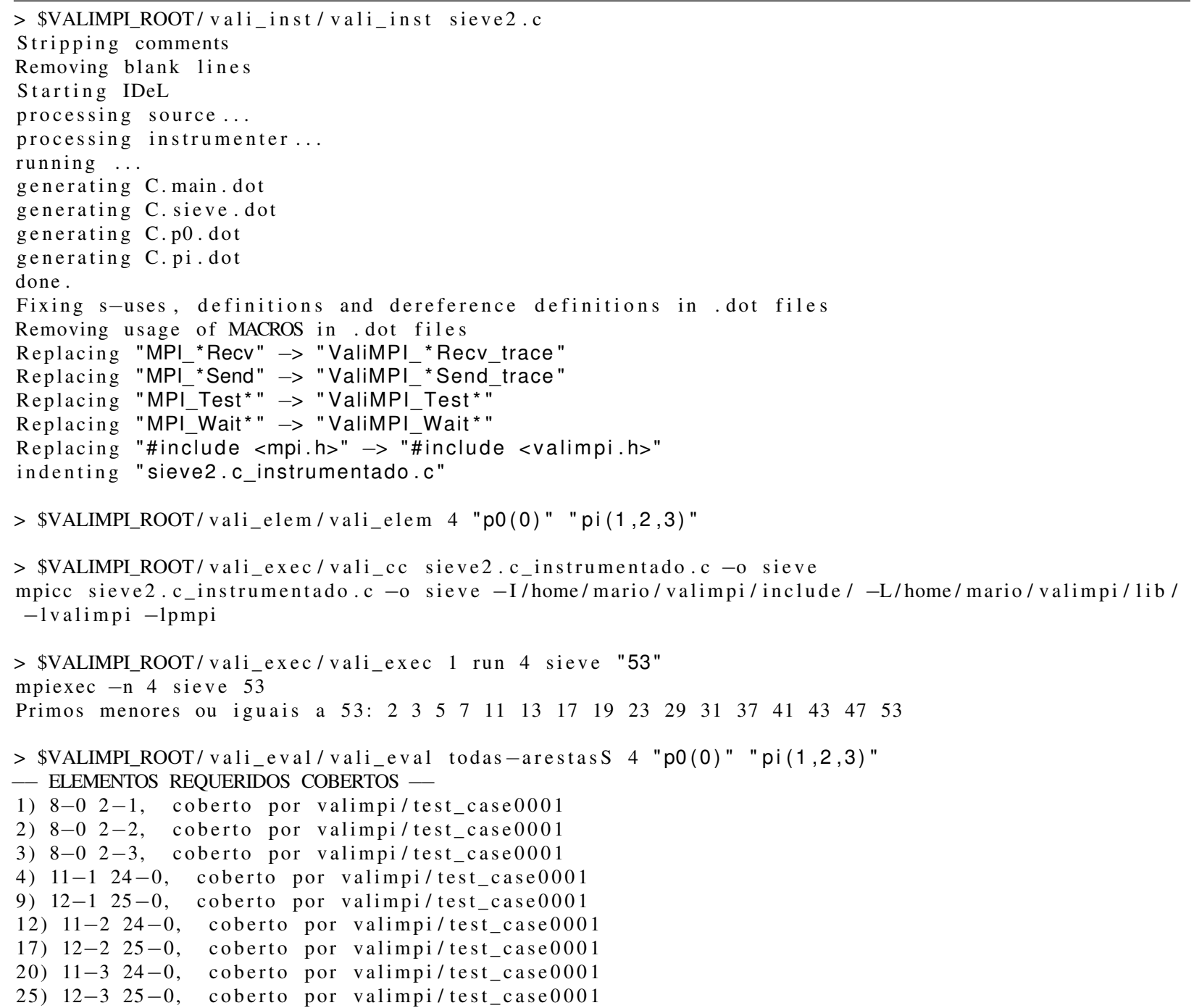

\section{- ELEMENTOS REQUERIDOS NAO COBERTOS -}

5) $11-1 \quad 25-0$

6) $11-1 \quad 2-2$

7) $11-1 \quad 2-3$

8) $12-1 \quad 24-0$

10) $12-1 \quad 2-2$

11) $12-1 \quad 2-3$

13) $11-2 \quad 25-0$

14) $11-2 \quad 2-1$

15) $11-2 \quad 2-3$

16) $12-2$ 24-0

18) $12-2 \quad 2-1$

19) $12-2 \quad 2-3$

21) $11-3 \quad 25-0$

22) $11-3 \quad 2-1$

23) $11-3 \quad 2-2$

24) $12-3 \quad 24-0$

26) $12-3 \quad 2-1$

27) $12-3 \quad 2-2$

Cobertura para o criterio todas-arestass : $33.33 \%$

Figura A.2: Exemplo de execução da ferramenta ValiPar. 